DANILO CARREIRA ITAO

\title{
ESTUDO DE UM SISTEMA ALTERNATIVO DE AR CONDICIONADO AUTOMOTIVO BASEADO NA APLICAÇÃO DE TUBOS DE VÓRTICE UTILIZANDO O CONCEITO DE REGENERAÇÃO ENERGÉTICA
}


DANILO CARREIRA ITAO

ESTUDO DE UM SISTEMA ALTERNATIVO DE AR CONDICIONADO AUTOMOTIVO BASEADO NA APLICAÇÃO DE TUBOS DE VÓRTICE UTILIZANDO O CONCEITO DE REGENERAÇÃO ENERGÉTICA

Trabalho de Conclusão de curso Apresentado à Escola Politécnica da Universidade de São Paulo, para obtenção do Título de Mestre em Engenharia Automotiva (Mestrado Profissionalizante)

Área de Concentração: Engenharia Automotiva

Orientador: Prof. Dr. Silvio de Oliveira Jr.

São Paulo 
AUTORIZO A REPRODUÇÃO E DIVULGAÇÃO TOTAL OU PARCIAL DESTE TRABALHO, POR QUALQUER MEIO CONVENCIONAL OU ELETRÔNICO, PARA FINS DE ESTUDO E PESQUISA, DESDE QUE CITADA A FONTE.

Este exemplar foi revisado e alterado em relação à versão original, sob responsabilidade única do autor e com a anuência de seu orientador.

São Paulo, de novembro de 2005.

Assinatura do autor

Assinatura do orientador

Itao, Danilo Carreira

Estudo de um sistema alternativo de ar condicionado automotivo baseado na aplicação de tubos de vórtice utilizando o conceito de regeneração energética / D.C. Itao. - ed.rev. -- São Paulo, 2005.

$113 \mathrm{p}$.

Trabalho de curso (Mestrado Profissionalizante em Engenharia Automotiva). Escola Politécnica da Universidade de São Paulo.

1.Tubos de vórtice 2.Ar condicionado 3.Veículos automotores 4.Regeneração energética 5.Frenagem I.Universidade de São Paulo. Escola Politécnica Il.t. 


\section{DEDICATÓRIA}

Dedico este trabalho aos meus familiares Isabel, Jorge e Leonardo que me auxiliaram nessa jornada de dois anos, estando presente em todos os momentos difíceis e me fornecendo todo o apoio possível para a conclusão deste curso. 


\section{AGRADECIMENTOS}

Ao MSc. Tim Cockerill da Universidade de Sunderland (Reino Unido), pelo auxílio e fornecimento de sua dissertação que aborda vastamente o tema Tubos de Vórtices.

Ao Prof. Dr. Jürgen U. Keller do Instituto de Fluídos e Termodinâmica da Universidade de Siegen (Alemanha), por disponibilizar informações relativas ao artigo de Rudolf Hilsch, um dos primeiros trabalhos que se tem conhecimento a respeito dos tubos de vórtices.

À EXAIR Corporation, nas pessoas dos Srs. Neal Raker e Gary Gunkel, que permitiram a utilização de dados relativos ao desempenho e modelos de tubos de vórtices comercialmente disponíveis, neste trabalho.

Ao meu orientador Prof. Dr. Silvio de Oliveira Jr. pela compreensão, paciência e pelas valiosas orientações passadas a mim neste período de convivência, que possibilitaram a finalização deste trabalho e conclusão do curso.

À toda minha família e amigos, pelo apoio dado nos vários momentos de dificuldade durante esse período. 
“Faça apenas uma vez o que os outros disseram que nunca poderia ser feito, e você nunca mais irá prestar atenção às limitações deles”.

Capt. James Cook (1728 - 1779) 


\section{RESUMO}

ITAO, D. C. Estudo de um Sistema Alternativo de Ar Condicionado Automotivo baseado na aplicação de Tubos de Vórtice utilizando o conceito de Regeneração Energética. 2005. 113 p. Trabalho de Conclusão de Curso (Mestrado Profissionalizante) - Escola Politécnica, Universidade de São Paulo, São Paulo, 2005.

Os sistemas de ar condicionado automotivos sempre se utilizaram do conceito de operação do ciclo termodinâmico por compressão de vapor, sendo necessário para isso componentes básicos tais como fluído refrigerante, trocadores de calor e compressor. Apesar de diversas décadas de pesquisa e desenvolvimento desse sistema, algumas dificuldades ainda permanecem nos dias de hoje. Dessa forma, a investigação de outros mecanismos de refrigeração, que possam ser aplicados em sistemas automotivos de ar condicionado, é bem vinda. Uma dessas possibilidades é a aplicação dos tubos de vórtices, utilizados atualmente para fins industriais. Os tubos de vórtices são dispositivos que operam através da introdução de um fluxo de ar comprimido, sendo que ele possibilita a divisão deste fluxo em duas parcelas: um fluxo de alta temperatura e um fluxo de baixa temperatura. Tal dispositivo apresenta vantagens tais como a não necessidade da utilização de trocadores de calor e de fluídos refrigerantes. Desta forma, ele possibilita uma maior flexibilidade de posicionamento de saídas de ar em pontos do habitáculo do veículo os quais não são permitidos atualmente. A alimentação do tubo de vórtices se dá exclusivamente com fluxo de ar comprimido, que pode ser armazenado para consumo conforme necessidade. Adicionalmente, devido a esta característica, surge a possibilidade de executar o reaproveitamento de energia cinética, que no processo de frenagem é dissipada ao ambiente. O reaproveitamento energético pode ser efetuado através do redirecionamento dessa energia cinética para o compressor de ar. Baseado nessa possibilidade, foram inicialmente obtidos os dados de operação de um sistema de ar condicionado convencional, além do potencial de regeneração energética, sendo estes dados obtidos através de publicações técnicas e cálculos teóricos. Estabeleceu-se uma proposta de configuração dos componentes, assim como modos de operação do sistema. Posteriormente seguiu-se com uma pré-seleção dos componentes que influem diretamente na viabilidade do sistema. Os resultados mostraram a dificuldade de implementação dessa filosofia de sistema para veículos leves (automóveis de passeio), mostrando maior viabilidade para veículos comerciais de grande porte (tais como caminhões), principalmente aqueles dotados de sistema pneumático para a operação dos freios a ar e suspensão pneumática.

Palavras-Chave: Tubos de vórtice, ar condicionado, veículos automotores, regeneração energética, frenagem. 


\begin{abstract}
ITAO, D. C. Study of an alternative automotive air conditioning system with the application of Vortex Tubes utilizing the concept of energetic regeneration. 2005. 113 p. Conclusion Course Work (Master) - Escola Politécnica, Universidade de São Paulo, São Paulo, 2005.

Automotive air conditioning systems have always utilized the thermodynamic vaporcompression cycle concept, with the necessity of some basic components as refrigerant fluid, heat exchangers and compressor. Although research and development of these systems have been made along many decades, some difficulties still remain nowadays. Then, the investigation of other mechanisms of refrigeration that could be applied to automotive air conditioning systems are welcome. One of these possibilities is the application of the Vortex Tubes, utilized nowadays for industrial applications. Vortex Tubes are devices that work with the introduction of an air compressed flow. These devices enable the division of the inlet flow in two flow fractions: one high and one low temperature flow. The application of these devices brings advantages, as an example no necessity of heat exchangers and refrigerant fluids. Then it enables a higher flexibility in the positioning of air outlets in some cabin position, that are not possible nowadays. The feeding of vortex tubes occurs only with compressed air flow, which can be stored for consumption when necessary. In addition, because of this characteristic, there is the possibility of the kinetic energy reutilizing, that is dissiped to the environment in the braking process currently. This possibility of energetic reutilizing can be made through the transfer of this kinetic energy to the air compressor. Based on this possibility, it was obtained data about the operation of a conventional air conditioning system, besides the energetic regeneration potential data. These data were obtained through technical publications and theoretical calculations. It was established a configuration proposal for the components, as well as the system operation modes. Later, it was made a first selection of the components that have direct influence in the system viability. The results showed the difficulties in the application of this philosophy for light vehicles (passenger cars) with more viability for commercial vehicles use (for example trucks), mainly those vehicles that are equiped with a pneumatic system to the air brakes and air suspension.
\end{abstract}

Keywords: vortex tubes, air conditioning, motor vehicles, energetic regeneration, braking. 


\section{LISTA DE ILUSTRAÇÕES}

Figura 1. Esquema simplificado de sistema de ar condicionado automotivo 20

Figura 2. Exemplo de tubo de vórtices..... .21

Figura 3. Exemplo de tubo de vórtices configuração contra-fluxo .24

Figura 4. Exemplo de tubo de vórtices configuração unifluxo .25

Figura 5. Tubo de vórtices utilizado por Hilsch .26

Figura 6. Temperatura e pressão nos fluxos de saída em função da vazão em massa do fluxo de ar frio em relação à em vazão em massa de entrada

Figura 7. Relação de similaridade comparada com dados experimentais do ar, Helio e oxigênio

Figura 8. Representação das linhas de fluxo dentro do tubo de vórtices.

Figura 9. Eficiência em função da relação diâmetro / comprimento.

Figura 10. Variação de temperatura do fluxo de ar frio em função do diâmetro adimensional do orifício central de saída do fluxo de ar frio

Figura 11. Eficiência em função do diâmetro adimensional do orifício central de saída do fluxo de ar frio

Figura 12. Variação de temperatura do fluxo de ar frio em função da fração de fluxo de de ar frio para as configurações de 3 e 4 entradas.

Figura 13. Eficiência em função da fração de fluxo de ar frio para as configurações de 3 e 4 entradas

Figura 14. Variação de temperatura do fluxo de ar frio em função da fração de fluxo de ar frio para diversas pressões de entrada.

Figura 15 Eficiência em função da fração de fluxo de ar frio para diversas pressões de entrada

Figura 16. Variação de temperatura do fluxo de ar frio em função da pressão de entrada ......35

Figura 17. Eficiência em função da pressão de entrada

Figura 18. Ciclo de refrigeração Brayton 
Figura 19. Ciclo de refrigeração Carnot

Figura 20. Ciclo de refrigeração por compressão de vapor

Figura 21. Componentes de um sistema de ar condicionado automotivo (utilizando válvula de expansão)

Figura 22. Compressor de pistões axiais tipo “wobbleplate”

Figura 23: Condensador de um sistema de ar condicionado convencional 45

Figura 24. Válvula de expansão .46

Figura 25. Tubo de orifício 46

Figura 26. Evaporador tipo placas. 48

Figura 27. Sistema de desumidificação .53

Figura 28. Carta Psicrométrica 54

Figura 29. Exemplo de um sistema de distribuição de ar complexo de um veículo Maybach 57/62 .56

Figura 30. Sistema de frenagem regenerativo Toyota THS II ${ }^{\circledR}$ 59

Figura 31. Sistema de frenagem regenerativo-dissipativo .59

Figura 32. Variação de temperatura do fluxo frio em função da fração de fluxo frio .66

Figura 33. Relação entre variação de temperatura parcial do fluxo frio e a variação máxima de temperatura do fluxo frio versus a fração de fluxo frio

Figura 34. Disco de freio de alta performance .....

Figura 35. Coeficientes de resistência ao rolamento

Figura 36. Gráfico da variação de velocidade e montante parcial de energia líquida disponível em função do tempo (ciclo de condução conforme NBR 6601 para veículos de passeio)

Figura 37. Gráfico da variação de velocidade e evolução da energia líquida acumulada disponível em função do tempo (ciclo de condução conforme NBR 6601 para veículos de passeio)

Figura 38. Gráfico da variação de velocidade / evolução da energia líquida acumulada disponível em função do tempo (desaceleração linear $40 \mathrm{~km} / \mathrm{h}$ - 0km/h para veículo de passeio) 
Figura 39. Gráfico da variação de velocidade / evolução da energia líquida acumulada disponível em função do tempo (desaceleração linear $40 \mathrm{~km} / \mathrm{h}$ - 0km/h para veículos comerciais sem reboque)

Figura 40. Gráfico da variação de velocidade / evolução da energia líquida acumulada disponível em função do tempo (desaceleração linear $40 \mathrm{~km} / \mathrm{h}$ - 0km/h para veículos comerciais com reboque)

Figura 41. Esquema básico dos componentes para operação de um sistema de tubo de vórtices.

Figura 42. Proposta de sistema de ar condicionado com a aplicação de tubos de vórtices

Figura 43. Proposta de sistema de ar condicionado com a aplicação de tubos de vórtices e regeneração energética

Figura 44. Fluxograma dos modos de operação do sistema de ar condicionado com aplicação de tubos de vórtices e regeneração energética

Figura 45. Proposta de sistema de ar condicionado com a aplicação de tubos de vórtices e regeneração energética (representação dos sensores)

Figura 46. Variação de temperatura em função da fração de fluxo de ar Frio

Figura 47. Aplicação do tipo de compressor conforme pressão de descarga e capacidade de admissão 


\section{LISTA DE TABELAS}

Tabela 1 - Valores Ótimos de $\mathrm{A}_{\text {entrada, }} \mathrm{A}_{\text {Orificio }}$ e L / D para máxima variação de temperatura do fluxo de ar frio

Tabela 2 - Dados de operação de sistema de ar condicionado

Tabela 3 - Dimensões principais do tubo de vórtices.

Tabela 4 - Modelos de tubos de vórtices EXAIR ${ }^{\circledR}$

Tabela 5 - Queda de temperatura do fluxo de ar frio em função da fração de fluxo frio em tubos de vórtices EXAIR ${ }^{\circledR}$

Tabela 6 - Acréscimo de temperatura do fluxo de ar quente em função da fração de fluxo de ar frio em tubos de vórtices EXAIR ${ }^{\circledR}$

Tabela 7 - Vazões necessárias para diversas pressões de operação dos tubos de vórtices

Tabela 8 - Análise da potência de compressão necessária para diversas condições de operação

Tabela 9 - Tempo de descarga em função do volume do reservatório para diversas pressões

Tabela 10 - Potência necessária em função da pressão de operação

Tabela 11 - Potencial de regeneração versus potência máxima necessária para compressão..94 


\section{LISTA DE ABREVIATURAS E SIGLAS}

EVOP Metodologia das Operações Revolucionárias

V.C. Volume de Controle

SAE Sociedade de Engenheiros da Mobilidade

CFC Clorofluorcarbono

HCFC Hidroclorofluorcarbono

GWP Potencial de aquecimento global

ASHRAE Associação americana de engenheiros de aquecimento, refrigeração e ar condicionado

TR

Tonelada de Refrigeração 


\section{LISTA DE SÍMBOLOS}

$\mathrm{y}_{\mathrm{c}}$

$d_{e}$

A $_{\text {entrada }}$

$\mathrm{A}_{\text {orificio }}$

$\mathrm{X}$

$\mathrm{p}_{0}$

prrio

$\mathrm{L}$

D

$\mathrm{d}_{\mathrm{C}} *$

$\mathrm{d}_{\mathrm{c}}$

$\eta$

$\Delta \mathrm{T}_{\mathrm{c}}$

$\mathrm{T}_{\mathrm{H}}$

$\mathrm{T}_{\mathrm{L}}$

$\dot{Q}$

$\dot{W}$

$\dot{m}$

$\mathrm{h}$
Temperatura

Fração do fluxo de ar frio (relação entre a vazão em massa de ar frio e a vazão em massa de entrada)

Diâmetro do orifício de entrada de ar

Área da seção transversal do orifício de entrada em relação à àrea da seção do tubo

Área da seção transversal do orifício central do fluxo de saída de ar frio em relação à área da seção do tubo

Queda de pressão

Pressão do fluxo de ar de entrada

Pressão do fluxo de ar frio

Comprimento do tubo de saída do fluxo do ar quente

Diâmetro do tubo de saída do fluxo do ar quente

Diâmetro adimensional do orificio central do fluxo de saída de ar frio

Diâmetro do orificio central do fluxo de saída de ar frio

Eficiência

Variação de temperatura do fluxo de ar frio

Temperatura do reservatório quente

Temperatura do reservatório frio

Fluxo de calor

Fluxo de Trabalho

Vazão em massa

Entalpia específica 
$\phi$

$\varpi$

$\dot{m}_{a}$

$\dot{m}_{w}$

$\mathrm{T}_{\mathrm{w}}$

$\mathrm{h}_{\mathrm{a}}$

$\mathrm{h}_{\mathrm{v}}$

$\mathrm{h}_{\mathrm{W}}$

f

$\mathrm{M}_{\mathrm{t}}$

$\Delta K E$

$\triangle P E$

$\Delta U$

Q

W

m

Ppneus

$\mathrm{R}_{\mathrm{R}}$

$\mathrm{R}_{\mathrm{a}}$

$\mathrm{R}_{\alpha}$

$\mathrm{R}_{\mathrm{E}}$
Velocidade

Aceleração da gravidade

Cota de altitude

Coeficiente de eficácia do ciclo de refrigeração

Umidade relativa

Umidade absoluta

Vazão em massa de ar

Vazão em massa da água condensada

Temperatura da água condensada

Entalpia específica do ar

Entalpia específica do vapor

Entalpia específica da água condensada

Força resistiva

Torque

Variação de energia cinética

Variação de energia potencial

Variação de energia interna

Calor

Trabalho

Massa

Pressão dos pneus

Resistência ao rolamento

Resistência aerodinâmica

Resistência à inclinação do piso

Resistência ao engrenamento 
Coeficiente global de resistência ao rolamento

$f_{s}$

Coeficiente básico de resistência ao rolamento

$\mathrm{f}_{0}$

Coeficiente de velocidade da resistência ao rolamento

$\rho$

Densidade do ar

Cd

Coeficiente de arrasto aerodinâmico

$\mathrm{A}_{\mathrm{f}}$

Área frontal projetada do veículo

$\alpha$

Ângulo de inclinação do piso

$\mathrm{E}_{\text {liq }}$

Energia líquida disponível para regeneração

$\dot{V}_{\text {req }}$

Vazão volumétrica de entrada de ar requerida

$\dot{m}_{r e q}$

Vazão mássica de entrada de ar requerida

$\mathrm{k}$

Razão de calor específico

$\mathrm{p}_{1}$

Pressão de entrada do compressor

$\mathrm{p}_{2}$

Pressão de saída do compressor

$\mathrm{r}_{\mathrm{p}}$

Razão de pressões

$\mathrm{t}$

Tempo de descarga

$V_{\text {reserv }}$

Volume total do reservatório

$\mathrm{P}_{\min }$

Pressão mínima do reservatório

$\mathrm{P}_{\max }$

Pressão máxima do reservatório

$\mathrm{p}_{\mathrm{atm}}$

Pressão atmosférica 


\section{SUMÁRIO}

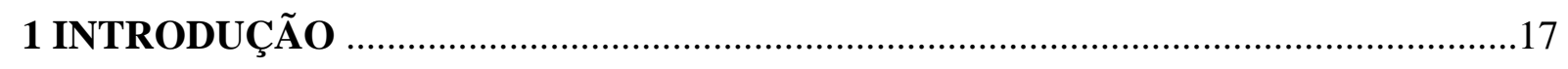

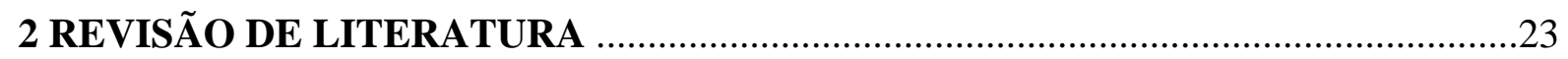

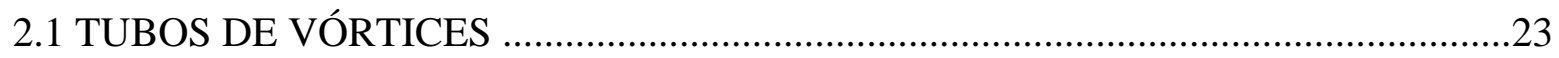

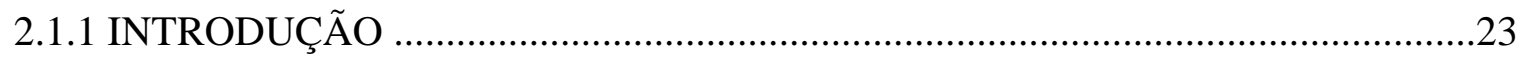

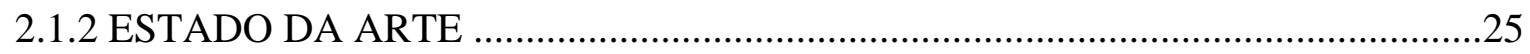

2.2 SISTEMAS CONVENCIONAIS DE AR CONDICIONADO VEICULAR .................36

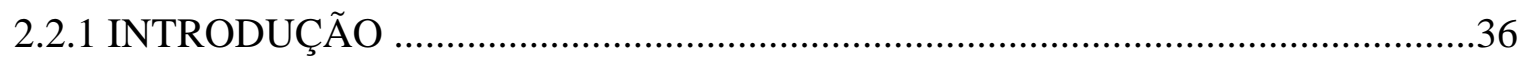

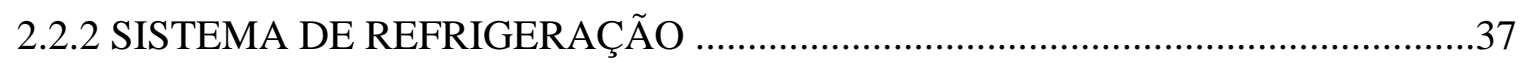

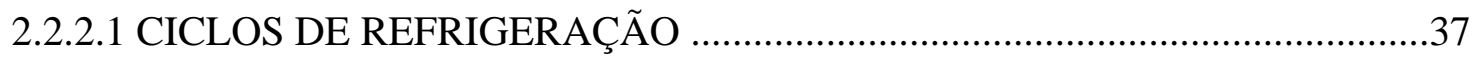

2.2.2.2 TERMODINÂMICA E DESEMPENHO DO CICLO POR COMPRESSÃO

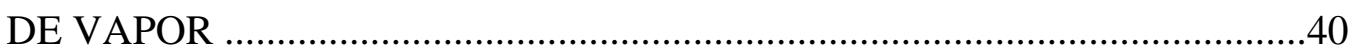

2.2.2.3 COMPONENTES DO SISTEMA DE AR CONDICIONADO

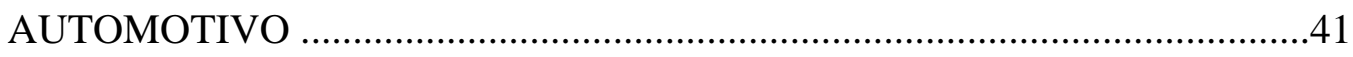

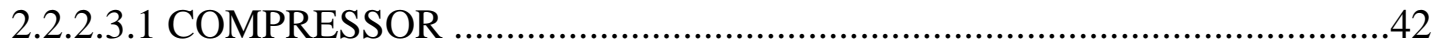

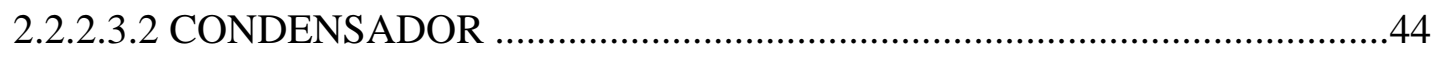

2.2.2.3.3 DISPOSITIVO DE EXPANSÃO …......................................................45

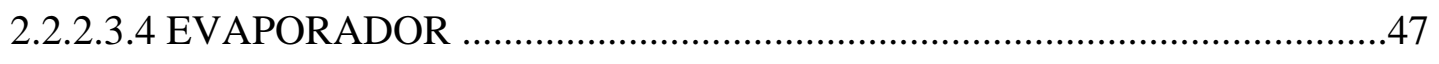

2.2.2.3.5 FLUÍDO REFRIGERANTE ................................................................48

2.2.2.3.6 RESERVATÓRIO DE LÍQUIDO ..........................................................50

2.2.2.3.7. INTERRUPTOR DE ALTA E BAIXA PRESSÃO .................................50

2.2.2.3.8. SENSOR DE TEMPERATURA (TERMOSTATO) ….............................51

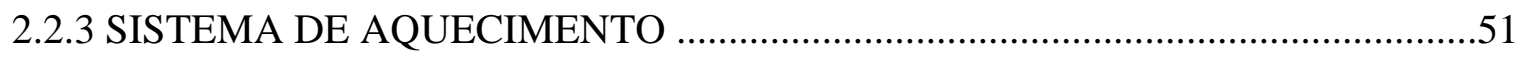

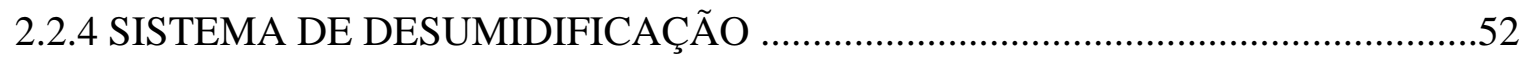


2.2.5 CAIXA DE DISTRIBUIÇÃO DE AR

2.2.6 MODOS DE OPERAÇÃO DO SISTEMA DE AR CONDICIONADO ...................56

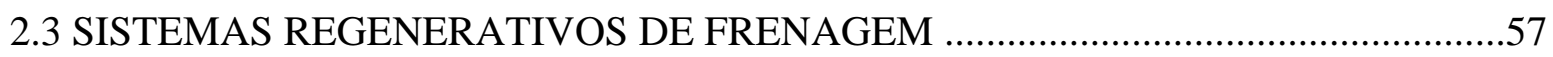

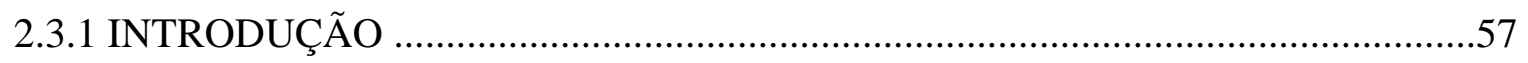

2.3.2 SISTEMAS DE FRENAGEM REGENERATIVOS ELÉTRICOS ...........................58

2.3.3 SISTEMA DE FRENAGEM REGENERATIVO-DISSIPATIVO HIDROPNEUMÁTICO ...................................................................................59

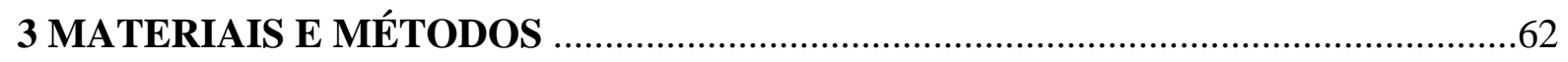

4 REQUISITOS DE OPERAÇÃO E BALANÇO ENERGÉTICO ……………………....64

4.1 PARÂMETROS DE OPERAÇÃO DE UM SISTEMA DE AR CONDICIONADO VEICULAR CONVENCIONAL..............................................................................64

4.2 LIMITES DE APLICAÇÃO DE UM TUBO DE VÓRTICES............................................66

4.3 POTENCIAL DE REGENERAÇÃO ENERGÉTICA NA FRENAGEM DE UM

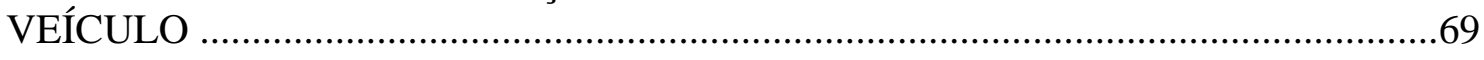

4.3.1 FORMULAÇÃO DO BALANÇO ENERGÉTICO NA FRENAGEM ..................... 69

4.3.2 ENERGIA DISPONÍVEL PARA REGENERAÇÃO …………………………......75

5 SISTEMA DE AR CONDICIONADO VEICULAR BASEADO NA APLICAÇÃO DE TUBOS DE VÓRTICES COM REGENERAÇÃO ENERGÉTICA ……………….....79

5.1 FILOSOFIA DE FUNCIONAMENTO DO SISTEMA.................................................79

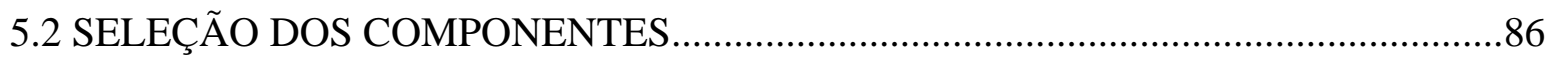

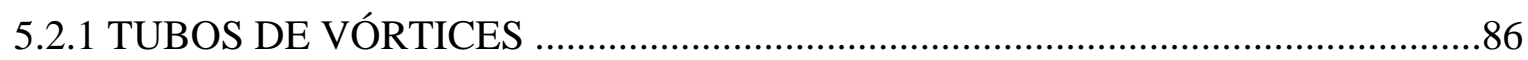

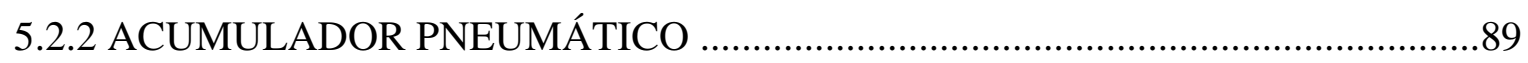

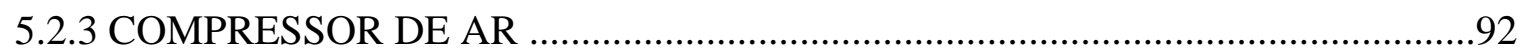

5.3 COMPARAÇÃO DA ENERGIA NECESSÁRIA PARA COMPRESSÃO EM RELAÇÃO Â ENERGIA DE REGENERAÇÃO DISPONÍVEL.......................................94

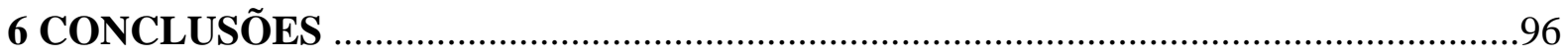

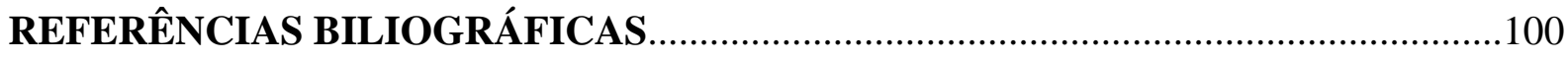

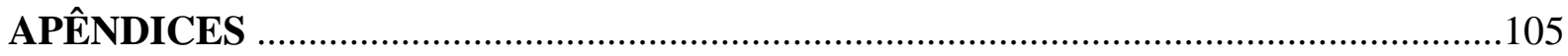




\section{INTRODUÇÃO}

A humanidade, através dos anos tem-se empenhado em desenvolver dispositivos que possibilitem e facilitem sua vida. Um dos segmentos mais importantes citados por Derry e Williams (1993), consiste no desenvolvimento dos transportes.

Derry e Williams (1993) supõe que o primeiro meio de transporte utilizado pela humanidade possa ter sido o transporte braçal, há milhares de anos atrás. Nesta época, os indivíduos do sexo masculino eram responsáveis pela obtenção de alimento, enquanto as mulheres eram responsáveis por preparar os alimentos e cuidar das crianças. Neste contexto, as mulheres eram obrigadas a executar tarefas de transporte, carregando alimentos, utensílios e as próprias crianças.

Somente milhares de anos mais tarde, a humanidade pode usufruir de outros meios de transporte. Derry e Williams (1993) citam quatro fatos que tiveram papel importante para tal avanço: a criação da roda, que possibilitou a construção das primeiras carruagens pelos sumérios por volta de 3500 a.C.; a criação da vela, que possibilitou o aproveitamento dos ventos como forma de propulsão marítima; a construção de estradas, que tiveram papel importante no desenvolvimento de grandes impérios, tais como o império egípcio e o mesopotâmico; a domesticação de animais, tais como os cavalos, dotados de velocidade e resistência.

Através dos milênios, a humanidade otimizou os meios acima citados, de acordo com as suas necessidades, possibilitando o sucesso de seus respectivos impérios. No entanto, foi a revolução industrial, que marcou a introdução de novos materiais e processos de fabricação, que por sua vez revolucionaram os meios de transporte. 
A introdução do aço, a criação das máquinas a vapor e motores de combustão interna, a construção de ferrovias e obras de infraestrutura de transporte (pontes, túneis, estradas estações) foram os primeiros passos que possibilitaram o avanço dos transportes terrestres até o grau de evolução existente hoje (DERRY; WILLIAMS, 1993).

Um dos pioneiros no desenvolvimento de veículos automotores terrestres para transporte fora de trilhos, utilizando-se um motor de combustão interna, foi Karl Benz, considerado o pai dos automóveis. Sua criação, um triciclo que utilizava como propulsão um motor de combustão interna monocilindro, alcançava a velocidade de $13 \mathrm{~km} / \mathrm{h}$. O ano era 1885 e foi seguido pelo lançamento de um motor monocilindro de alta rotação por Gottlieb Daimler (DERRY; WILLIAMS, 1993).

Mais importante que a criação foi a possibilidade da produção em massa de tais dispositivos, com custos e produtividade otimizados. Foi o que fez Henry Ford, revolucionando a manufatura e produzindo o seu Ford-T, com vendas que alcançaram 15.000.000 de unidades em 19 anos de produção (DERRY; WILLIAMS, 1993).

Com o desenvolvimento dos modos de produção em massa, a quantidade de veículos evoluiu bruscamente. A evolução dos sistemas viários na maior parte das grandes cidades não acompanhou tal evolução, resultando em congestionamentos viários qua são observados tão frequentemente e são temas de discussão atualmente.

Desta forma, o automóvel tem passado de mero meio de transporte, para uma extensão do lar das pessoas, uma vez que é comum um indivíduo passar mais de 2 horas diárias dentro de um automóvel, nas grandes cidades. Por esse motivo, tem havido um crescente esforço no sentido de atender aos requisitos de conforto dos ocupantes.

Estudos ergonômicos relacionados ao posicionamento dos assentos e localização de comandos, são exemplos de tentativas de minimizar o estresse do ocupante durante a utilização do automóvel. 
Uma outra ramificação de estudo focada na minimização do estresse do ocupante diz respeito à climatização veicular, realizado convencionalmente através de um sistema de ar condicionado, adaptado à automóveis.

Conforme menciona Kaynakli e Horuz (2003), o sistema de ar condicionado, antes tratado como um mero opcional, presente apenas em automóveis de luxo, tem se tornado item obrigatório não somente em veículos leves de passeio como também em veículos pesados de carga. Não somente o conforto é otimizado, mas também a segurança do ocupante. Isso pode ser explicado pelo fato de que os vidros são mantidos fechados, minimizando a ação de ladrões e minimizando também o estresse térmico do motorista, aumentando consequentemente seu nível de alerta no trânsito. Tribess (2004, p. 6.1) define o estresse térmico como “o resultado de condições microclimáticas desfavoráveis que requerem a intervenção do sistema termoregulador”. É citado ainda que, o estresse térmico pode levar à morte, se a exposição à um ambiente quente ou frio for excessiva.

Em países desenvolvidos, onde as condições socio-econômicas permitem a aquisição de um automóvel de superior grau de sofisticação, o ar condicionado na maior parte das vezes é encarado como um item de série. No entanto, principalmente em países em desenvolvimento essa realidade é menos frequente e o acréscimo do sistema de ar condicionado como item de série implica em aumento significativo do custo do veículo, às vezes inviabilizando a compra do veículo com essas configurações.

Adicionalmente, o sistema de ar condicionado naturalmente necessita de energia para seu funcionamento. Kaynakli e Horuz (2003), apresenta os componentes básicos de funcionamento de um sistema de ar condicionado automotivo, mostrado na Figura 1. 


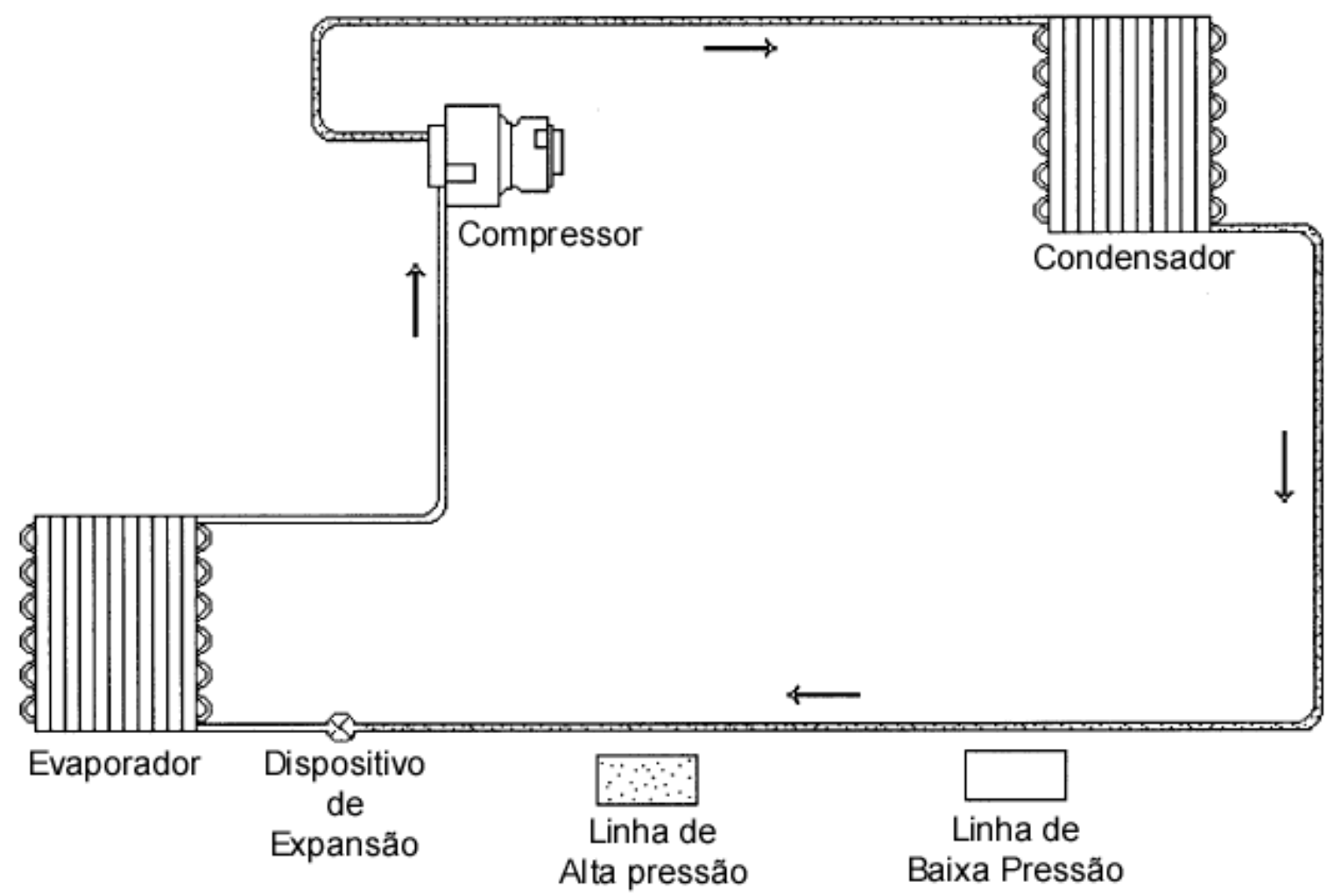

Figura 1. Esquema simplificado de um sistema de ar condicionado automotivo (KAYNAKLI; HORUZ, 2003)

O sistema funciona conforme um ciclo de refrigeração, e por isso é necessário o fornecimento de trabalho ao sistema. Convencionalmente, tal trabalho é injetado ao sistema através do compressor, que é obtido através da transferencia de energia do motor de combustão interna do automóvel. Kaynakli e Horuz (2003) mencionam um exemplo de consumo do compressor de cerca de 1,6 kW (rotação do compressor = $3000 \mathrm{rpm}$, temperatura ambiente $=16^{\circ} \mathrm{C}$, temperatura do ar na entrada do evaporador $=26^{\circ} \mathrm{C}$, fluxo de massa de refrigerante $=0,030 \mathrm{~kg} / \mathrm{s}$, temperatura do condensador $=41^{\circ} \mathrm{C}$ ).

Desta forma, o trabalho executado pelo compressor reflete num aumento de consumo de combustível pelo motor de combustão interna do automóveis, afetando a eficiência global do mesmo. Além do aumento de consumo de combustível apresentado anteriormente, existe uma diminuição na potência disponível para o movimento do veículo. A não existência de dispositivos que administrem o redirecionamento de potência em condições críticas de 
utilização dos veículo, tais como aceleração em ultrapassagem, pode representar perigo real para a vida do motorista e ocupantes em veículo compactos de potência inferior.

Assim, a popularização do sistema de ar condicionado convencional está condicionada à transposição de obstáculos, como a minimização do custo do sistema e a otimização do consumo de energia.

A transposição de tais obstáculos, pode ser alcançado através de diversos caminhos: otimização da eficiência do ciclo de refrigeração, redução de custos dos processos de manufatura e custos de materia prima. Uma vez que esses dois caminhos tem sido fruto de pesquisa nas ultimas décadas e apresentam dificuldades para serem transpostas, uma terceira hipótese seria a utilização de um conceito alternativo de sistema de climatização, diferente de qualquer tipo de sistema já construído.

Neste caminho, a introdução de dispositivos alternativos de climatização, tais como os tubos de vórtices, pode oferecer uma nova solução de climatização veicular.

Conforme Cockerill (1998), os tubos de vórtices (também chamados de tubos de Ranque-Hilsch) são dispositivos simples que separam um fluxo primário de gás em dois fluxos secundários, um deles com temperatura superior à temperatura de entrada e outro com temperatura inferior à temperatura de entrada. Ahlborn et al. (1994) exemplifica a magnitude do diferencial de temperatura: para condições de fluído de entrada com pressão de entrada de $300 \mathrm{kPa}$ e Temperatura $\mathrm{T}=17^{\circ} \mathrm{C}$, é possível extrair fluxos com temperaturas da ordem de $\mathrm{T}=$ $57^{\circ} \mathrm{C}$ (fluxo de alta temperatura) e $\mathrm{T}=-13^{\circ} \mathrm{C}$ (fluxo de baixa temperatura). A simplicidade de tais dispositivos é citado por Saidi e Valipour (2003), conforme apresentado na Figura 2.

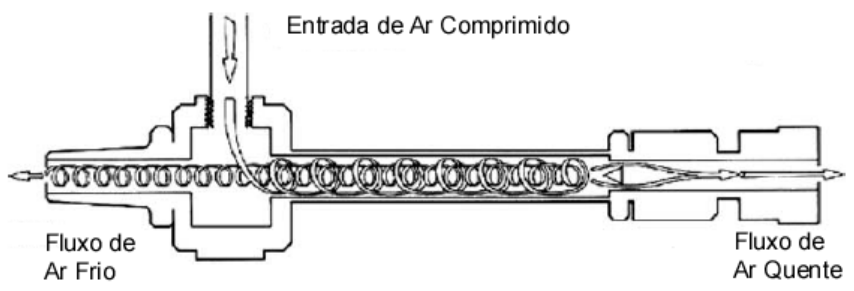

Figura 2. Exemplo de tubo de vórtices (SAIDI; VALIPOUR, 2003) 
A otimização de consumo energético para fins de climatização, pode ser executada mediante estudo de formas de reaproveitamento energético. Analisando um veículo automotor convencional, verifica-se que a energia armazenada é convertida em energia mecânica e posteriormente dissipada no momento da frenagem do veículo, através de dissipação térmica pelo sistema de frenagem. Existem no entanto atualmente, conforme cita Chicurel (1999) e Cikanek e Bailey (2002), sistemas de frenagem regenerativos que armazenam a energia do veículo em movimento em acumuladores de energia, seja em forma elétrica (baterias) ou hidráulica-pneumática.

Desta forma, o objetivo do presente trabalho é estudar a aplicação de um dispositivo alternativo de refrigeração, o tubo de vórtices, em um sistema de ar condicionado veicular. Uma vez que os sistema regenerativos de frenagem são uma realidade atualmente, será também avaliado a aplicação conjunta de um sistema regenerativo em um tubo de vórtices, visando o reaproveitamento energético e otimização de consumo de combustível do veículo. Espera-se encontrar como resultados deste estudo uma alternativa viável aos sistemas de ar condicionado convencionais. 


\section{REVISÃO DE LITERATURA}

A revisão de literatura a ser apresentada a seguir será dividida em três partes distintas: tubos de vórtices, sistemas convencionais de ar condicionado veicular e sistemas regenerativos de frenagem.

Na primeira ramificação de estudo, serão apresentados os conceitos fundamentais de funcionamento e estado da arte dos tubos de vórtices. A seguir, na segunda ramificação, serão abordados o funcionamento e as configurações convencionais de sistema de ar condicionado veiculares. Na terceira ramificação serão apresentados características e configurações de sistemas regenerativos de frenagem.

O objetivo da abordagem das três ramificações é fornecer subsídio básico para o início do estudo de um sistema ar condicionado veicular baseado na aplicação da tecnologia de tubos de vórtices, alimentado por um sistema regenerativo de frenagem.

\subsection{Tubos de Vórtices}

\subsubsection{Introdução}

Os tubos de vórtices, também denominados Tubos de Ranque-Hilsch, são dispositivos mecânicos, sem partes móveis, que possibilitam a divisão de um fluxo principal de fluído em dois fluxos secundários de vazões e temperaturas distintas ${ }^{1}$ (COCKERILL, 1998).

\footnotetext{
${ }^{1}$ Para o melhor entendimento, o fluxo de gás de alta temperatura será identificado neste trabalho como fluxo de gás "quente” e o fluxo de gás de baixa temperatura será identificado como fluxo de gás “frio”.
} 
Fisicamente, tal dispositivo consiste em um tubo cilíndrico dotado de uma entrada de fluído, posicionada de forma que o fluxo adentre-se ao dispositivo radialmente, tangenciando a face interna do tubo. Os fluxos secundários de fluído saem do tubo de vórtices em direções axiais e sentidos opostos ou coincidentes, dependendo do tipo de construção utilizado, conforme citado por Cockerill (1998).

A Figura 3 apresenta o tipo de construção mais comum, denominado contrafluxo. Tal configuração recebe tal denominação, uma vez que os fluxos secundários saem do dispositivo em direções contrárias. Cockerill (1998) indica que o fluxo de gás frio é expulso do tubo de vórtices através de uma das extremidades do tubo, que é restringida através de uma tampa com um orifício circular posicionada no centro do tubo. O fluxo de gás quente é expulso do dispositivo na direção oposta à saída do fluxo de gás frio. Tal extremidade do dispositivo também apresenta uma válvula no formato de um cone que realiza o ajuste da relação entre fluído de baixa temperatura / fluído aquecido.

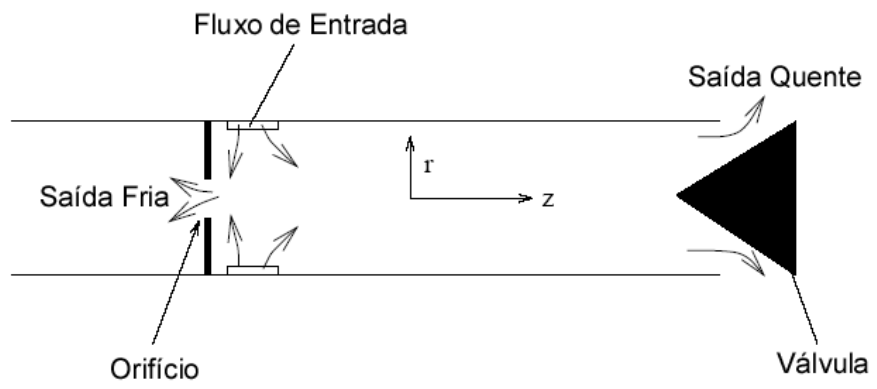

Vista Lateral

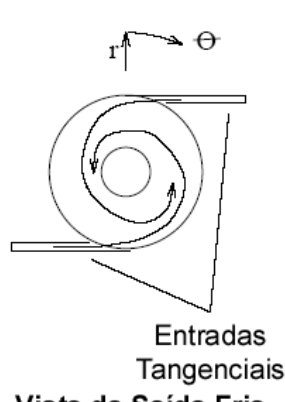

Vista da Saída Fria

Figura 3. Exemplo de tubo de vórtices configuração contra-fluxo (COCKERILL, 1998)

A Figura 4 apresenta uma variação do tubo de vórtices denominado unifluxo. Cockerill (1998) cita que, ao contrário do caso anterior, os dois fluxos saem do dispositivo na mesma extremidade, sendo que a separação entre fluxo de gás frio e fluxo de gás quente é realizada pela válvula que é dotada de um orifício, por onde o fluxo de gás frio é expulso. 
Observando as Figuras 3 e 4, fica evidente a não existência de partes móveis no tubo de vórtices, minimizando a complexidade de tais dispositivos. Essa característica compõe uma das vantagens de tais dispositivos. A outra vantagem de tais dispositivos, constitui a magnitude do diferencial de temperatura entre os fluxos quente e frio.

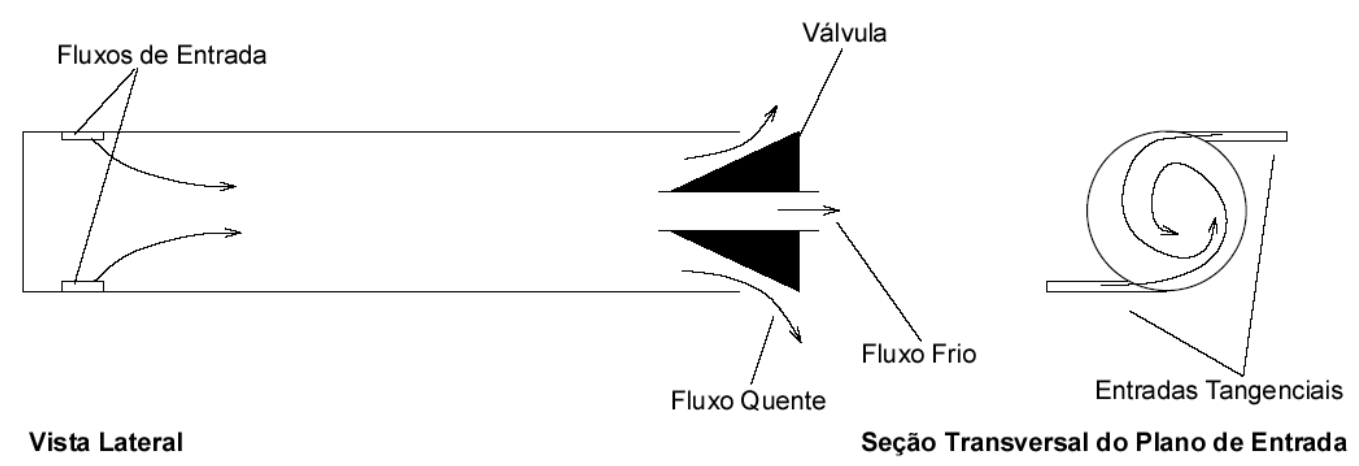

Figura 4. Exemplo de tubo de vórtices configuração unifluxo (COCKERILL, 1998)

Ranque (1933) cita que o diferencial de temperatura depende da relação entre as vazões de saída de fluxo de ar quente e fluxo de ar frio. Utilizando um tubo de vórtices de diâmetro 12mm e pressão do fluxo de entrada de 6 kgf/cm² (589 kPa), Ranque (1933) obteve uma diferença de temperatura de $70^{\circ} \mathrm{C}$ para a condição de débito mínimo do fluxo quente.

\subsubsection{Estado da arte}

Os primeiros registros da existência de um dispositivo capaz de gerar fluxos distintos de ar frio e ar quente, através de processo de troca de energia em escoamentos rotativos, datam de 1933 pelo cientista francês Georges Ranque.

Em seu estudo dos escoamentos rotativos, Ranque (1933) compõe dois enunciados básicos. O primeiro enunciado menciona a existência de uma camada de fluído dentro de um escoamento giratório, denominanda como “camada ativa” por Ranque (1933), delimitando uma zona central em depressão. O segundo enunciado menciona a existência de uma migração energética, das regiões internas para as regiões externas da camada ativa. Para isso, 
foi aplicada a hipótese de que a camada ativa é suficientemente espessa e longa, estando na condição de regime permanente.

A fim de comprovar tais enunciados, Ranque (1933) executou uma série de experimentos, que constituem os primeiros registros dos tubos de vórtices que se tem notícia. No entanto tais experimentos possuem caráter qualitativo, sendo que uma abordagem quantitativa e detalhada foi apresentado por Hilsch (1946).

Hilsch (1946) afirma que, para que os efeitos do diferencial térmico seja alcançado, algumas características construtivas devem ser obedecidas. O fluxo de alimentação deve ser posicionado tangencialmente e o mais próximo possível do diafragma, garantindo que o escoamento rotativo do fluído tenha o centro de rotação coincidente com o centro do tubo. Hilsch (1946) cita ainda a dificuldade de realizar uma simulação teórica, devido à quantidade de variáveis existentes. Por esse motivo, ele executou uma série de experimentos, utilizando um tubo de vórtices cujo esquema é mostrado na figura 5.

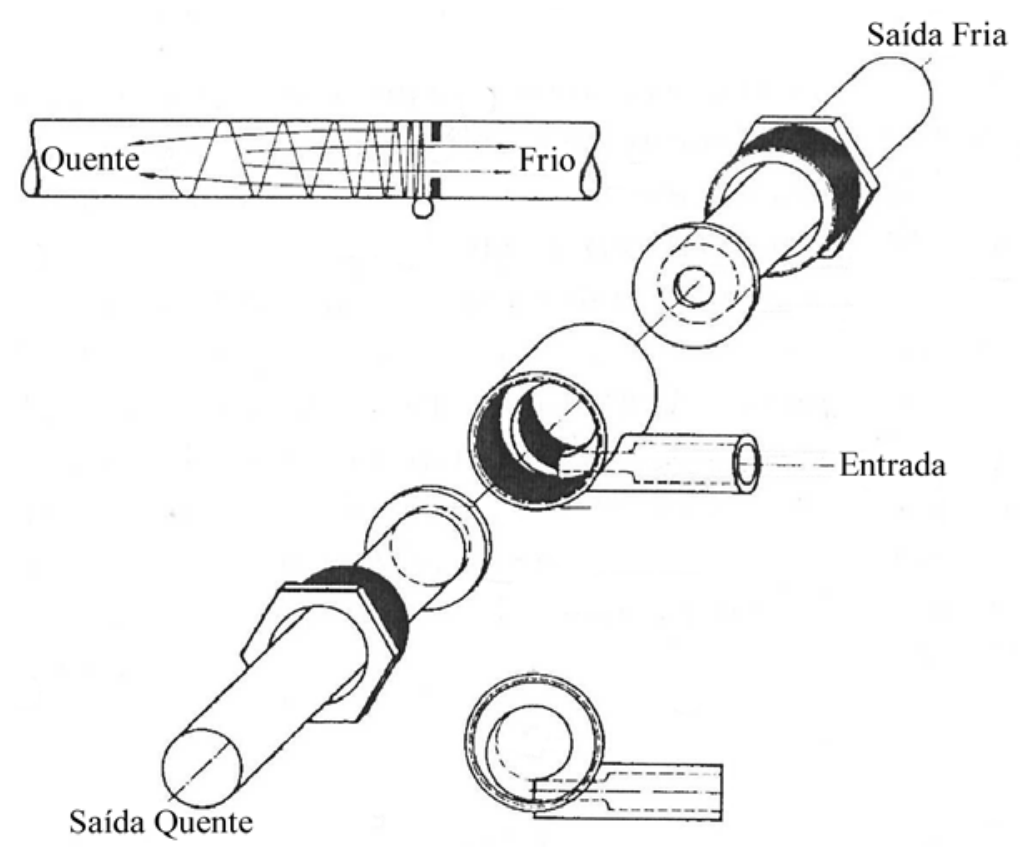

Figura 5. Tubo de vórtices utilizado por Hilsch (HILSCH, 1946)

Hilsch (1946) executou os experimentos em diversas condições, com a variação do diâmetro do orifício central localizado do lado da saída do fluxo de ar frio, pressão do fluído 
de entrada e relação entre a vazão em massa do fluxo frio e fluxo quente. Os resultados de tais experimentos são apresentados na Figura 6.

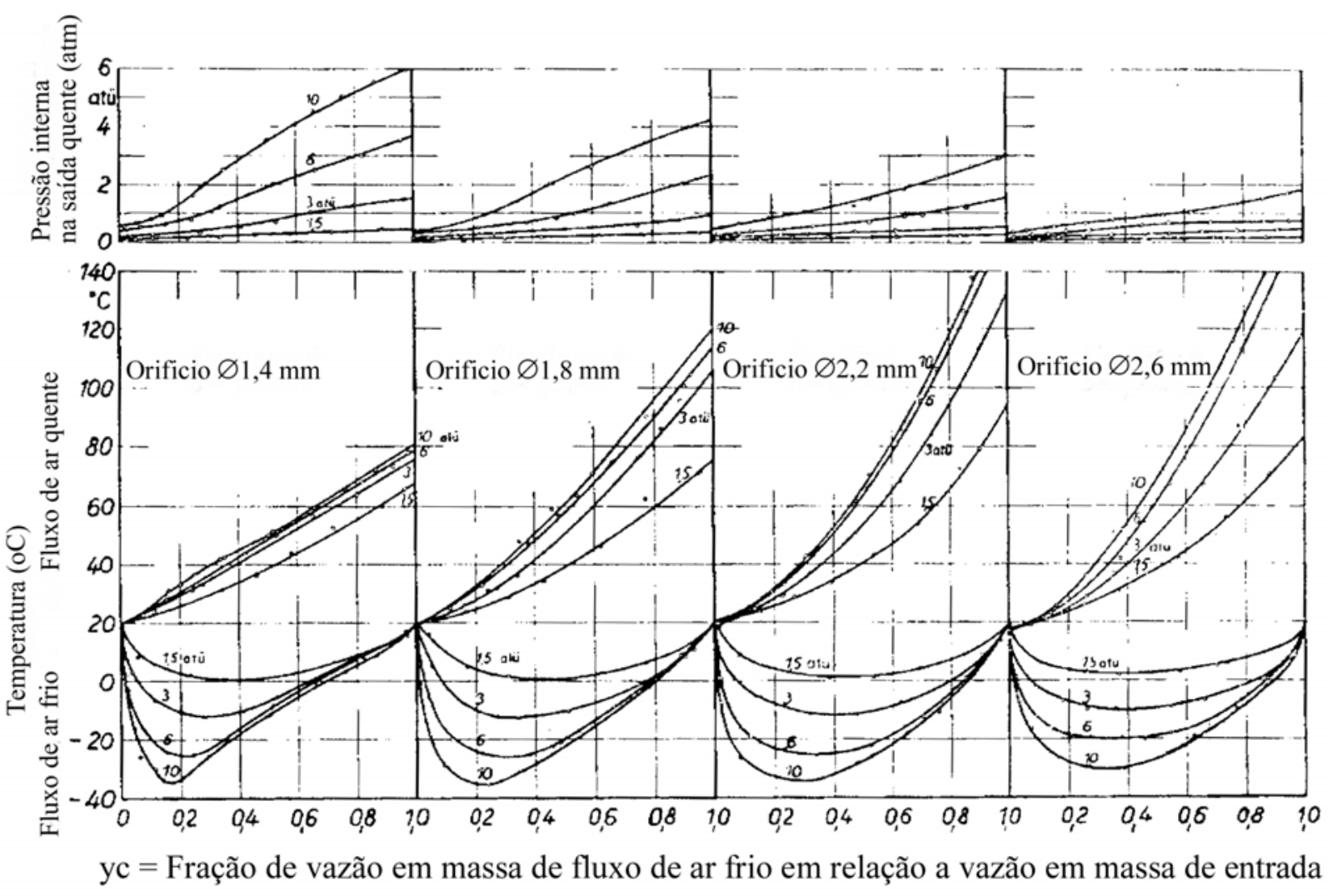

Figura 6. Temperatura e pressão nos fluxos de saída em função da fração de vazão em massa de fluxo de ar frio em relação à vazão em massa de entrada (HILSCH, 1946)

Pengelley (1957) cita que até aquela data, muitos estudos haviam sido feitos sobre os tubos de vórtices, no entanto a maior parte dos estudos eram de caráter qualitativo ou empírico. Nenhum dos estudos anteriores deixava claro o entendimento do mecanismo físico envolvido. Desta forma, Pengelley (1957) extendeu o estudo focado na termodinâmica de vórtices bidimensionais, iniciado anteriormente por outros pesquisadores tais como Dornbrand (1950) apud Pengelley (1957). As conclusões obtidas por Pengelley (1957) informam que as ações das forças viscosas em vórtices compressíveis podem transferir energia na forma de trabalho ao longo do raio, permitindo assim uma redução de temperatura em direção ao centro, sendo este um efeito equivalente à expansão de gás através de uma turbina. 
Sibulkin (1962) realizou uma investigação avançada do fenômeno dos tubos de vórtices. Numa primeira fase da investigação obteve-se perfis de temperatura e velocidade, calculados teoricamente, sendo que numa segunda fase Sibulkin (1962) desenvolveu uma teoria a fim de predizer as características de performance de um tubo de vórtices.

Em função da quantidade de variáveis que afetam a performance dos tubos de vórtices

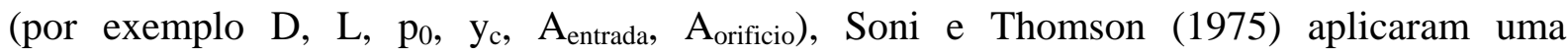
metodologia de análise experimental a fim de identificar as variáveis que apresentam uma grande influência na performance dos tubos de vórtices. A aplicação da metodologia das Operações Evolucionárias (EVOP), resultou na obtenção dos seguintes valores ótimos, que são mostrados na Tabela 1.

Tabela 1 - Valores ótimos de $A_{\text {entrada }} A_{\text {orificio }}$ e L / D para máxima variação de temperatura do fluxo de ar frio (SONI; THOMSON, 1975)

\begin{tabular}{ccc}
\hline & Unidade & Valor \\
\hline $\mathrm{A}_{\text {entrada }}$ & $(-)$ & $0,11+-0,01$ \\
$\mathrm{~A}_{\text {orificio }}$ & $(-)$ & $0,08+-0,01$ \\
$\mathrm{~L} / \mathrm{D}$ & $(-)$ & $>45$ \\
\hline
\end{tabular}

Até aquela data vários estudos relacionados à geometria dos tubos de vórtices foram realizados no intuito de obter o máximo de diferença de temperatura. No entanto não existia nenhum estudo focado na relação entre a geometria do tubo e o fluxo espiral resultante. Takahama e Yokosawa (1981) citam que o fluxo espiral obtido pelo tubo de vórtices poderia ter grande importância em algumas aplicações industriais, tais como otimização de transferência de calor, controle de combustão e concentração de urânio. Desta forma Takahama e Yokosawa (1981) iniciaram um estudo examinando a possibilidade de diminuir o comprimento da câmara, sem grandes queda na eficiência de separação energética. Para a comparação da performance de tubos com diversos comprimentos de câmaras, Takahama e Yokosawa (1981) definiram a eficiência de separação energética conforme a equação 1. 


$$
\eta=\frac{\left(h_{d e}-h_{d c}\right)}{\left[(\Delta h)_{j a t o}+(\Delta h)_{d e-p d c}\right]}
$$

Onde: $h_{\text {de }}=$ Entalpia específica do ar na entrada de $d_{e}(k J / k g)$

$\mathrm{h}_{\mathrm{dc}}=$ Entalpia específica do ar na saída de $\mathrm{d}_{\mathrm{c}}(\mathrm{kJ} / \mathrm{kg})$

$(\Delta \mathrm{h})_{\text {jato }}=$ Variação de entalpia específica dinâmica do jato $(\mathrm{kJ} / \mathrm{kg})$

$(\Delta \mathrm{h})_{\mathrm{de}-\mathrm{pdc}}=$ Variação de entalpia específica isoentropica entre o estado da saída de $\mathrm{d}_{\mathrm{e}} \mathrm{e}$ a pressão em $\mathrm{d}_{\mathrm{c}}(\mathrm{kJ} / \mathrm{kg})$

As conclusões obtidas por Takahama e Yokosawa (1981) demonstram que a obtenção de máxima energia de separação só é possível quando L > 100D, sendo que a eficiência de separação energética em câmaras divergentes é maior que em câmaras de diâmetro constante, para o mesmo comprimento. Takahama e Yokosawa (1981) verificaram também que para uma conicidade de 3\% , o comprimento da câmara faz pequena diferença na performance do tubo para L > 38D. Desta forma, concluiu-se que para câmaras divergentes, é possível diminuir o comprimento da mesma sem afetar em muito a eficiência.

A determinação do mecanismo do fenômeno de Ranque-Hilsch tem gerado uma grande disputa ao longo dos anos. Kurosaka (1982) apresenta uma teoria em que ondas acústicas induzem distúrbios ordenados dentro do fluxo espiral em tal nível, de forma a causar a separação energética. A fim de comprovar a influência de tais ondas, Kurosaka (1982) realizou um experimento equipando um tubo de vórtices unifluxo com supressores acústicos que minimizavam a amplitude das ondas e reduziam a diferença de temperatura.

Stephan et al. (1983) realizariam mais tarde um estudo do processo de separação energética cujo resultado mostrou a distribuição da variação de temperatura do fluxo de ar de baixa temperatura ao longo do comprimento da câmara do tubo de vórtices. Além disso, Stephan et al. (1983) afirma que os Vórtices de Görtler são as forças principais que atuam na separação de energia dentro do tubo de vórtices: a partir de um experiência, utilizando tubos isolados e não isolados, verificou-se que a variação de temperatura em tubos não isolados é 
menor que em tubos isolados. A justificativa fornecida por Stephan et al. (1983) é que havendo a troca de calor com o meio externo nos tubos não isolados, o comprimento dos vórtices de Görtler agindo na parede interna da câmara diminui, diminuindo assim as forças que agem na separação energética.

Stephan et al. (1984) estabeleceram uma relação de similaridade entre a variação de temperatura do fluxo frio em função da fração de fluxo frio, para tubos de vórtices geometricamente similares, através de uma formulação matemática. A formulação matemática foi aplicada para diversos gases (ar, Helio e Oxigênio), sendo obtido gráficos de variação de temperatura do fluxo frio em função da fração de fluxo frio $\left(\mathrm{y}_{\mathrm{c}}\right)$. Em paralelo foram extraídos dados experimentais nas mesmas condições da simulação teórica. Os resultados experimentais vieram a confirmar a relação de similaridade proposta pela formulação matemática. A figura 7 demonstra tal relação.

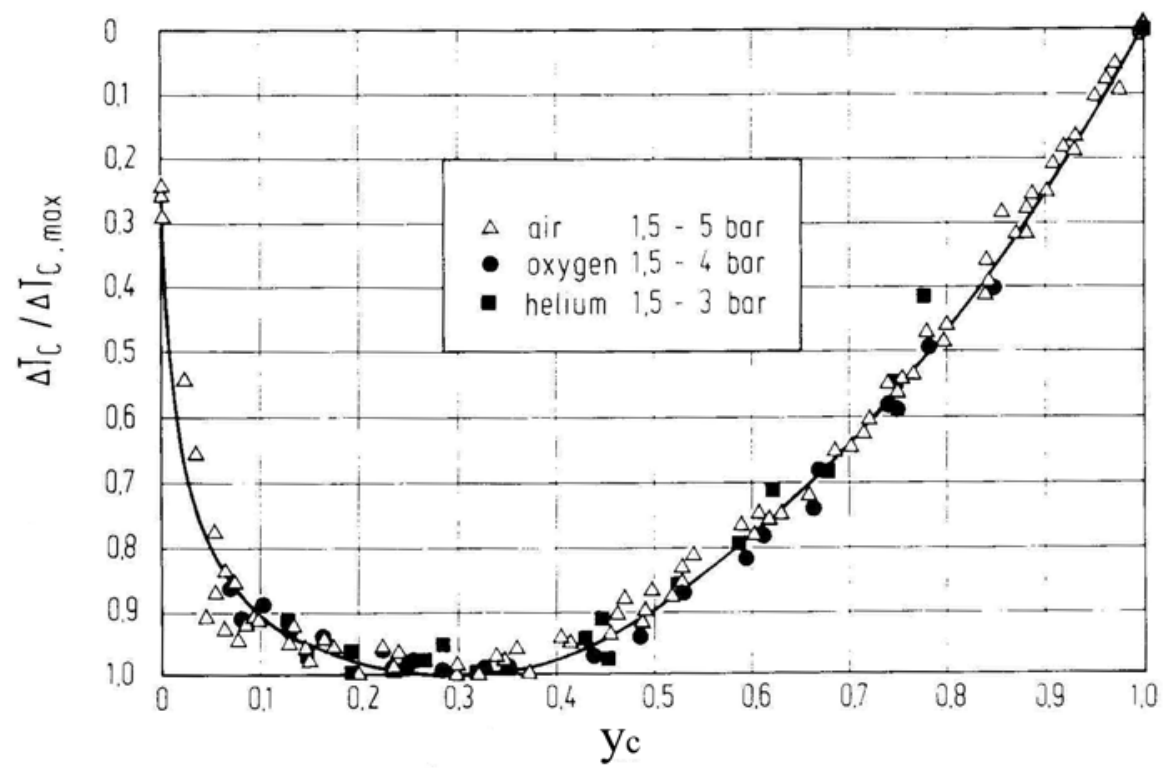

Figura 7. Relação de similaridade comparada com dados experimentais do ar, Oxigênio e Helio (STEPHAN et al, 1984)

Analisando a figura 7, verifica-se que a relação entre a variação parcial de temperatura do fluxo de ar frio $\left(\Delta \mathrm{T}_{\mathrm{c}}\right)$ e a variação máxima de temperatura do fluxo de ar frio $\left(\Delta \mathrm{T}_{\mathrm{c}}\right.$, max $)$, é 
independente do gás de trabalho / pressão de entrada, dependente apenas da fração de fluxo de ar frio.

Mais recentemente Alhborn et al (1994) realizaram um estudo focado na influência da energia cinética nos fluxos de ar quente e frio sendo expulsos do tubo de vórtices. Para isso, Alhborn et al. (1994) utilizaram equações integrais simplificadas das equações de conservação de energia a fim de obter os limites de operação de um tubo de vórtices com fluxos de saída bilateral. A primeira conclusão de Alhborn et al (1994) consiste no fato de que o aquecimento ou o resfriamento dos fluxos de entrada e saída são função da queda de pressão (X), que é dado pela equação 2. A Figura 8 demonstra a representação das linhas de fluxo do fluído dentro do tubo de vórtices.

$$
X=\left(\frac{p_{0}-p_{\text {frio }}}{p_{0}}\right)
$$

onde: $\quad \mathrm{X}=$ queda de pressão (-)

$\mathrm{p}_{0}=$ pressão do fluxo de ar de entrada $(\mathrm{kPa})$

$\mathrm{p}_{\text {frio }}=$ pressão do fluxo de saída de ar frio $(\mathrm{kPa})$

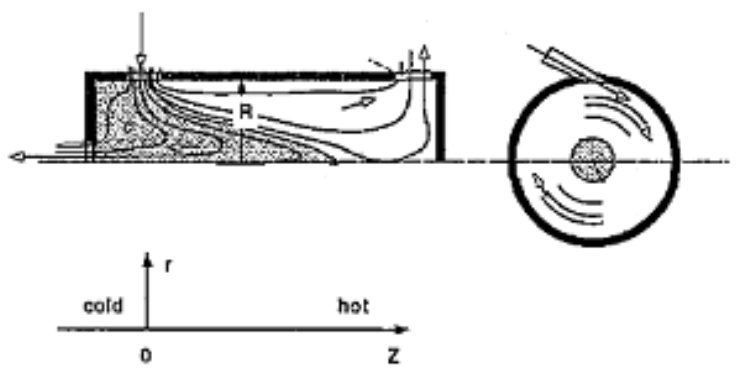

Figura 8. Representação das linhas de fluxo dentro do tubo de vórtices (ALHBORN et al., 1994)

A segunda conclusão que Alhborn et al. (1994) obtiveram, diz respeito ao fato que o número de Mach é função da queda de pressão citada anteriormente. Desta forma, uma variação na queda de pressão de forma que o número de Mach ultrapasse o limite de 1,0 é indesejável, uma vez que isso resultaria na formação de ondas de choque, cujas descontinuidades poderiam reduzir as velocidades para valores subsonicos. Alhborn et al. 
(1994) citam que, foram utilizados valores de $\mathrm{p}_{0}$ e $\mathrm{p}_{\text {frio }}$ de forma a resultar em escoamentos supersônicos, porém observou-se escoamento subsonicos no interior do tubo, o que confirmou a teoria apresentada anteriormente. Alhborn et al. (1994) obtiveram um valor ótimo de operação, com o valor de queda de pressão $X=0,7$. Vale lembrar que o alcance de tal valor está relacionado com a diferença de pressões de entrada e saída, ou seja, pressões relativas. Desta forma, Alhborn et al. (1994) mostram que é possível o alcance de tal queda de pressão mesmo em pressões de entrada baixas desde que as pressões de saída sejam subatmosféricas.

Alhborn, Camire e Keller (1996) analisaram o efeito da operação de tubos de vórtices em baixas pressões. Para isso, foi realizado um experimento onde foi acrescentado uma bomba de vácuo nas saídas do tubo de vórtices. A operação do tubo de vórtices em tais condições, mostrou a possibilidade de incorporação de tubos de vórtices em ciclos fechados com pressões subatmosféricas.

A procura de novas formas de otimizar a eficiência dos tubos de vórtices, levaram Piralishvili e Polyaev (1996), a estudar geometrias otimizadas dos tubos de vórtices de circuito-duplo, anteriormente estudados por Piralishvili e Mikhailov (1973) apud Piralishvili e Polyaev (1996) e Suslov et al. (1985) apud Piralishvili e Polyaev (1996). Os resultados obtidos neste experimento mostraram um aumento na eficiência de separação energética, chegando numa otimização de até $70 \%$ para algumas condições de trabalho ( $\mathrm{y}_{\mathrm{c}}=0,85 \sim 1,00$ ), no entanto demonstrando também grande instabilidade. Piralishvili e Mikhailov (1973) definiram a eficência de separação energética como a eficiência adiabática, ou seja, a relação entre a queda de temperatura do fluxo de ar frio e a queda de temperatura obtida em um expansor de gás operando com a mesma diferença de pressão do tubo de vórtices, multiplicado pela fração de fluxo de ar frio.

Saidi e Yazdi (1998) realizaram um estudo de obtenção de dimensões e condições de operação otimizadas, aplicando a abordagem de análise de exergia. 
A fim de avaliar o efeito da variação de parâmetros geométricos na eficiência isoentrópica e nos parametros termofísicos do tubo de vórtices, Saidi e Volipour (2003) realizaram um modelamento experimental de um tubo de vórtices operando com a função de refrigeração. Para isso foram utilizadas variações de tubos de vórtices, porém obedecendo algumas características principais: diâmetro do tubo (18mm), área da seção transversal da somatória dos orificio do fluxo de entrada constante $\left(28,9 \mathrm{~mm}^{2}\right)$, diâmetro do orifício do diafragma (9mm).

O primeiro parâmetro avaliado consistiu em L/D, sendo que o intervalo otimizado de L/D encontra-se entre 20 e 55,5 (conforme apresentado na Figura 9). Logo:

$$
20 \leq \frac{L}{D} \leq 55,5
$$

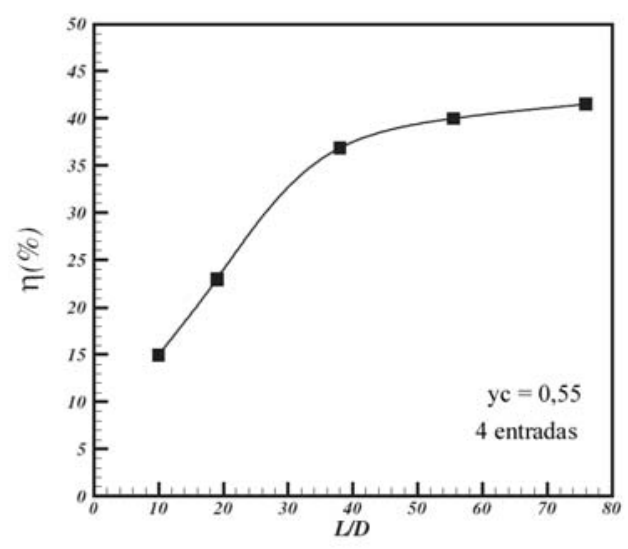

Figura 9. Eficiência em função da relação diâmetro / comprimento (SAIDI; VALIPOUR, 2003)

O segundo parâmetro avaliado por Saidi e Volipour (2003) constitui o diâmetro adimensional do orificio do fluxo secundário de ar frio $\left(\mathrm{d}_{\mathrm{c}}{ }^{*}\right)$, que pode ser descrito como:

$$
d_{c}^{*}=\frac{d_{c}}{D}
$$

onde: $\mathrm{d}_{\mathrm{c}} *=$ diâmetro adimensional do orifício central do fluxo de ar frio (-)

$\mathrm{d}_{\mathrm{c}}=$ diâmetro do orifício central do fluxo de ar frio (mm) 
Experimentalmente, obteve-se que o diâmetro que fornece a eficiência otimizada corresponde $a d_{c}^{*}=0,5$. A avaliação de $d_{c}$ pode ser efeita analisando a Figura 10 e a Figura 11 , que apresentam respectivamente as curvas $\Delta \mathrm{T}_{\mathrm{c}} \mathrm{x} \mathrm{d}_{\mathrm{c}}{ }_{\mathrm{c}}$ e $\eta \mathrm{x} \mathrm{d}_{\mathrm{c}}{ }_{\mathrm{c}}$ :

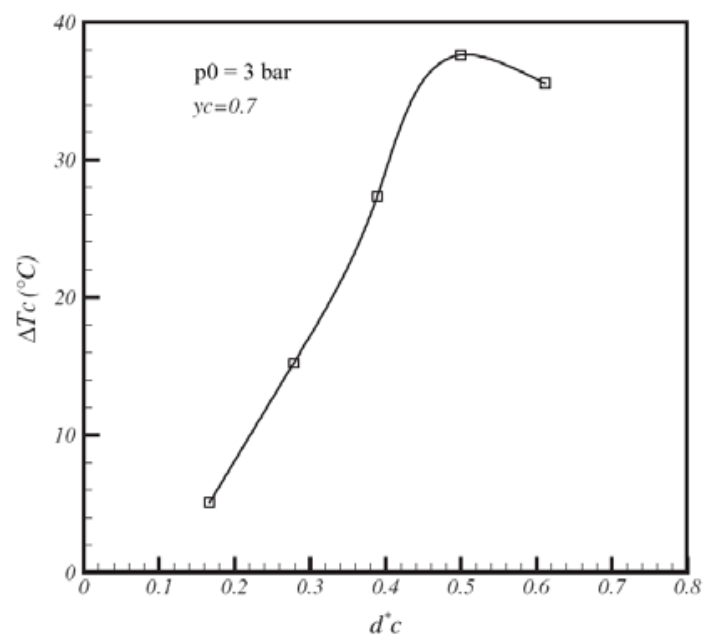

Figura 10. Variação de temperatura do fluxo de ar frio em função do diâmetro adimensional do orificio central de saída do fluxo frio (SAIDI; VALIPOUR, 2003)

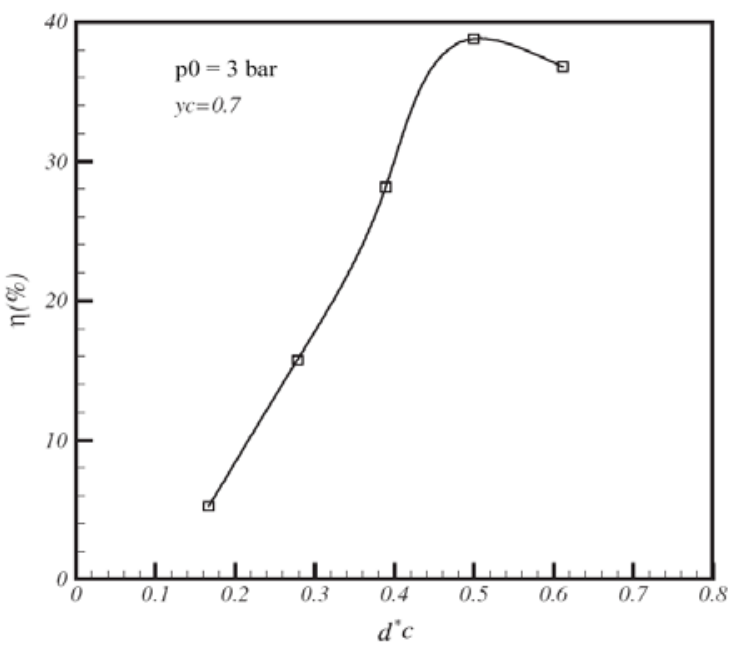

Figura 11. Eficiência em função do diâmetro adimensional do orifício de saída do fluxo frio (SAIDI; VALIPOUR, 2003)

O terceiro parâmetro avaliado por Saidi e Volipour (2003) constitui o número de orifícios de entrada de fluxo de ar. Analisando as Figuras 12 e 13, Saidi e Volipour (2003) concluem que a melhor alternativa dentre estas duas opções, corresponde à entrada com três entradas ${ }^{2}$.

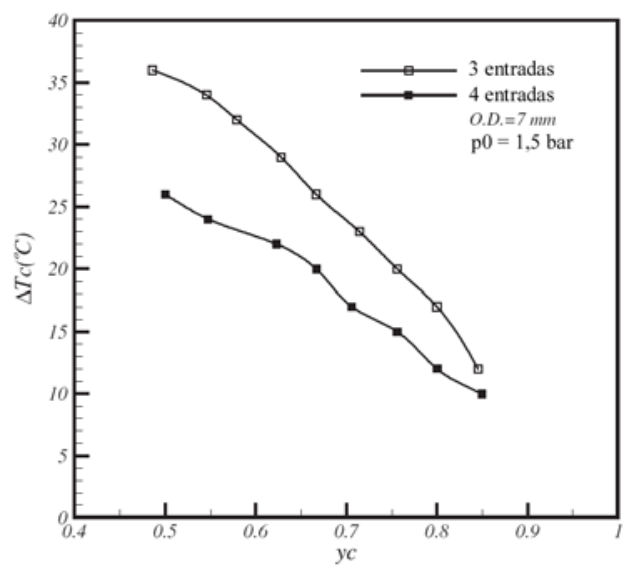

Figura 12. Variação de temperatura do fluxo de ar frio em função da fração de fluxo frio para configurações de 3 e 4 entradas (SAIDI; VALIPOUR, 2003)

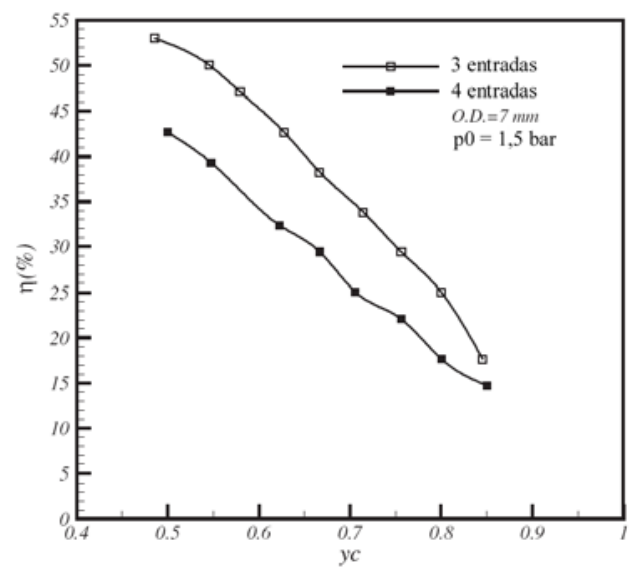

Figura 13. Eficiência em função da fração de fluxo de ar frio para configurações de 3 e 4 entradas (SAIDI; VALIPOUR, 2003)

\footnotetext{
${ }^{2}$ Manteve-se a somatória das área da seção transversal constante a fim de manter a vazão em massa de entrada constante.
} 
A segunda parte do trabalho de Saidi e Volipour (2003) investiga as propriedades termofísicas. A primeira análise realizada avalia a fração do fluxo frio de saída em relação ao fluxo de entrada do tubo de vórtices $\left(\mathrm{y}_{\mathrm{c}}\right.$ ) com a eficiência isentrópica ( $\eta$ ) e a variação de temperatura do fluxo refrigerado $\left(\Delta \mathrm{T}_{\mathrm{c}}\right)$. As Figuras 14 e 15, apresentam respectivamente o resultado dessas relações.

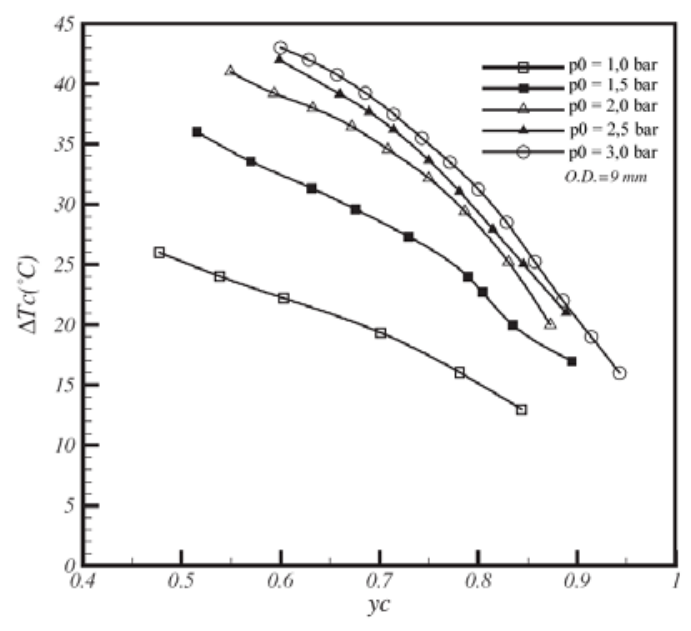

Figura 14. Variação de temperatura do fluxo de ar frio em função da fração de fluxo frio para diversas pressões de entrada (SAIDI; VALIPOUR, 2003)

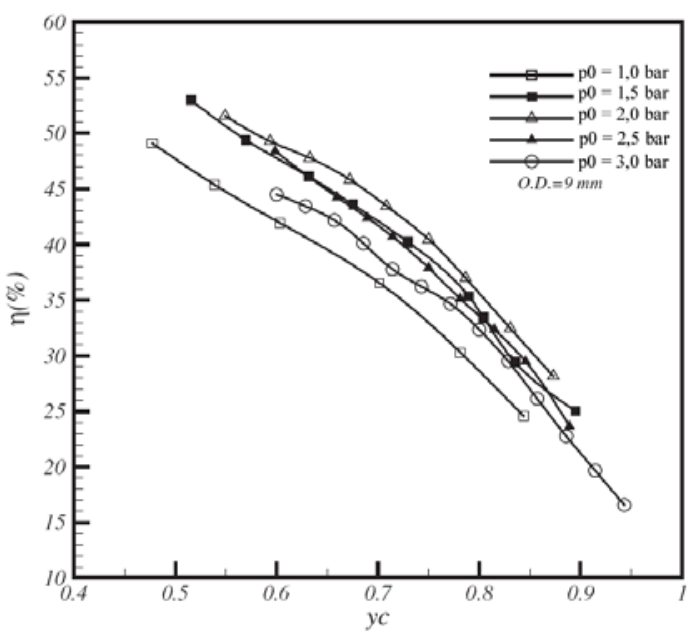

Figura 15. Eficiência em função da fração de fluxo de ar frio para diversas pressões de entrada (SAIDI; VALIPOUR, 2003)

Saidi e Volipour (2003) também avaliaram a relação entre a pressão do fluxo de entrada $\left(\mathrm{p}_{0}\right)$ e a eficiência isentrópica $(\eta)$ e a variação de temperatura do fluxo refrigerado $\left(\Delta \mathrm{T}_{\mathrm{c}}\right)$. As Figuras 16 e 17, apresentam respectivamente o resultado dessas relações:

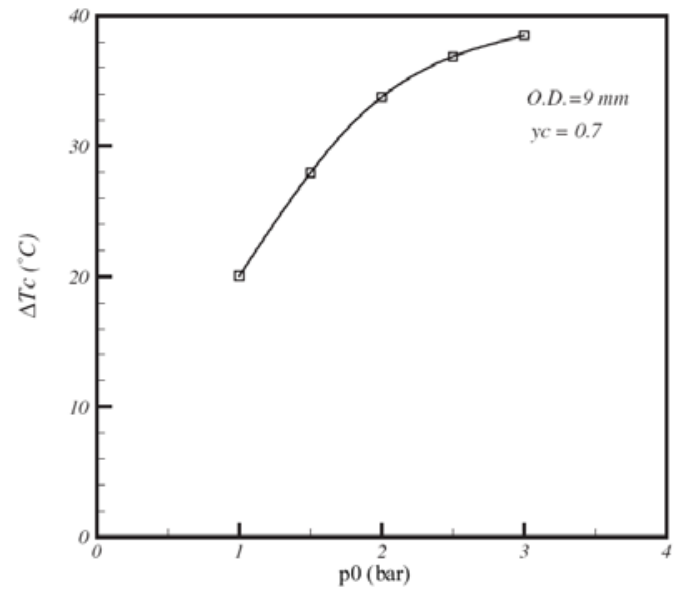

Figura 16. Variação de temperatura do fluxo de ar frio em função da pressão de entrada (SAIDI; VALIPOUR, 2003)

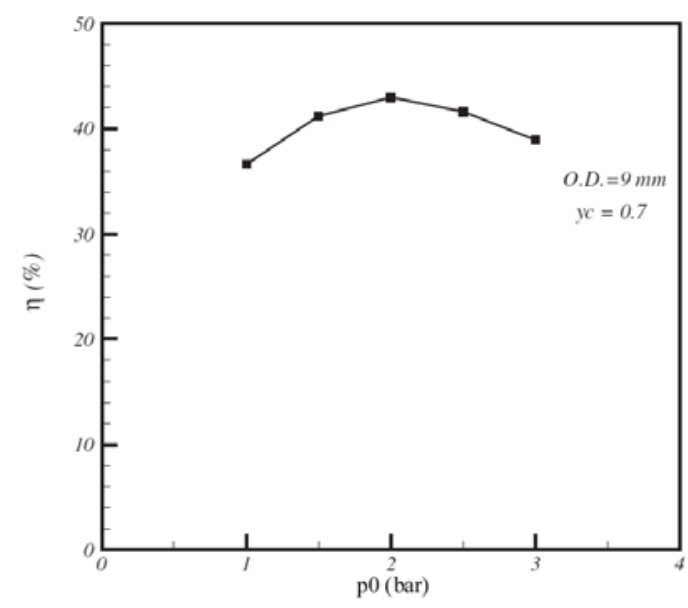

Figura 17. Eficiência em função da pressão de entrada (SAIDI; VALIPOUR, 2003) 
Prosseguindo com seu estudo, Saidi e Volipour (2003) avaliaram a influência da umidade na variação da temperatura do fluxo refrigerado. O resultado obtido através de medições antes e depois de umidificações do fluído, foi que a umidificação do ar comprimido injetado no tubo de vórtices, aumenta a temperatura do fluxo refrigerado.

\subsection{Sistemas Convencionais de Ar Condicionado Veicular}

\subsubsection{Introdução}

O sistema de ar condicionado veicular não somente possui a função de prover conforto térmico aos ocupantes do veículo. Através do controle de temperatura e umidade do habitáculo, o sistema de ar condicionado aumenta o nível de alerta do motorista e a segurança dos ocupantes, mantendo os vidros fechados do veículo, conforme cita Kaynakli e Horuz (2003). Já Forrest e Bhatti (2002), citam que um sistema de ar condicionado compreende quatro distintas funções: controle de temperatura, controle de umidade, controle de circulação e ventilação de ar e limpeza do ar.

Ao contrário do que se geralmente se pensa, um sistema de ar condicionado possui não somente o sistema de refrigeração, mas também outros subconjuntos que trabalham em conjunto para promover o funcionamento do sistema completo. A seguir serão abordados tais sistemas. 


\subsubsection{Sistema de Refrigeração}

\subsubsection{Ciclos de Refrigeração}

São vários os tipos de ciclos de refrigeração que podem ser aplicados num sistema de ar condicionado. Conforme Moran e Shapiro (2004) os ciclos de refrigeração mais utilizados são: ciclo de refrigeração Brayton e o ciclo de refrigeração por compressão de vapor.

O ciclo de refrigeração Brayton consiste em um ciclo de refrigeração a gás, que não sofre mudança de estado, conforme cita Moran e Shapiro (2004). As aplicações de tais ciclos são diversas, tais como a liquefação de fluídos e refrigeração de cabines de aeronaves. O esquema de um ciclo Brayton, é apresentado na figura 18:

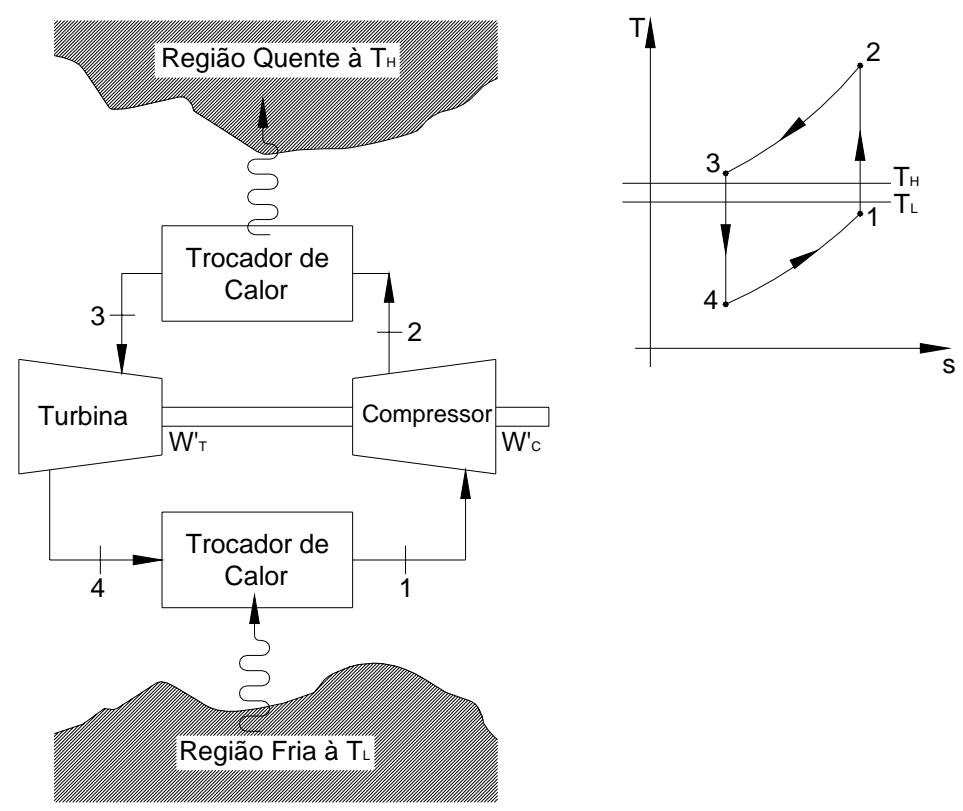

Figura 18. Ciclo de refrigeração Brayton (MORAN; SHAPIRO, 2004)

Dos ciclos de refrigeração utilizados atualmente, o ciclo de refrigeração por compressão de vapor é o mais aplicado, conforme cita Moran e Shapiro (2004), sendo que o mesmo é baseado no ciclo de refrigeração de Carnot. A figura 19 apresenta o ciclo de Carnot. 


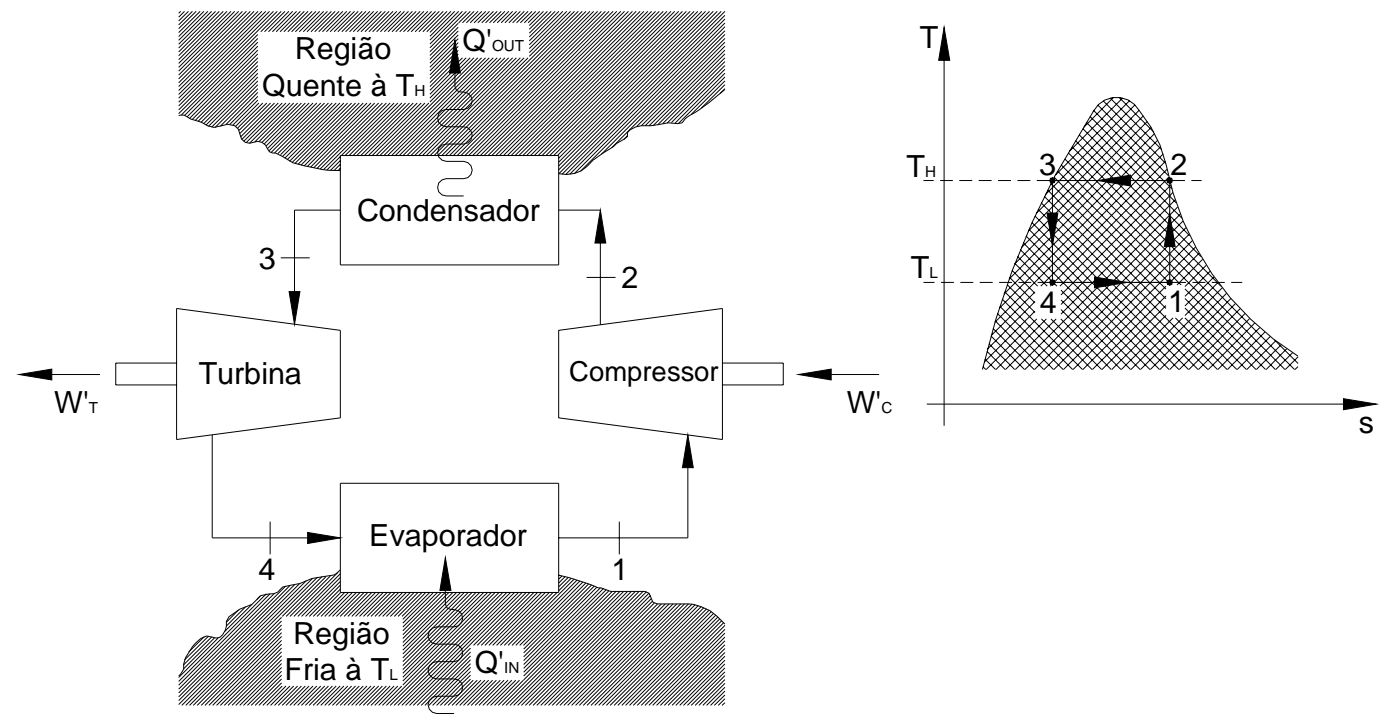

Figura 19. Ciclo de refrigeração de Carnot (MORAN; SHAPIRO, 2004)

No ciclo de refrigeração de Carnot, um fluído deve circular através de componentes específicos, num ciclo fechado reversível. A seguir será feito um detalhamento das etapas do ciclo, conforme apresentado em Moran e Shapiro (2004):

a) Inicialmente, um determinado fluído num estado de líquido-vapor (estado 1), é comprimido adiabaticamente passando para vapor saturado (estado 2). A compressão é feita por um compressor, logo existe trabalho sendo fornecido ao sistema. Nessa operação, o fluído não somente tem sua temperatura elevada (de $T_{L}$ para $T_{H}$ ), como também sua pressão.

b) Após a saída do compressor, o vapor saturado (estado 2) passa por um condensador, que tem a propriedade de trocar calor com um reservatório quente a uma temperatura $\mathrm{T}_{\mathrm{H}}$. Neste processo existe a mudança de estado, de vapor saturado para líquido saturado (estado 3), mantendo porém a pressão e temperatura do estado 2.

c) Saindo do condensador, o fluído no estado 3 passará por uma turbina, onde haverá a expansão do fluído, passando este para o estado 4. No estado 4, a temperatura do fluído retorna para $T_{L}$, havendo também uma redução de pressão do mesmo. No 
estado 4 o fluído é caracterizado como líquido-vapor. Uma vez que a turbina é acionada, existe trabalho de eixo saindo do sistema.

d) Após a saída do fluído da turbina, adquirindo um estado 4, o fluído em estado líquidovapor passa pelo evaporador, onde existe transferência de calor do reservatório frio para o fluído. Logo, o fluído retorna para o estado 1, sendo que não há mudança de temperatura e pressão nesta fase do processo.

Como citado anteriormente, o ciclo de refrigeração Carnot é considerado um ciclo reversível. Desta forma, é impossível a reprodução de um ciclo reversível em uma aplicação real, uma vez que existem perdas nos processos.

Moran e Shapiro (2004) citam algumas observações que devem ser feitas no processo, de maneira que os mesmos sejam adequados à realidade.

a) A primeira observação diz respeito à passagem do fluído (estado 4) pelo evaporador. Para que a temperatura do reservatório frio seja mantida a uma temperatura $T_{L}$, o fluído no estado 4 (que entra no evaporador) deve estar à uma temperatura abaixo de $T_{L}$. Isso acontece devido ao fato de que os evaporadores reais não proveem uma taxa de troca de calor suficiente para manter a temperatura do reservatório frio em $T_{L}$. De forma análoga, a temperatura do fluído no condensador deve ser superior à temperatura do reservatório quente $\left(\mathrm{T}_{\mathrm{H}}\right)$, para que se obtenha uma taxa de troca de calor suficiente.

b) A segunda observação diz respeito ao estado do fluído no processo de compressão. Existem restrições técnicas por parte do compressor, no que diz respeito à compressão de um fluído no estado líquido-vapor. A presença de líquido no compressor causa o chamado "calço-hidráulico" que resulta em danos no compressor, devido ao fato do 
líquido ser um fluído não-compressível. Desta forma, deve-se sempre trabalhar com fluído no estado de vapor, no compressor.

c) A terceira observação diz respeito ao processo de expansão através da turbina. As condições do fluído no estado 3, fazem com que a eficiência da turbina seja muito baixa, com a geração de uma quantidade pequena de trabalho. Desta forma, a turbina pode ser trocada por dispositivos de expansão de custo bem inferior, tais como as válvulas de expansão ou tubos capilares.

Levando-se em conta as observações apresentadas acima, obtem-se o ciclo por compressão de vapor, que corresponde ao ciclo base dos sistemas de refrigeração dos automóveis atuais. O esquema de tal ciclo é apresentado na figura 20.

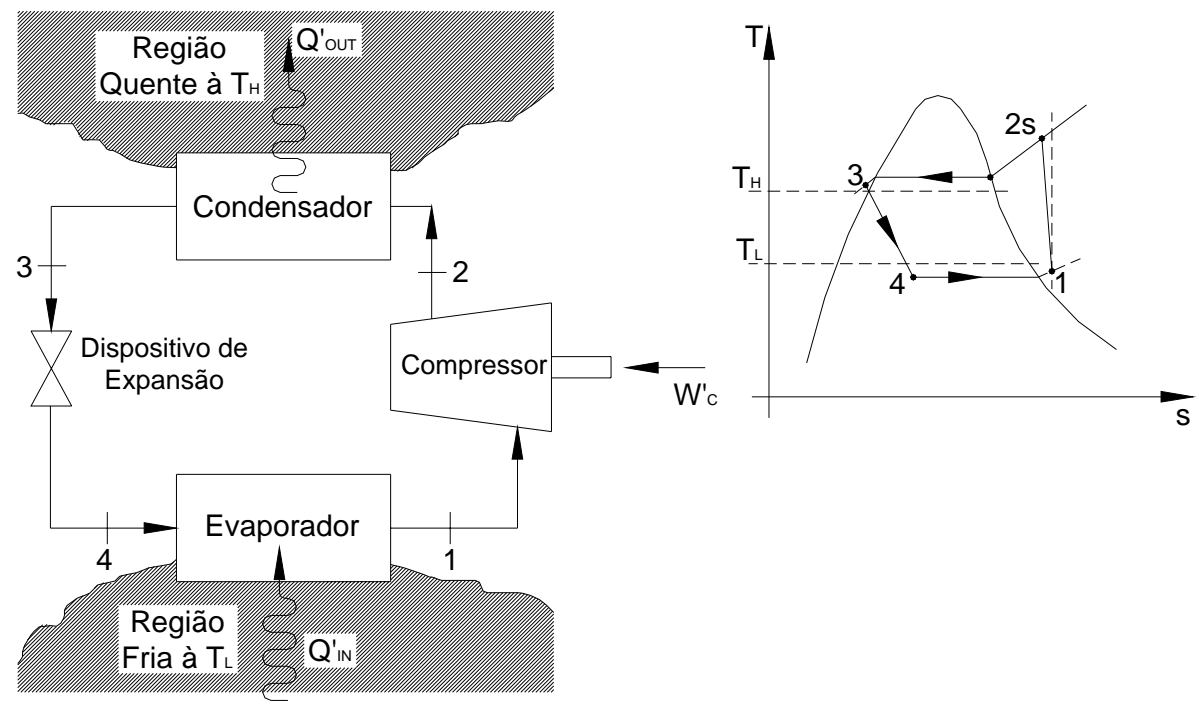

Figura 20. Ciclo de refrigeração por compressão de vapor (MORAN; SHAPIRO, 2004)

\subsubsection{Termodinâmica e desempenho do ciclo por compressão de vapor}

A avaliação do taxa de calor e potência do ciclo, pode ser realizado através da aplicação da Primeira Lei da Termodinâmica para Volumes de Controle, conforme cita Van Wylen, Sonntag e Borgnakke (1998), apresentado na equação 5.

$$
\dot{Q}_{v . c .}+\dot{m}\left(h+v^{2} / 2+g \cdot Z\right)_{\text {entrada }}=\dot{W}_{v . c .}+\dot{m}\left(h+v^{2} / 2+g \cdot Z\right)_{\text {saída }}
$$


Adotando as hipóteses apresentadas a seguir, tem-se a equação simplificada da primeira lei da termodinâmica para volumes de controle:

- Regime Permanente;

- Energia Potencial por unidade de massa entre entrada e saída é desprezível;

- Energia Cinética por unidade de massa entre entrada e saída é desprezível.

$$
\dot{Q}-\dot{W}=\dot{m}\left(h_{\text {saída }}-h_{\text {entrada }}\right)
$$

A avaliação da performance de um ciclo de refrigeração pode ser feita através da aplicação do coeficiente de eficácia ( $\beta$ ). Tal coeficiente corresponde na relação entre o efeito da refrigeração e o trabalho de eixo a ser injetado no sistema a fim de obter tal efeito da refrigeração, conforme apresenta Moran e Shapiro (2004).

$$
\beta=\left(h_{1}-h_{4}\right) /\left(h_{2}-h_{1}\right)
$$

Os estados de 1 a 4 representados da equação 7 podem ser visualizados na figura 20.

A avaliação da performance do compressor pode ser obtida através da do cálculo do rendimento isoentrópico. Tal eficiência avalia a relação entre a potência de eixo consumida num caso real e a potência de eixo consumida num processo adiabático reversível, conforme cita Moran e Shapiro (2004).

$$
\eta_{\text {isoentropico }}=W_{\text {eixo }} / W_{\text {isoentropico }}
$$

\subsubsection{Componentes do sistema de ar condicionado automotivo}

Conforme apresentado anteriormente, o sistema de ar condicionado de um veículo tem seu funcionamento baseado no ciclo de compressão de vapor, apresentado na figura 20. Um esquema dos componentes de um sistema de ar condicionado automotivo é apresentado na figura 21 . 


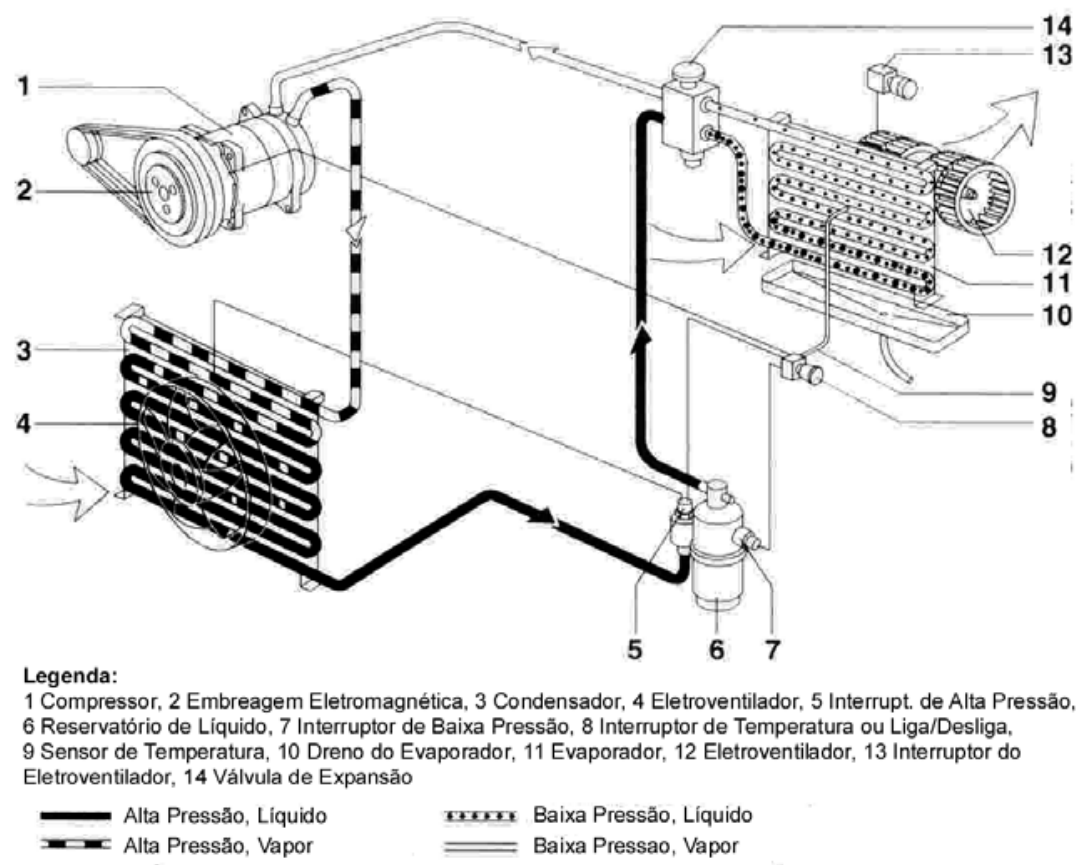

Figura 21. Componentes de um sistema de ar condicionado automotivo (utilizando válvula de expansão) (BOSCH, 2000)

Os componentes apresentados na figura 21, serão melhor detalhados a seguir, apresentando sua variações construtivas e demais peculiaridades.

\subsection{Compressor}

Um compressor de um sistema de Ar Condicionado Automotivo consiste num dispositivo que promove a movimentação do fluído refrigerante num circuito fechado, conforme cita Tribess (2004). A movimentação do fluído e consequente passagem pelos diversos componentes do sistema de refrigeração atribui diversas condições de pressão e temperatura ao fluído refrigerante. Conforme apresentado por Bosch (2000) na figura 21, o fluído refrigerante possui diferentes pressões e estados, em cada das 4 etapas do processo.

Convencionamente, o acionamento do compressor é realizado através de correias ligadas ao motor do veículo, conforme pode ser visualizado na figura 21. Uma vez que o compressor está constantemente acoplado ao motor do veículo, torna-se necessário algum 
mecanismo que permita que o compressor permaneça em repouso quando o sistema de ar condicionado esteja desligado, mesmo com o motor do veículo em funcionamento. Tal mecanismo consiste na embreagem magnética, que é disposto entre o eixo e a polia do compressor, conforme é apresentado por General Motors (2003) (informação corrente).

A embreagem magnética é composta por uma bobina indutora e um prato de acionamento que quando acionada, há a passagem de corrente elétrica na bobina resultando na atração desta ao prato de acionamento. A atração entre os dois elementos resulta na transmissão do movimento rotativo da polia para o eixo do compressor.

O mecanismo de compressão difere conforme o tipo de compressor. Tribess (2004) apresenta 5 tipos de compressores: radial de pistões, axial de pistões “Washplate”, axial de pistões “Wobbleplate”, rotativo de palhetas e tipo caracol "Scroll”. É citado ainda por Tribess (2004), que os compressores mais utilizados atualmente são os tipo de pistões axiais e rotativos dotados de controle de deslocamento volumétrico. A figura 22 exemplifica um compressor "Wobbleplate”.

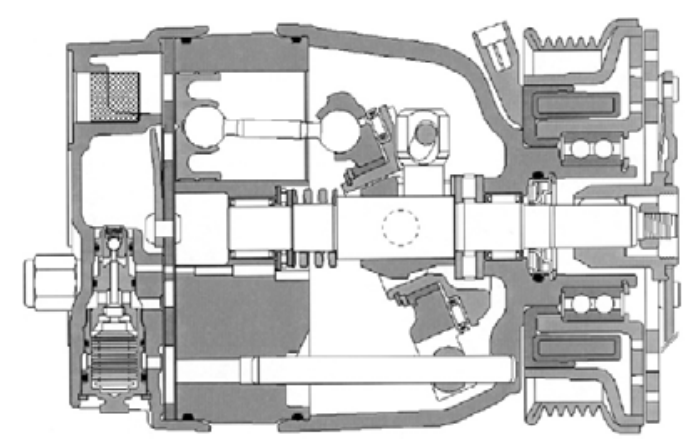

Figura 22. Compressores de pistões axiais tipo “wobbleplate” (DELPHI AUTOMOTIVE, 2005)

Um compressor de ar condicionado deve ser capaz de trabalhar numa ampla faixa de rotação e vazão. A potência de compressão varia conforme as características de trabalho do sistema. 
Ianella (1998) apud Tribess (2004), realizou um estudo relacionado ao desempenho de um sistema de ar condicionado de um veículo de passeio (Seat Ibiza 1.6L Gasolina). É apresentado um gráfico que informa uma potência de compressão que varia entre 1,0 e 1,5 $\mathrm{kW}$, capacidade de refrigeração por volta de 3,2 kW, taxa de calor de rejeição no condensador que varia entre 4,2 e 4,5 kW, em função da rotação do compressor que varia entre 1500 e 5500 rpm (Temperatura do ar na entrada no evaporador $=20^{\circ} \mathrm{C}$; Vazão de ar no evaporador $=$ $500 \mathrm{~kg} / \mathrm{h}$; velocidade do ar no condensador $=3 \mathrm{~m} / \mathrm{s})$.

Joudi et al. (2003) realizaram um estudo experimental de desempenho de um sistema de ar condicionado analisando diversos fluídos refrigerantes. Para uma rotação de 3000 rpm, a uma capacidade de refrigeração de 3,5 kW, a potência de acionamento do compressor foi de 3,5 kW (fluído R12, Temperatura Ar externo $=50{ }^{\circ} \mathrm{C}, \mathrm{COP}=1,37$ ).

\subsection{Condensador}

O condensador consiste em um trocador de calor responsável pela dissipação do calor absorvido pelo fluído refrigerante no evaporador. A fim de otimizar a troca de calor, o condensador é posicionado na parte frontal do veículo, entre a grade frontal e o radiador do veículo. A dissipação de calor do fluído para o ambiente, provoca uma mudança de estado do fluído, que entra no condensador no estado gasoso e deve sair do evaporador no estado líquido.

Tribess (2004) informa que os condensadores são feitos preferencialmente em Alumínio, onde tubos são dispostos paralelamente, unidos por aletas a fim de aumentar a área de troca de calor com o ambiente.

São diversos os tipos de condensadores existente atualmente no mercado. Tribess (2004) cita que para uma dada taxa de transferencia, o peso, volume e carga de refrigerante 
necessária pode variar até respectivamente 30\%, 15\% e 25\%. A figura 23 apresenta um exemplo de condensador.

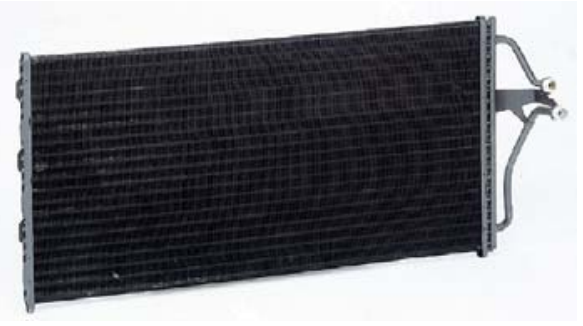

Figura 23: Condensador de um sistema de ar condicionado convencional (DELPHI AUTOMOTIVE, 2005)

\subsection{Dispositivo de Expansão}

O dispositivo de expansão consiste num componente que tem a função de reduzir a pressão do fluído refrigerante que sai no estado líquido do condensador, além de controlar a vazão no circuito. Conforme Tribess (2004), existem dois tipos de dispositivos de expansão, utilizados em sistemas de refrigeração automotivos: a válvula termostática e os tubos de orificio.

A válvula termostática consiste no tipo de dispositivo utilizado na indústria automotiva. Tribess (2004) informa que tal dispositivo permite a regulagem de vazão do fluído refrigerante, que é feito através da avaliação do superaquecimento do fluído refrigerante no evaporador.

Tal avaliação é executada através de um bulbo fixado na parede do evaporador, que mantem-se em comunicação com uma câmara, através de um duto de ligação. A câmara por sua vez, faz parte da válvula de expansão, e possui um diafragma ligado à uma válvula. O bulbo assim como o duto e a câmara, estão preenchidos com fluído refrigerante líquido (denominado fluído ativo) que possui propriedade de expandir se este for submetido à um aumento de temperatura. Desta forma, havendo um aumento de temperatura no evaporador, o fluído ativo expandirá deslocando o diafragma, que por sua vez acionará a válvula a fim de liberar a passagem de mais fluído refrigerante para o evaporador. Uma diminuição da 
temperatura no evaporador ocasionará o efeito contrário ao descrito anteriormente, fechando assim a válvula. A figura 24 exemplifica uma válvula de expansão.

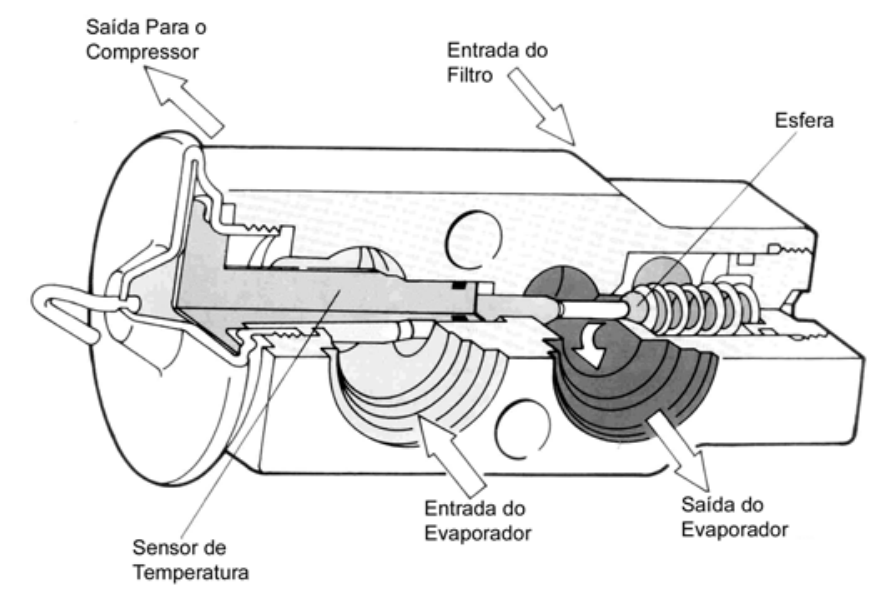

Figura 24. Válvula de expansão (VOLKSWAGEN, 1994)

Os tubos de orifício consistem no segundo tipo de dispositivo de expansão, utilizado na indústria automotiva. Tribess (2004) cita que, havendo a passagem pelo tubo de orifício (de comprimento constante), é introduzido uma grande perda de carga ao fluído, provocando uma grande redução de pressão. Tal redução de pressão é capaz de converter o fluído refrigerante que está em estado líquido, para o estado de vapor.

Em geral, os tubos de orifício são envoltos por tela nas regiões de entrada e saída. A tela na região de entrada tem o objetivo de filtrar o fluído, evitando à passagem de eventuais detritos pelo tubo: tais detritos poderiam obstruir o tubo. Já a tela na região de saída, tem o obejtivo de minimizar a transmissão de ruídos, gerados no processo de vaporização, para o resto do sistema. A figura 25 apresenta um exemplo tubo de orifício.

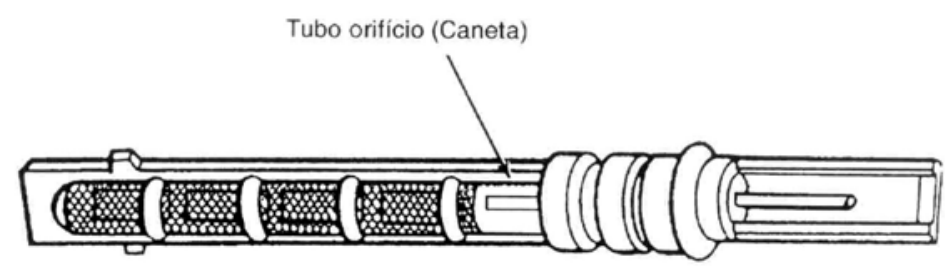

Figura 25. Tubo de orifício (GENERAL MOTORS, 2003) 
Tribess (2004) afirma ainda que os tubos de orifícios possuem um custo bem inferior às válvulas de expansão termostáticas (aproximadamente R\$ 2,00 / un). Tal custo facilita na manutenção do sistema, uma vez que havendo falhas no dispositivo de expansão, simplesmente há a troca do tubo de orifício.

\subsection{Evaporador}

O evaporador, assim como o condensador, consiste num trocador de calor. Tribess (2004) cita a existência de três variações de tipos de evaporadores: tubos e aletas, serpentina e placas.

Conforme Tribess (2004), os evaporadores de tubos e aletas são formadas por placas planas dispostas paralelamente que são atravessadas por tubos que tem o objetivo de condução do fluído refrigerante. As placas tem o objetivo de aumentar a área de troca de calor, assim como caso do condensador. Apesar da fácil construção, esse tipos de evaporador possui baixo desempenho por unidade de volume.

Os evaporadores do tipos serpentina são formados por tubos contínuos de seção retangular, dobrados em formato de serpentina e unidos por aletas, estas soldadas ao tubo. Esse tipos de construção oferece uma eficiência superior à construção anterior (TRIBESS, 2004).

A última configuração de evaporadores é formada por placas metálicas dotadas de canais internos. Tais canais distribuem o fluído de uma extremidade à outra da placa até os coletores receptores, onde conduzirão por sua vez à próxima placa metálica disposta paralelamente à primeira placa. Este tipo de construção é o que apresenta maior desempenho dentre os três, provocando assim um aumento na sua aplicação na indústria automotiva nos ultimos anos (Tribess, 2004). A figura 26 apresenta um evaporador tipo placas. 


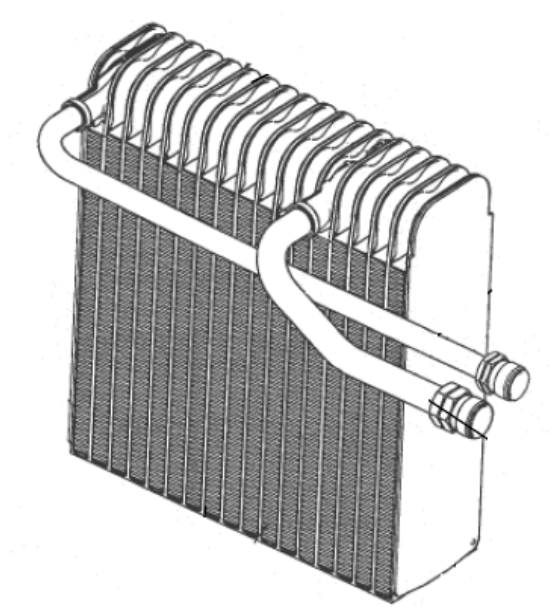

Figura 26. Evaporador tipo placas (DELPHI AUTOMOTIVE, 2005)

\subsection{Fluído Refrigerante}

O fluído refrigerante é o meio pelo qual a energia térmica presente no habitáculo será transferida para o ambiente externo. Para isso, é necessário que o fluído tenha algumas propriedades básicas, conforme cita Tribess (2004):

- Não inflamável e tóxico;

- Estável quimica e termicamente;

- Alta miscibilidade com lubrificantes;

- Possibilidade de produção em grande escala;

- Entalpia de vaporização elevada;

- Baixa temperatura de saturação à pressão atmosférica;

- Pressões de saturação não muito elevadas;

- Temperatura crítica elevada.

Os crescentes estudos iniciados na década de 70 sobre a relação entre o CFC (Clorofluorcarbono) e a camada de ozônio e posterior constatação da diminuição de espessura da camada de ozônio estratosférica, levaram à assinatura de acordos mundiais vizando 
diminuir a utilização de substâncias que sejam prejudiciais à camada de ozônio, como é o caso do CFC e HCFC (Hidroclorofluorcarbono), conforme apresenta Tribess (2004).

Por esse motivo, a utilização dos fluídos refrigerantes R-12 e R-502 foi banida nos países desenvolvidos. Alternativamente ao R-12, que era o fluído refrigerante até então usado em sistemas de ar condicionado automotivo, foi implementado o R-134a conforme citam Brown et al (2001).

Mais recentemente com o avanço dos estudos relacionados ao aquecimento global, tem se criado uma corrente de pensamento direcionada para a utilização dos chamados "fluídos naturais", tais como o $\mathrm{CO}_{2}$ (R-744) e os hidrocarbonetos propano (R-290) e isobutano (R-600a), em substituição do R-134a. Brown et al (2001), citam que o fluído R134a possui um GWP (potencial de aquecimento global) 1300 vezes maior que alguns fluídos naturais, como o $\mathrm{CO}_{2}$.

Brown et al. (2001) realizaram um estudo comparativo de performance entre R-134a e o $\mathrm{CO}_{2}$. Suas conclusões mencionam que um sistema com $\mathrm{CO}_{2}$ fornece um COP inferior a um sistema com R-134a, se mantido os mesmos trocadores de calor.

Joudi et al. (2003), que executaram um estudo de performance de dois sistemas ( um deles com uma mistura de hidrocarbonetos R-290/R-600a e outro com R-12), verificaram que existem vantagens e desvantagens do uso desta mistura como fluído refrigerante: o tempo requerido para o alcance do conforto térmico no habitáculo de um veículo equipado com sistema de AC R-290/R-600a é menor que para um sistema com R-12. Verificou-se também um superior consumo de energia no sistema R-290/R-600a se comparado ao sistema R-12. 


\subsection{Reservatório de Líquido}

O reservatório de líquido, em sistemas que utilizam válvula de expansão, é posicionado entre o condensador e a válvula de expansão na linha de alta pressão. Tribess (2004) cita que o motivo disso é garantir que apenas líquido seja encaminhado à válvula de expansão, garantindo a correta operação do sistema. Além de atuar como meio de armazenamento e separação de fluído, o reservatório possui um desumidificador (que remove a umidade do sistema) e um filtro que impede a passagem de impurezas que possam prejudicar o desempenho do sistema.

Caso o sistema utilize tubo de orifício como dispositivo de expansão, o posicionamento do reservatório é alterado, havendo seu deslocamento para a linha de baixa pressão, entre o evaporador e o compressor. Isso torna-se necessário, a fim de garantir que apenas gás seja encaminhado ao compressor, fazendo com que o excesso de fluído que sai do evaporador fique armazenado no reservatório. Tribess (2004) informa que a entrada de líquido no compressor provoca danos ao compressor, o chamado “calço hidráulico”. Neste caso o reservatório possui algumas peculiaridades construtivas correto funcionamento nesta diferente condição.

\subsubsection{Interruptores de Alta e Baixa Pressão}

Os interruptores de alta e baixa pressão são dispositivos de segurança do sistema. O interruptor de baixa pressão pode estar disposto tanto na linha de alta como na linha de baixa pressão, conforme é citado por General Motors (2003). Sua função é garantir que o sistema seja desligado caso a pressão do sistema esteja muito abaixo do limite inferior de trabalho, 
evitando assim o travamento do compressor por falta de lubrificação. Neste caso, o sistema é desligado através do corte de corrente elétrica na embreagem eletromagnética.

Também é mencionado por General Motors (2003) que o interruptor de alta pressão, tem a função de cortar a corrente elétrica da embregem eletromagnética, caso a pressão da linha de alta pressão esteja numa faixa de trabalha muito acima do normal. Isso evita que haja o rompimento das mangueiras e/ou outros componentes do sistema.

\subsection{Sensor de Temperatura (Termostato)}

O termostato consiste em um sensor de temperatura dotado de um capilar em contato térmico com o evaporador, que tem a função de acionar o compressor conforme a temperatura do evaporador (VOLKSWAGEN, 1994). Quando o valor de temperatura do evaporador chega próximo de $0^{\circ} \mathrm{C}$, o termostato corta a corrente elétrica do compressor, evitando assim o congelamento do evaporador. É citado ainda por Volkswagen (1994) que o congelamento do evaporador obstrui o fluxo de ar, prejudicando a eficiência do sistema. General Motors (2003) cita que tais dispositivos são apenas utilizados em sistemas dotados de compressores de deslocamento volumétrico fixo, uma vez os compressores de deslocamento volumétrico variável possuem uma válvula interna que monitora a temperatura do evaporador.

\subsubsection{Sistema de Aquecimento}

Nos veículos com motores de combustão interna refrigerados a água, o aquecimento do habitáculo do veículo é feito através da transferência do calor do fluído de arrefecimento do motor para o habitáculo, conforme é citado por Bosch (2000). 
O fluído de arrefecimento quente é direcionado para um trocador de calor disposto dentro da caixa de distribuição de ar do veículo. Lá existe a passagem forçada de ar pelo trocador, havendo assim o aquecimento do ar e encaminhamento para o habitáculo.

Bosch (2000) cita ainda que existem formas distintas de controle do aquecimento: a primeira opção pode ser feito através do controle do fluído de arrefecimento, necessitando assim de válvulas que permitam um controle preciso do fluxo de fluído de arrefecimento ao longo do trocador de calor; a outra forma, que é a mais utilizada consiste no livre fluxo de fluído de arrefecimento, onde o controle do aquecimento é feito pelo fluxo de ar pelo trocador de calor. Essa opção no entanto demanda um maior volume na caixa de distribuição de ar, uma vez que é necessário a existência um circuito "by-pass” para redirecionamento do fluxo de ar que não necessita ser aquecido.

Sistemas Auxiliares de aquecimento que não dependem do calor gerado por motores de combustão interna, utilizam uma câmara de combustão, alimentada por um reservatório de combustível. Neste caso, os gases de exaustão são direcionados para o trocador de calor que por sua vez pode trabalhar de duas formas: trocando calor com ar, que por sua vez é direcionado ao habitáculo; ou trocando calor com o fluído de arrefecimento que ao mesmo tempo circulará por um trocador de calor na caixa de distribuição de ar e ao mesmo tempo circulará pelo motor otimizando a partida do motor em ambientes de baixa temperatura, conforme cita Bosch (2000).

\subsubsection{Sistema de desumidificação}

Quando o ar umido à pressão de vapor constante é refrigerado até uma temperatura inferior à sua temperatura de orvalho, existe a condensação do vapor de água contida na mistura. Desta forma, um sistema de desumidificação pode ser baseado em tal conceito. 
A figura 27 apresenta um exemplo de um sistema de ar condicionado que realiza a desumidificação do ar.

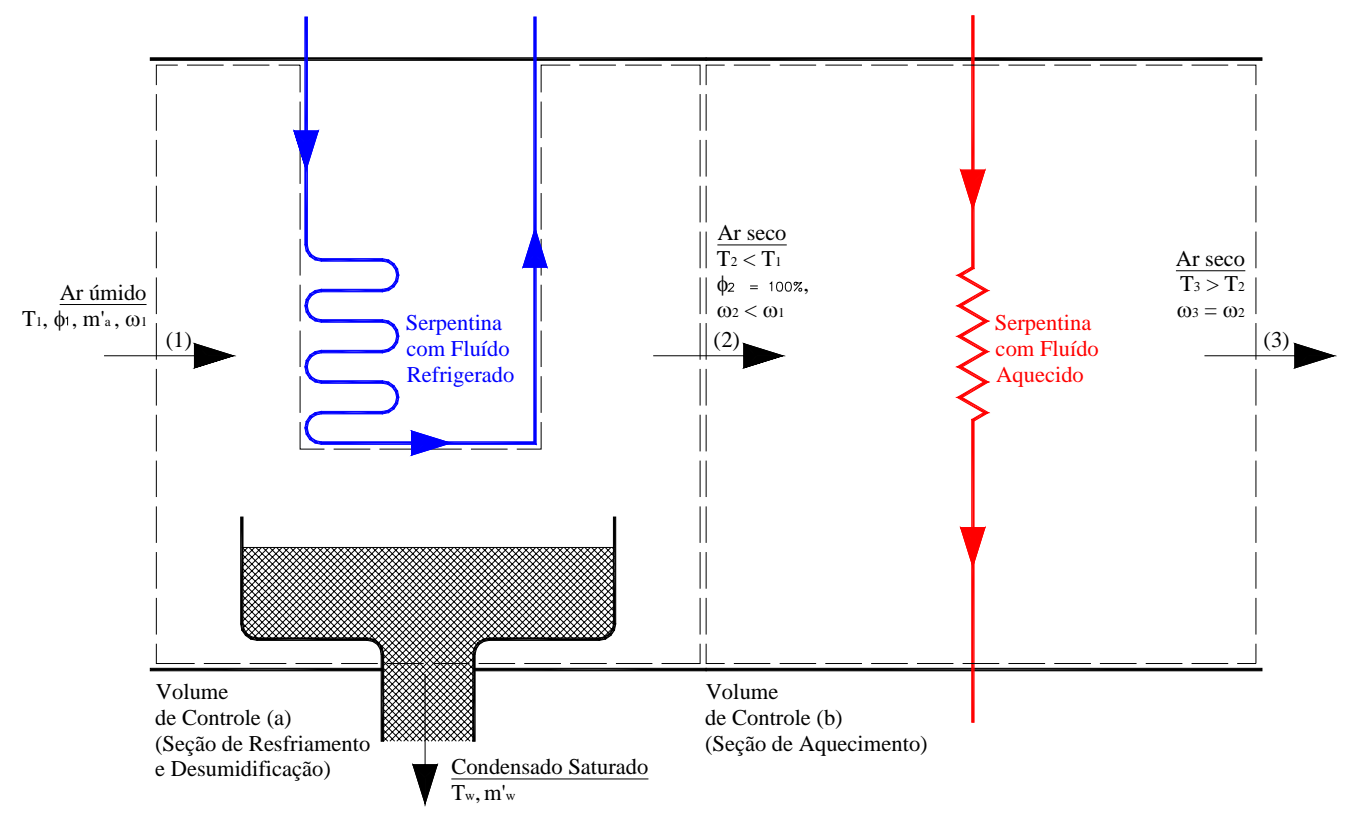

Figura 27. Sistema de desumidificação

No sistema representado na figura 27, o ar com umidade relativa $\phi_{1}$, temperatura $T_{1}$, umidade absoluta $\omega_{1}$ com uma vazão em massa $\mathrm{m}^{\prime}$ a, entra no volume de controle (a). Ao passar pela serpentina com fluído refrigerante, existe a redução de temperatura até abaixo da temperatura de orvalho do ar úmido, causando a condensação do vapor d’água que resulta numa vazão em massa de água $\mathrm{m}_{\mathrm{w}}$ a uma temperatura $\mathrm{T}_{\mathrm{w}}$. $\mathrm{O}$ ar úmido sai do volume de controle (a) a uma temperatura $\mathrm{T}_{2}$ com umidade relativa $100 \%$ e uma umidade absoluta $\omega_{2}$ inferior à condição de entrada $\omega_{1}$. Uma vez que o ar úmido que sai do volume de controle (a) está em condição saturada a uma temperatura bem inferior à temperatura de entrada, este se encontra em condições impróprias para o ambiente da cabine. Por esse motivo, o ar úmido é direcionado ao volume de controle (b), onde é forçado a passar por uma serpentina com fluído refrigerante aquecido, resultando assim no aquecimento do ar úmido até uma temperatura 3, umidade relativa $\phi_{3}$, mas mantendo a mesma umidade absoluta de $\omega_{2}$. Essa condição resultante de ar úmido representa ser mais confortável para os ocupantes do habitáculo 
(Moran e Shapiro, 2004). Esse processo também é demonstrado na carta psicrométrica representada peça figura 28.

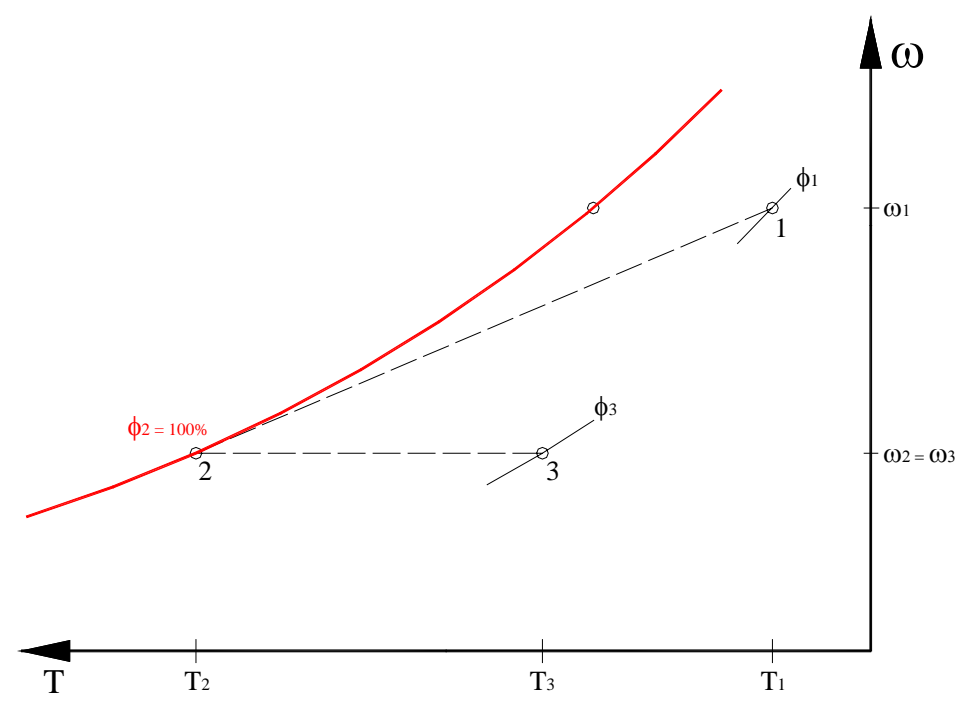

Figura 28. Carta Psicrométrica

O equacionamento do balanço de energia para o volume de controle (a) é baseado na equação da energia, cuja simplificação foi demonstrada anteriormente:

$$
\dot{Q}=\dot{m}_{a} \cdot\left[\left(h_{a}+\omega \cdot h_{v}\right)_{2}-\left(h_{a}+\omega \cdot h_{v}\right)_{1}-\left(\omega_{2}-\omega_{1}\right) \cdot h_{w}\right]
$$

Onde: $\dot{Q}=$ Fluxo de calor $(\mathrm{kW})$

$$
\begin{aligned}
& \dot{m}_{a}=\text { Vazão em massa de ar }(\mathrm{kg} / \mathrm{s}) \\
& \mathrm{h}_{\mathrm{a}}=\text { Entapia específica do ar }(\mathrm{kJ} / \mathrm{kg}) \\
& \mathrm{h}_{\mathrm{v}}=\text { Entapia específica do vapor }(\mathrm{kJ} / \mathrm{kg}) \\
& \mathrm{h}_{\mathrm{w}}=\text { Entalpia específica da água }(\mathrm{kJ} / \mathrm{kg}) \\
& \omega=\text { Umidade absoluta (kg vapor } / \mathrm{kg} \text { ar seco) }
\end{aligned}
$$




\subsubsection{Caixa de Distribuição de Ar}

A caixa de distribuição de ar consiste num dispositivo dotados de dutos e compartimentos, onde um fluxo de ar antes de ser transferido para o habitáculo dos passageiros, terá sua temperatura e umidade ajustada conforme desejo do condutor do veículo. Desta forma, o evaporador, assim como o aquecedor e o ventilador, são alocados em compartimentos dentro da caixa de ar.

Tribess (2004) cita a dificuldade de executar a correta distribuição do fluxo de ar condicionado de modo a prover o conforto térmico dos passageiros. Numa tentativa de prover conforto térmico, a caixa de distribuição de ar possui inúmeras saídas de ar que devem atender a uma circulação geral sobre os ocupantes.

A passagem do ar através dos diferentes trocadores e dutos dentro da caixa de ar definirá a natureza do ar (refrigeração, aquecimento, ar natural, desembaçamento, etc...).

É citado ainda por Tribess (2004) que, frequentemente não se consegue efetuar o resfriamento da região traseira do habitáculo, que leva mais tempo, uma vez que o fluxo de ar deve passar primeira pela parte dianteira do habitáculo. Na tentativa de ultrapassar tal dificuldade, alguns veículos utilizam um sistema de distribuição complexo, com a existência de dutos de distribuição passando pelo assoalho e colunas do veículo. As saídas de tais dutos fornecem o ar climatizado diretamente à região traseira do habitáculo, conforme pode ser visualizado na figura 29. 


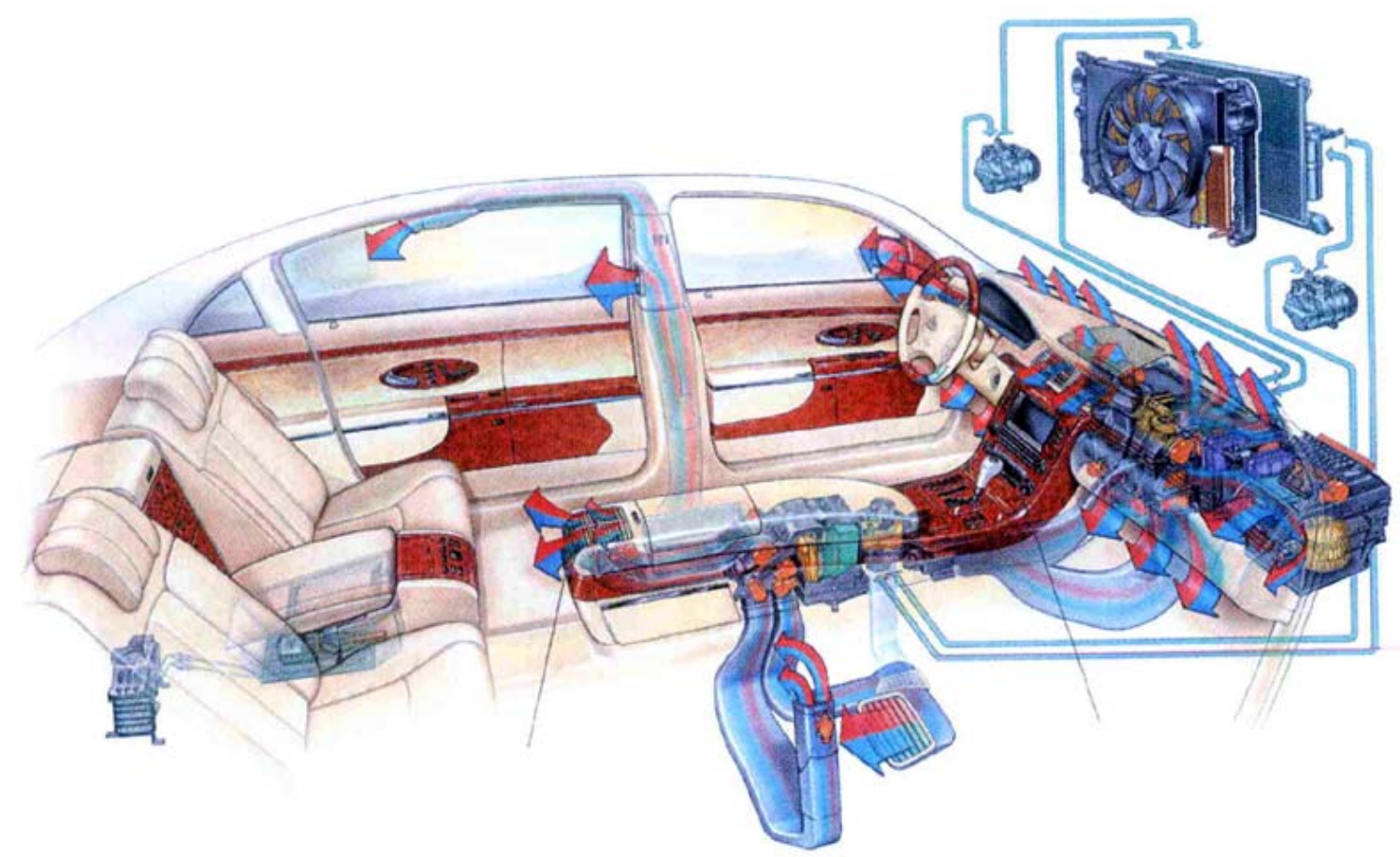

Figura 29. Exemplo de um sistema complexo de distribuição de ar de um veículo Maybach 57/62 (BIRCH, 2002)

\subsubsection{Modos de operação do Sistema de Ar Condicionado}

Forrest e Bhatti (2002) citam que os atuais sistemas de ar condicionado operam através de dois modos: ventilação e recirculação. Operando no modo ventilação, o ar ambiente é limpo, refrigerado, desumidificado, passando através do habitáculo e sendo exaurido para o ambiente. Operando no modo recirculação, existe a combinação do ar recirculado com o ar do ambiente externo. Forrest e Bhatti (2002) citam que na operação por recirculação é possível manter o conforto desejado satisfazendo as normas de qualidade de ar interno definidas pela ASHRAE. Além disso, Forrest e Bhatti (2002) citam ainda uma economia de energia na operação por recirculação uma vez que é necessária uma capacidade de refrigeração inferior a fim de alcançar os requisitos de temperatura e umidade necessários.

Jackson (1961) apud Forrest e Bhatti (2002), citam que uma mistura dos fluxos obedecendo uma razão de $25 \%$ ar fresco externo e $75 \%$ de ar recirculado ajuda a preservar a qualidade do ar do habitáculo a um nível aceitável. 


\subsection{Sistemas regenerativos de frenagem}

\subsubsection{Introdução}

A constante mudança nas legislações no sentido de minimizar as emissões de gases ao ambiente, tem obrigado uma mudança nos meios de transporte. Schaible e Szabados (1994) citam que uma das formas possíveis de eliminar as emissões presentes nos motores atuais, seria a substituição dos motores de combustão interna por motores elétricos. Uma outra forma de minimização das emissões é a utilização de sistemas regenerativos de frenagem.

No ato da frenagem de um veículo, observam-se dois processos termodinâmicos, conforme citam Wicks e Donnelly (1997). O primeiro processo termodinâmico consiste na atrito, o qual a energia ordenada do veículo é convertida em energia interna desordenada nos freios, que resulta num aumento de temperatura dos mesmos durante o processo de parada do veículo. O segundo processo termodinâmico, consiste na dissipação da energia dos freios para o ambiente. Com isso, conforme observado por Wicks e Donnelly (1997), durante o processo de frenagem existe a perda irreversível de energia disponível para o ambiente.

Os sistemas regenerativos de frenagem, trabalham no conceito do reaproveitamento de parte da energia que seria dissipado para o ambiente no ato da frenagem, de forma que tal energia possa ser reutilizado posteriormente, miminizando assim o consumo de combustível.

Na maior parte dos casos, os sistemas regenerativos são aplicados a veículos elétricos que já dispõe de um motor elétrico que poderia trabalhar no sentido contrário como um gerador, conforme cita Schaible e Szabados (1994). Neste processo, seria fornecido um torque ao gerador que por sua vez converteria a energia mecânica de movimento do eixo em energia elétrica que seria armazenado em um banco de baterias. 
Wicks e Donnelly (1997) alertam no entanto, que as vantagens fornecidas por um veículo com um sistema de frenagem regenerativo, podem resultar aumento de consumo de combustível e custos, caso não haja o correto dimensionamento. Um exemplo de um sistema em tais condições seria o caso de um veículo com excesso de peso de baterias de armazenamento, longa distância entre paradas e paradas muito rápidas (a taxa de transferência de energia mecânica em elétrica não é suficiente para o recarregamento das baterias).

Existem caso em que o sistema regenerativo é aplicado a veículos com sistemas de propulsão convencionais, dotados de motores de combustão interna. Chicurel (1999) cita um exemplo da utilização de um sistema combinado regenerativo-dissipativo de frenagem dotado de um acumulador hidropneumático. Neste caso, o acumulador hidropneumático executa a função do banco de baterias, acumulando energia na forma de fluído pressurizado, para ser utilizada posteriormente.

\subsubsection{Sistemas de frenagem regenerativos elétricos}

Os sistemas de frenagem regenerativos elétricos são geralmente incorporados em veículos híbridos, que dispõe de baterias de armazenamento de energia conforme cita Cikanek (2002).

O veículo híbrido combina o conceito de propulsão de veículo elétrico com o conceito de propulsão de um veículo convencional. Cikanek (2002) cita ainda que os modos de trabalho do sistema de propulsão de tais veículos pode ser: a) somente motor de combustão interna, b) somente motor elétrico ou c) propulsão híbrida. O sistema de frenagem regenerativo atuará somente nas condições b) e c) onde o motor proverá uma tração negativa absorvendo a energia cinética do veículo e convertendo em energia elétrica a ser armazenada em baterias, conforme é apresentado na figura 30: 


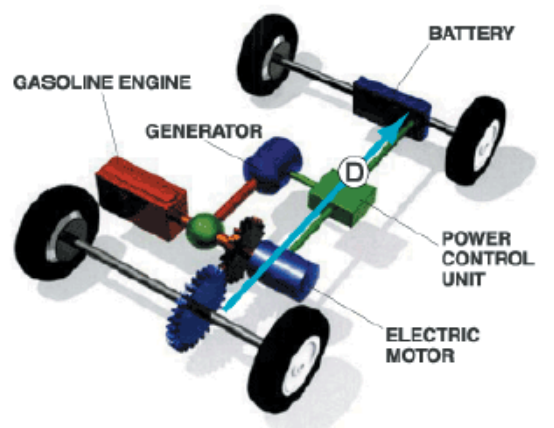

Figura 30. sistema de frenagem regenerativo toyota THS II ${ }^{\circledR}$ (TOYOTA, 2005)

\subsubsection{Sistema de Frenagem Regenerativo-Dissipativo Hidropneumático}

O sistema combinado regenerativo-dissipativo citado por Chicurel (1999) é composto basicamente por um acumulador hidropneumático, um motor-bomba e um sistema de controle composto de uma válvula direcional 3 posições 2 vias. A figura 31 apresenta o esquema de tal sistema.

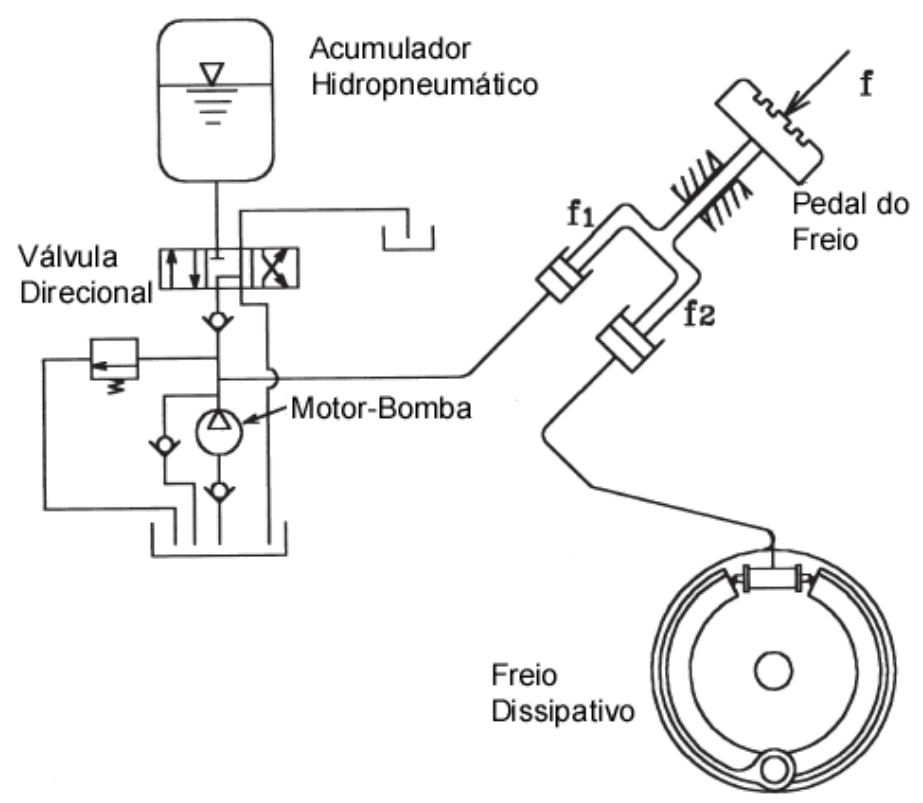

Figura 31. Sistema de frenagem regenerativo-dissipativo (CHICUREL, 1999)

Uma moto-bomba hidráulica está ligada à transmissão do veículo, sendo que o seu modo de operação é determinado através da válvula direcional. O posicionamento da válvula depende da condição de força $\mathrm{f}$, aplicada ao pedal de freio do veículo e das forças resistivas $\mathrm{f}_{1}$ 
e $f_{2}$ respectivamente as forças resistivas provenientes da pressão de descarga do motor-bomba e do freio dissipativo.

No caso da força $\mathrm{f}$ ser igual ou menor que $\mathrm{f}_{1}$, a força total do pedal será transmitida para o freio dissipativo, uma vez que o cilindro que fornece uma força $\mathrm{f}_{1}$ não será deslocado. No entanto, se a força $\mathrm{f}$ for maior que $\mathrm{f}_{1}$, haverá o deslocamento do cilindro com a força $\mathrm{f}_{1}$ que por sua vez deslocará a válvula direcional para a direita, fechando o circuito com o acumulador hidropneumático. Um possível aumento de pressão na linha devido ao armazenamento de fluído no acumulador, resultará num aumento de $\mathrm{f}_{1}$ até que f seja igual a $\mathrm{f}_{1}$ quando toda a força $\mathrm{f}$ do pedal será transmitida ao freio dissipativo e a válvula é disposta novamente na posição neutra.

No caso da aceleração do veículo, Chicurel (1999) cita que o controle é realizado por por um transdutor de deslocamento posicionado no pedal do acelerador. Esse transdutor de deslocamento converte o deslocamento em informação de torque do motor $\mathbf{M}_{t}$, que seria desenvolvido caso o pedal estivesse pressionado em determinada intensidade. Tal torque $\mathrm{M}_{\mathrm{t}}$ seria comparada a um torque $\mathrm{M}_{\mathrm{t} 1}$, que seria fornecido caso o motor hidráulico tivesse sido acionado.

No caso de $\mathrm{M}_{\mathrm{t}}$ ser menor que $\mathrm{M}_{\mathrm{t} 1}$, não há acionamento da válvula direcional e o torque necessário é fornecido pelo motor convencional do veículo. No entanto caso $\mathrm{M}_{\mathrm{t}}$ seja inferior a $\mathrm{M}_{\mathrm{t} 1}$, a válvula direcional é deslocada para a esquerda, acionando o motor hidráulico que transmitirá torque ao eixo do veículo. Neste caso o motor convencional do veículo fornecerá um torque complementar $\mathrm{M}_{\mathrm{t} 2}$ que é equivalente a $\mathrm{M}_{\mathrm{t}}-\mathrm{M}_{\mathrm{t} 1}$.

Chicurel (1999) alerta ainda para o correto dimensionamento do tamanho do motorbomba: uma motor-bomba de pequena capacidade forneceria uma pequena força de frenagem, sendo acionado frequentemente, porém sua capacidade de armazenamento de energia é 
pequeno. Por outro lado um motor-bomba grande fornece uma grande força de frenagem, porém raramente seria ativado.

Desta forma, Chicurel (1999) cita que é muito importante a avaliação das futuras condições de operação que serão base para o dimensionamento. 


\section{MATERIAIS E MÉTODOS}

O estudo da aplicação dos tubos de vórtices em um sistema de ar condicionado automotivo, aliado a um sistema regenerativo de frenagem foi executado em duas fases principais.

A primeira fase do trabalho consistiu em uma fase investigativa, abordando os parâmetros de operação de um sistema de ar condicionado veicular convencional, limites de aplicação dos dispositivos tubos de vórtices aplicados à refrigeração e potencial de regeneração energética de automóveis.

A investigação dos parâmetros de operação de um sistema de ar condicionado veicular convencional, tais como capacidade de refrigeração necessária e vazão de ar condicionado, possui importância no sentido de apresentar as necessidades as quais o tubo de vórtices e o Sistema Regenerativo de Frenagem devem atender. Tais informações serviram como base para uma pré-seleção do tubo de vórtices assim como a definição da configuração do sistema. As fontes de informação desta fase do trabalho consistem em dados experimentais e teóricos presentes em artigos técnicos e catálogos de fabricantes.

A investigação dos limites de aplicação dos tubos de vórtices, tem sua importância na avaliação da viabilidade técnica de aplicação de tais dispositivos. Esse estudo não se prestará ao desenvolvimento de tubos de vórtices otimizados para a aplicação veicular, mas apenas a avaliação de sua aplicação a um sistema de ar condicionado veicular convencional. As fontes de informações relativas a esta investigação, consistem em dados de fabricantes de tubos de vórtices e modelos teóricos presentes em artigos técnicos.

O estudo da capacidade de regeneração energética se baseia na determinação teórica da energia dissipada durante a frenagem em veículos terrestres. Para tal análise, foram 
utilizadas as coordenadas do ciclo de condução urbana citado na norma NBR 6601 "Veículos rodoviários automotores leves - Determinação de hidrocarbonetos, monóxido de carbono, óxidos de nitrogênio e dióxido de carbono no gás de escapamento”. A utilização de tal ciclo de condução para a determinação de emissões veiculares, se fez necessário face à dificudade da determinação de um padrão de ciclo de condução, visto a grande diversidade de tráfego existente. Adicionamente, também foram obtidos dados teóricos de capacidade de regeneração energética para situações isoladas de frenagem em desaceleração constante, partindo da velocidade de $40 \mathrm{~km} / \mathrm{h}$, em veículos de passeio e veículos comerciais.

Com os dados relativos à operação dos sistemas de ar condicionado veiculares convencionais, limites de aplicação dos tubos de vórtices e potencial de regeneração energética na frenagem, foi possível especificar uma proposta de sistema de ar condicionado utilizando tubos de vórtices, assim como efetuar uma pré-seleção de seus componentes principais. Tal estudo corresponde à segunda fase do presente trabalho e o resultado apresentou uma análise de viabilidade do sistema em estudo para veículos de passeio e veículos comerciais. 


\section{REQUISITOS DE OPERAÇÃO E BALANÇO ENERGÉTICO}

\subsection{Parâmetros de operação de um sistema de ar condicionado veicular convencional}

ASHRAE (1999) apresenta algumas considerações no que se refere a alguns critérios de projeto de um sistema de ar condicionado automotivo convencional.

É citado que os aquecedores são especificados para operação na faixa de temperatura ambiente entre $-40^{\circ} \mathrm{C}$ e $21^{\circ} \mathrm{C}$. Sistemas de $\mathrm{Ar}$ Condicionado com reaquecimento são especificados para temperaturas operativas entre $4^{\circ} \mathrm{C}$ e $43^{\circ} \mathrm{C}$.

ASHRAE (1999) cita ainda que agentes bacterianos, corrosivos e poluentes devem ser considerados na seleção dos materiais de vedações e trocadores de calor. Filtros e purificadores de ar tem sido instalados nos sistemas de ar condicionado nos ultimos anos.

O sistema de ar condicionado não deve diminuir o desempenho do veículo a ponto de compremeter o controle do veículo. ASHRAE (1999) cita que um sistema adequado de recarga elétrica deve ser selecionado.

Os ventiladores que suprem o fluxo de ar adicional para a distribuição, geralmente são dotados de várias velocidades (normalmente 4 velocidades), sendo que o fluxo de ar no evaporador varia entre $0,05 \mathrm{~m}^{3} / \mathrm{s}$ e $0,19 \mathrm{~m}^{3} / \mathrm{s}$ (os limites devem ser estabelecidos conforme o projeto).

Forrest e Bhatti (2002) citam que num projeto padrão de um sistema de ar condicionado, geralmente são utilizados os dados citados na tabela 2. 


\begin{tabular}{|c|c|c|}
\hline Descrição & $\mathbf{U N}$ & $\begin{array}{c}\text { Valor } \\
\text { Padrão }\end{array}$ \\
\hline Temperatura do ar externo & $\mathrm{T}_{0} \quad\left({ }^{\circ} \mathrm{C}\right)$ & 38 \\
\hline Umidade de relativa do ambiente externo & $(\%)$ & 40 \\
\hline Temperatura do ar na saída do evaporador & $\mathrm{T}_{\mathrm{E}} \quad\left({ }^{\circ} \mathrm{C}\right)$ & 10 \\
\hline Umidade de relativa no evaporador & $(\%)$ & 100 \\
\hline Fluxo de massa de ar & $\mathrm{m}_{\mathrm{a}}{ }^{\prime}(\mathrm{kg} / \mathrm{s})$ & 0,1285 \\
\hline
\end{tabular}

Avila (2002) informa que a temperatura ótima do ar no habitáculo para o motorista deve estar na faixa de $18,5^{\circ} \mathrm{C}$ e $21,5^{\circ} \mathrm{C}$, para a hipótese de vestimenta normal. A justificativa para isso é que essa faixa de temperatura está pouco abaixo da condição de conforto, fazendo com que o motorista tenha uma leve sensação de frio, mantendo-o em alerta e aumentando assim sua segurança.

A carga térmica que define a capacidade do sistema de ar condicionado, é determinada avaliando os parâmetros do ambiente interno e externo ao habitáculo, que envolve não somente a temperatura como também umidade relativa dos ambientes. Uma simulação da capacidade de refrigeração necessária, baseado nos dados apresentados na tabela 2, é efetuada e demonstrada no APÊNDICE A.

Os resultados da simulação apresentam uma capacidade de refrigeração necessária de 5,68 kW equivalente a 1,6 tonelada de refrigeração no modo de operação sem recirculação. Tal valor é semelhante ao obtido por Ruth (1975), que menciona cargas térmicas que variam entre 1,0 e 1,5 toneladas de refrigeração dependendo da classe de veículo no qual o sistema de ar condicionado seria instalado. Para veículos de carga, Tribess (2004) cita que a carga térmica em cabines de caminhões, é equivalente a 5,40 kW (próximo de 1,5 TR). 


\subsection{Limites de aplicação de um Tubo de Vórtices}

Conforme apresentado inicialmente por Ranque (1933), Hilsch (1946) e muitos outros autores que tem pesquisado o assunto desde então, os tubos de vórtices podem fornecer fluxos de ar frio e quente, com variações de temperaturas superiores a $50^{\circ} \mathrm{C}$ e $35^{\circ} \mathrm{C}$, respectivamente. Stephan et al. (1984) obteve resultados da variação de temperatura do fluxo frio, mostrados na Figura 32 para um tubo de vórtices configurado conforme a Tabela 3.

Tabela 3 - Dimensões principais do tubo de vórtices (STEPHAN et al., 1984)

\begin{tabular}{lccc}
\hline \multicolumn{1}{c}{ Descrição } & Sigla & Valor & UN \\
\hline Diâmetro Interno & $\mathrm{D}$ & 0,0176 & $\mathrm{~m}$ \\
Comprimento do tubo & $\mathrm{L}$ & 0,3520 & $\mathrm{~m}$ \\
Diâmetro do bocal de entrada de ar & $\mathrm{d}$ & 0,0041 & $\mathrm{~m}$ \\
Diâmetro do orifício de saída do fluxo frio & $\mathrm{d}_{\mathrm{c}}$ & 0,0065 & $\mathrm{~m}$ \\
\hline
\end{tabular}

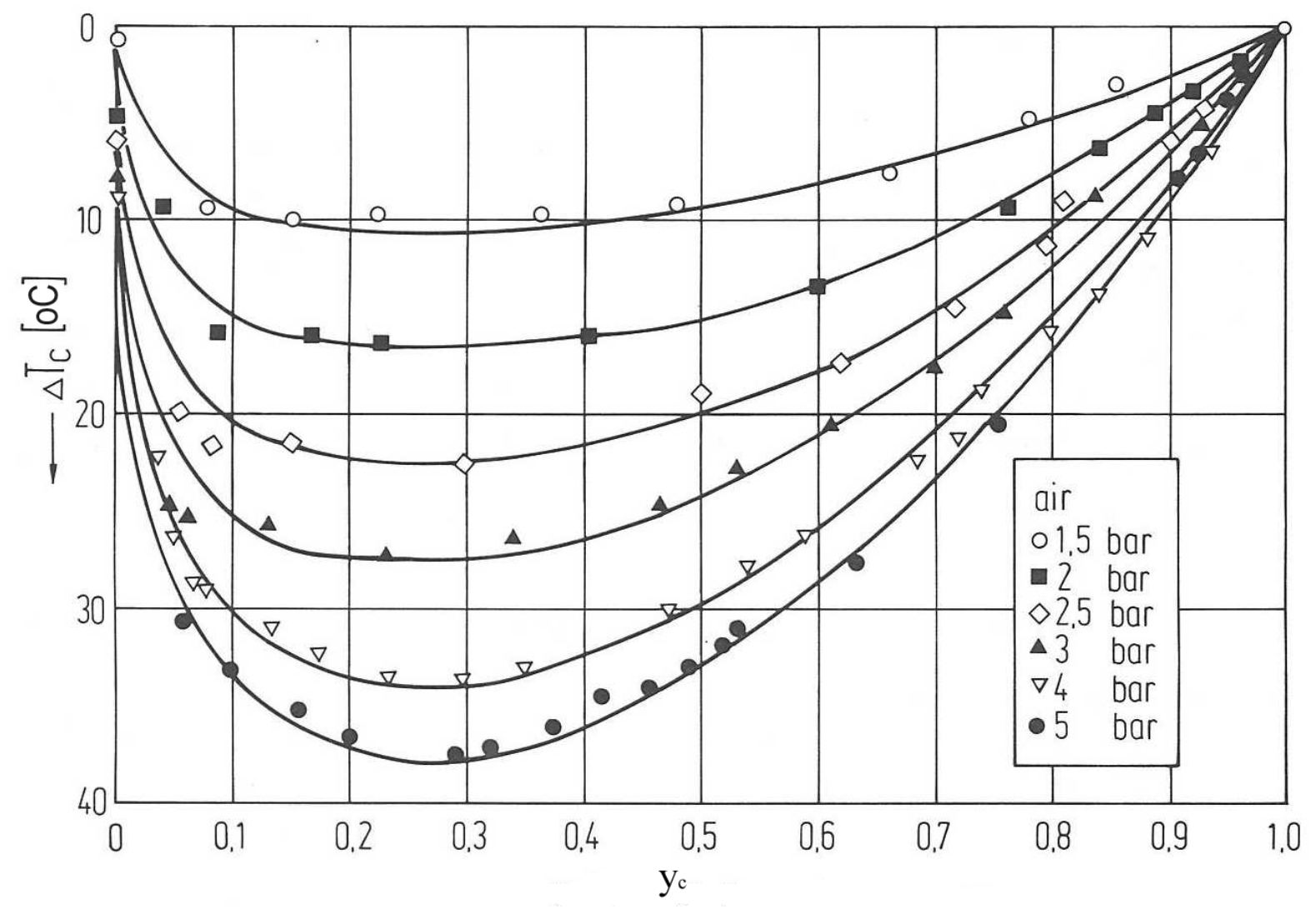

Figura 32. Variação de temperatura do fluxo frio em função da fração de fluxo frio (STEPHAN et al., 1984) 
A performance de um tubo de vórtices é uma função de diversas variáveis. O processo de separação energética em um tubo de vórtices, é dependente das variáveis citadas na equação 10, conforme estudo de Stephan et al. (1983).

$$
f\left(T_{C}, T_{0}, p_{0}, \rho_{0}, w_{0}, p_{\infty}, k, c_{p}, c_{v}, \mu, \beta, \dot{m}_{c}, L, D, \delta, d_{c}, d_{h}\right)=0
$$

Após analise dimensional, baseado na equação 10, Stephan et al. (1983) obtiveram uma relação de similaridade para a variação da temperatura do fluxo de ar frio em função da fração de fluxo frio, válido para tubos de vórtices similares geometricamente. A relação de similaridade é apresentada na equação 11, enquanto a figura 33 apresenta a curva obtida por tal equação, relacionando a relação $\Delta \mathrm{T}_{\mathrm{c}} / \Delta \mathrm{T}_{\mathrm{c} \max }$ em função da fração de fluxo frio.

$$
\frac{\Delta T_{C}}{\Delta T_{C \max }}=0,792+1,540 \cdot y_{c}+3,101 \cdot y_{c}^{2}+0,815 \cdot y_{c}^{3}
$$

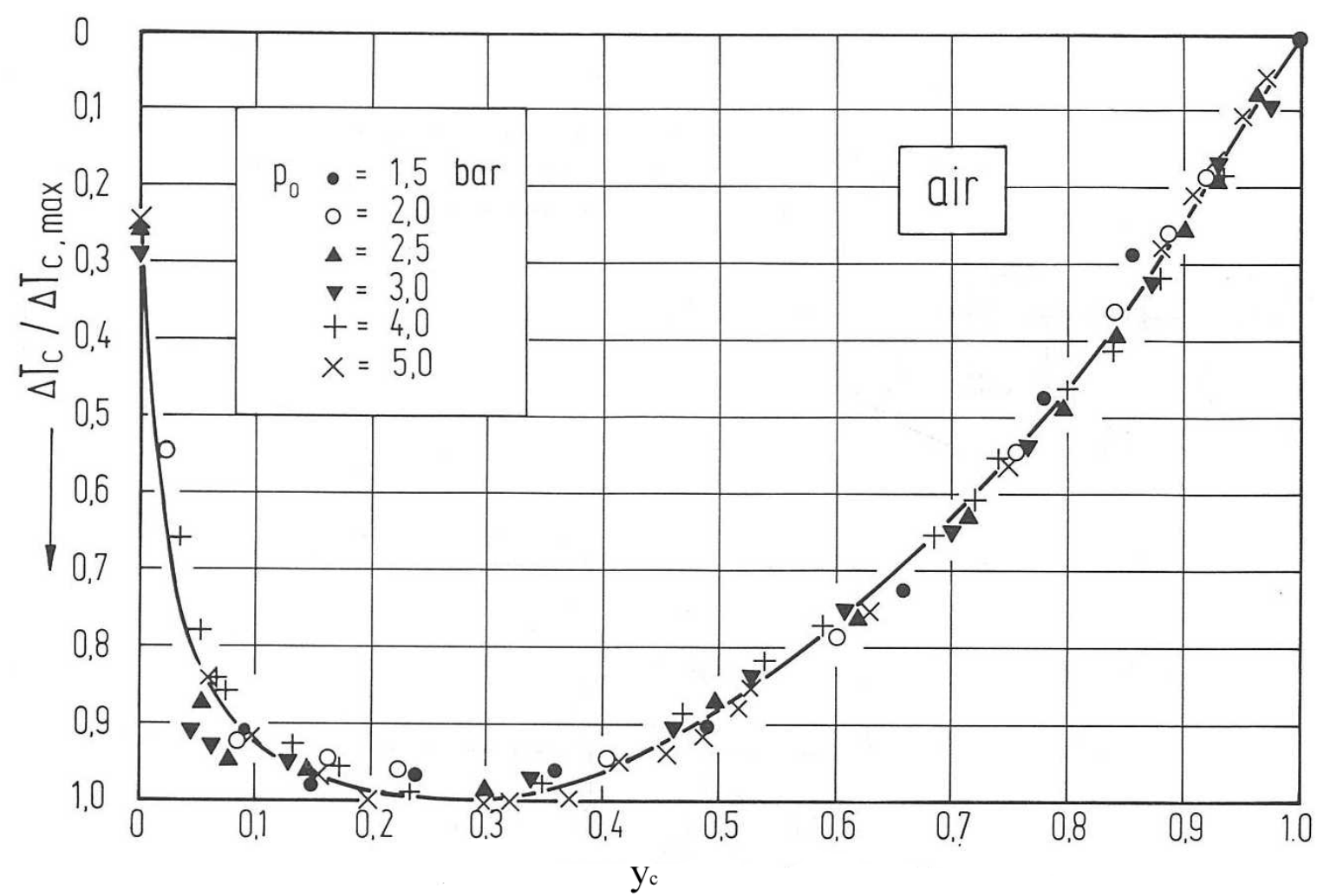

Figura 33. Relação variação de temperatura parcial do fluxo frio e variação máxima de temperatura do fluxo frio versus fração de fluxo frio (STEPHAN et al. 1983) 
Comercialmente, uma gama de dimensões de tubos de vórtices são disponíveis, sendo que sua classificação é baseada na vazão volumétrica de ar. EXAIR (2005) apresenta na Tabela 4, os modelos de tubos de vórtices disponíveis no mercado atualmente.

Tabela 4 - Modelos de tubos de vórtices EXAIR $\AA^{3}$ (EXAIR, 2005)

\begin{tabular}{cccc}
\hline \multirow{2}{*}{ Modelo } & \multirow{2}{*}{ Tamanho } & \multicolumn{2}{c}{$\mathbf{V}^{\prime *}$} \\
& SCFM & $\mathbf{~ m}^{3} / \mathbf{s}^{* *}$ \\
\hline 3202 & Pequeno & 2 & 0,0009 \\
3204 & Pequeno & 4 & 0,0019 \\
3208 & Pequeno & 8 & 0,0038 \\
3210 & Médio & 10 & 0,0047 \\
3215 & Médio & 15 & 0,0071 \\
3225 & Médio & 25 & 0,0118 \\
3230 & Médio & 30 & 0,0142 \\
3240 & Médio & 40 & 0,0189 \\
3250 & Grande & 50 & 0,0236 \\
3275 & Grande & 75 & 0,0354 \\
3298 & Grande & 100 & 0,0472 \\
3299 & Grande & 150 & 0,0708 \\
\hline * Dados de vazão massica para $\mathrm{P}_{0}=6,9 \mathrm{bar}(690 \mathrm{kPa})$ \\
**1 SCFM = 0,00047195 ${ }^{3} / \mathrm{s}$
\end{tabular}

EXAIR (2005) apresenta ainda dados de temperatura dos fluxos de saída nas tabelas 5 e 6, levando em conta a fração de fluxo frio e a pressão de ar do fluxo de entrada.

Tabela 5 - Queda de temperatura do fluxo de ar frio em função da fração de ar frio em Tubos de Vórtices EXAIR ${ }^{10}{ }^{10}($ EXAIR, 2005)

\begin{tabular}{|c|c|c|c|c|c|c|c|c|c|c|c|c|c|c|c|c|}
\hline \multirow{2}{*}{\multicolumn{3}{|c|}{$\begin{array}{c}\text { Pressão de } \\
\text { Entrada }\left(\mathbf{p}_{0}\right)\end{array}$}} & \multicolumn{14}{|c|}{ Fração de Fluxo de Ar Frio (y $\left.y_{c}\right)$} \\
\hline & & & \multicolumn{2}{|c|}{0,2} & \multicolumn{2}{|c|}{0,3} & \multicolumn{2}{|c|}{0,4} & \multicolumn{2}{|c|}{0,5} & \multicolumn{2}{|c|}{0,6} & \multicolumn{2}{|c|}{0,7} & \multicolumn{2}{|c|}{0,8} \\
\hline psig & bar & $\mathrm{kPa}$ & $\Delta^{\mathrm{o}} \mathrm{F}$ & $\Delta^{\circ} \mathrm{C}$ & $\Delta^{\mathrm{o}} \mathrm{F}$ & $\Delta^{\circ} \mathrm{C}$ & $\Delta^{\circ} \mathrm{F}$ & $\Delta^{\circ} \mathrm{C}$ & $\Delta^{\mathrm{o}} \mathrm{F}$ & $\Delta^{\mathrm{o}} \mathrm{C}$ & $\Delta^{\mathrm{o}} \mathrm{F}$ & $\Delta^{\circ} \mathrm{C}$ & $\Delta^{\mathrm{o}} \mathrm{F}$ & $\Delta^{\circ} \mathrm{C}$ & $\Delta^{\mathrm{o}} \mathrm{F}$ & $\Delta^{\circ} \mathrm{C}$ \\
\hline 20 & 1,4 & 138 & 62 & 34,4 & 60 & 33,3 & 56 & 31,1 & 51 & 28,3 & 44 & 24,4 & 36 & 20,0 & 28 & 15,6 \\
\hline 40 & 2,8 & 276 & 88 & 48,9 & 85 & 47,2 & 80 & 44,4 & 73 & 40,6 & 63 & 35,0 & 52 & 28,9 & 38 & 21,1 \\
\hline 60 & 4,1 & 414 & 104 & 57,8 & 100 & 55,6 & 93 & 51,7 & 84 & 46,1 & 73 & 40,6 & 60 & 33,3 & 46 & 25,6 \\
\hline 80 & 5,5 & 552 & 115 & 63,9 & 110 & 61,1 & 102 & 56,7 & 92 & 51,1 & 80 & 44,4 & 66 & 36,7 & 50 & 27,8 \\
\hline 100 & 6,9 & 689 & 123 & 68,3 & 118 & 65,6 & 110 & 61,1 & 100 & 55,6 & 86 & 47,8 & 71 & 39,4 & 54 & 30,0 \\
\hline 120 & 8,3 & 827 & 129 & 71,7 & 124 & 68,9 & 116 & 64,4 & 104 & 57,8 & 91 & 50,6 & 74 & 41,1 & 55 & 30,6 \\
\hline
\end{tabular}

\footnotetext{
${ }^{3}$ Dados apresentados com a autorização prévia da EXAIR Corporation, Cincinnati, OH, USA.
} 
Tabela 6 - Acréscimo de temperatura do fluxo de ar quente em função da fração de ar frio em Tubos de Vórtices EXAIR ${ }^{10}($ EXAIR, 2005)

\begin{tabular}{|c|c|c|c|c|c|c|c|c|c|c|c|c|c|c|c|c|}
\hline \multirow{2}{*}{\multicolumn{3}{|c|}{$\begin{array}{c}\text { Pressão de } \\
\text { Entrada }\left(\mathrm{p}_{0}\right)\end{array}$}} & \multicolumn{14}{|c|}{ Fração de Fluxo de Ar Frio $\left(\mathbf{y}_{c}\right)$} \\
\hline & & & \multicolumn{2}{|c|}{0,2} & \multicolumn{2}{|c|}{0,3} & \multicolumn{2}{|c|}{0,4} & \multicolumn{2}{|c|}{0,5} & \multicolumn{2}{|c|}{0,6} & \multicolumn{2}{|c|}{0,7} & \multicolumn{2}{|c|}{0,8} \\
\hline psig & bar & $\mathrm{kPa}$ & $\Delta^{\mathrm{o}} \mathrm{F}$ & $\Delta^{\circ} \mathrm{C}$ & $\Delta^{\mathrm{o}} \mathrm{F}$ & $\Delta^{\circ} \mathrm{C}$ & $\Delta^{\mathrm{o}} \mathrm{F}$ & $\Delta^{\circ} \mathrm{C}$ & $\Delta^{\mathrm{o}} \mathrm{F}$ & $\Delta^{\circ} \mathrm{C}$ & $\Delta^{\mathrm{o}} \mathrm{F}$ & $\Delta^{\circ} \mathrm{C}$ & $\Delta^{\mathrm{o}} \mathrm{F}$ & $\Delta^{\circ} \mathrm{C}$ & $\Delta^{\mathrm{o}} \mathrm{F}$ & $\Delta^{\circ} \mathrm{C}$ \\
\hline 20 & 1,4 & 138 & 15 & 8,33 & 25 & 13,9 & 36 & 20,0 & 50 & 27,8 & 64 & 35,6 & 83 & 46,1 & 107 & 59,4 \\
\hline 40 & 2,8 & 276 & 21 & 11,7 & 35 & 19,4 & 52 & 28,9 & 71 & 39,4 & 92 & 51,1 & 117 & 65,0 & 147 & 81,7 \\
\hline 60 & 4,1 & 414 & 24 & 13,3 & 40 & 22,2 & 59 & 32,8 & 80 & 44,4 & 104 & 57,8 & 132 & 73,3 & 166 & 92,2 \\
\hline 80 & 5,5 & 552 & 25 & 13,9 & 43 & 23,9 & 63 & 35,0 & 86 & 47,8 & 113 & 62,8 & 143 & 79,4 & 180 & 100,0 \\
\hline 100 & 6,9 & 689 & 26 & 14,4 & 45 & 25,0 & 67 & 37,2 & 90 & 50,0 & 119 & 66,1 & 151 & 83,9 & 191 & 106,1 \\
\hline 120 & 8,3 & 827 & 26 & 14,4 & 46 & 25,6 & 69 & 38,3 & 94 & 52,2 & 123 & 68,3 & 156 & 86,7 & 195 & 108,3 \\
\hline
\end{tabular}

Conforme mencionado por Raker (Informação pessoal) ${ }^{4}$, as Tabelas 5 e 6 são aplicáveis para todas as dimensões de tubos de vórtices, apresentadas na tabela 4, o que sugere que os diversos modelos de tubos de vórtices apresentam similaridades geométricas.

\subsection{Potencial de regeneração energética na frenagem de um veículo}

O estudo do potencial de regeneração energética se baseia na determinação teórica da energia disponível para regeneração. Esse capítulo será divido em duas fases: formulação do balanço energético e energia disponível para regeneração.

\subsubsection{Formulação do Balanço Energético na Frenagem}

Wicks e Donnelly (1997) citam que o processo de frenagem de um veículo converte a energia cinética / potencial ordenada de um veículo em energia desordenada. Isso acontece a partir de dois processos termodinâmicos. O primeiro processo consiste no atrito, onde a energia cinética ordenada é convertida em energia térmica, que é seguido do aquecimento dos

\footnotetext{
${ }^{4}$ RAKER, N. Your recent EXAIR.com download. Mensagem recebida por dan.itao@uol.com.br em 26 de abril de 2005
} 
componentes envolvidos na fricção. O segundo processo consiste na transmissão de calor entre os componentes envolvidos na friç̧ão e o ambiente externo.

Desta forma, o desenvolvimento de sistemas de frenagem de alta performance, atribuem grande atenção aos processos termodinâmicos de dissipação de calor. Um exemplo de tal atenção pode ser observado na figura 34, onde discos de freios de ultima geração são dotados de furos e dutos internos que otimizam a transferência de calor.

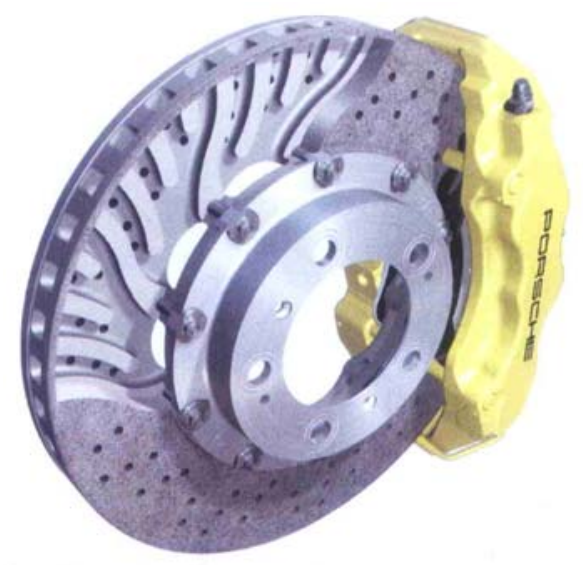

Figura 34. Disco de freio de alta performance (BIRCH, 2004)

A fim de analisar o fluxo de energia durante a frenagem de um veículo, será apresentado o balanço de energia para um sistema conforme a primeira Lei da Termodinâmica, citado por Moran e Shapiro (2004):

$$
\begin{gathered}
E_{2}-E_{1}=Q-W \\
\Delta K E+\Delta P E+\Delta U=Q-W \\
\Delta K E=\frac{1}{2} \cdot m \cdot\left(v_{2}^{2}-v_{1}^{2}\right) \\
\Delta P E=m \cdot g \cdot\left(Z_{2}-Z_{1}\right)
\end{gathered}
$$

Onde: $\Delta \mathrm{KE}=$ Variação de Energia Cinética $(\mathrm{J})$

$\Delta \mathrm{PE}=$ Variação de Energia Potencial $(\mathrm{J})$

$\Delta \mathrm{U}=$ Variação de Energia Interna $(\mathrm{J})$ 


$$
\begin{aligned}
& \mathrm{Q}=\text { Calor }(\mathrm{J}) \\
& \mathrm{W}=\operatorname{Trabalho}(\mathrm{J}) \\
& \mathrm{m}=\text { Massa }(\mathrm{kg}) \\
& \mathrm{v}=\text { velocidade }(\mathrm{m} / \mathrm{s}) \\
& \mathrm{g}=\text { aceleração da gravidade }\left(\mathrm{m} / \mathrm{s}^{2}\right) \\
& \mathrm{Z}=\text { cota de altitude }(\mathrm{m}) \\
& \mathrm{T}=\text { Temperatura }(\mathrm{K})
\end{aligned}
$$

Algumas hipóteses podem ser adotadas, a fim de simplificar a equação 13:

- Conforme apresenta Gillespie (1992), a energia cinética varia conforme diversas variáveis, entre as quais a massa do objeto. Desta forma, tornou-se necessário a adoção de um padrão de veículo a ser analisado, com a respectiva especificação das características do mesmo. Tal padrão é apresentado no APÊNDICE B.

- Num caso real, há um gradiente de massa do veículo, devido ao consumo de combustível. Para o caso em estudo, será considerada a massa do veículo constante, com especificação da massa conforme item anterior.

- Será adotada a hipótese de que o veículo percorre um percurso plano, durante o ciclo de condução: desta forma a variação da energia potencial será considerada nula.

- A massa do veículo será considerada constante, desprezando o consumo de combustível e considerando que não há fluxo de massa entrando ou saindo do veículo (proveniente da queima de gases e admissão de ar para o motor).

- Como ultima hipótese para simplificação da equação 13 , será considerada nula a variação de energia interna do veículo, uma vez que a maior parcela do potencial de regeneração energético provém da energia cinética.

Com isso, substituindo as hipóteses acima na equação 13, tem-se que: 


$$
\Delta K E=Q-W
$$

Analisando a frenagem de um veículo e relacionando com a equação 16, verifica-se que a parcela relacionada ao calor (Q) está relacionado à dissipação de calor do disco de freio para o ambiente, enquanto que o trabalho (W) esta relacionado às forças que atuam na desaceleração do veículo. Gillespie (1992) afirma que são diversas as forças atuantes que atuam na desaceleração do veículo: resistência ao rolamento, resistência aerodinâmica, resistência devido à inclinação e resistência devido ao engrenamento.

Para o estudo da parcela de trabalho durante a desaceleração, será adotada a seguinte hipótese:

- Durante as fases de desaceleração, será considerada a condição de veículo com transmissão não engrenada, logo será adotada a hipótese de $\mathrm{R}_{\mathrm{E}}=0$ (Resistência ao Engrenamento nula). Tal condição somente não se aplicará, quando as forças resistivas forem demasiadamente grandes, necessitando assim de engrenamento para que o nível de desaceleração seja atendido.

O trabalho total gerado pelas forças de resistência corresponde à integral dos trabalhos parciais devidos aos diversos tipos de resistência, conforme indicado na equação 17:

$$
W=\int_{v 1}^{v 2} \int_{s 1}^{s 2}\left(R_{R}+R_{a}+R_{\alpha}+R_{E}\right) \cdot d s \cdot d v
$$

Onde: $\mathrm{R}_{\mathrm{R}}=$ Resistência ao Rolamento $(\mathrm{N})$

$\mathrm{R}_{\mathrm{a}}=$ Resistência Aerodinâmica (N)

$\mathrm{R}_{\alpha}=$ Resistência devido à inclinação do piso (N)

$\mathrm{R}_{\mathrm{E}}=$ Resistência devido ao Engrenamento (N)

$\mathrm{s}=$ Espaço percorrido $(\mathrm{m})$ 
A resistência ao rolamento citado por Gillespie (1992) corresponde à força atuante contrária ao movimento do veículo devido à ação do atrito mecânico entre as superfícies do pneu e do solo. É citado que são muitos os fatores que afetam a intensidade da resistência ao rolamento tais como: temperatura do pneu, pressão de inflagem do pneu, carga submetida aos pneus, velocidade do veículo, material e características de projeto do pneu. A seguir é apresentado o equacionamento para o cálculo da resistência ao rolamento:

$$
\begin{gathered}
R_{R}=f_{r} \cdot m \cdot g \\
f_{r}=f_{0}+3,24 \cdot f_{s} \cdot(v / 100)^{2,5}
\end{gathered}
$$

Onde: $f_{r}=$ Coeficiente global de Resistência ao Rolamento (-)

$\mathrm{f}_{\mathrm{s}}=$ Coeficiente básico da Resistência ao Rolamento (-)

$\mathrm{f}_{0}=$ Coeficiente de velocidade da Resistência ao Rolamento (-)

Os coeficientes $f_{0}$ e $f_{S}$ variam conforme a pressão de inflamento dos pneus e são apresentados na figura 35.

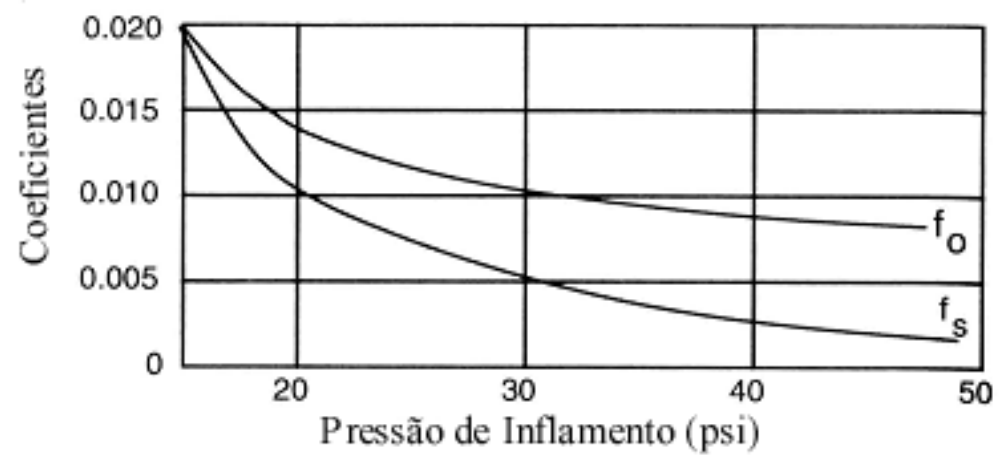

Figura 35. Coeficientes de resistência ao rolamento (GILLESPIE, 1992)

A resistência aerodinâmica citada por Gillespie (1992) pode ser equacionada conforme a seguir:

$$
R_{a}=1 / 2 \cdot \rho \cdot v^{2} \cdot C_{D} \cdot A_{f}
$$

Onde: $\rho=$ Densidade do $\operatorname{Ar}\left(\mathrm{kg} / \mathrm{m}^{3}\right)$ 
$\mathrm{C}_{\mathrm{D}}=$ Coeficiente de Arrasto Aerodinâmico (-)

$\mathrm{A}_{\mathrm{f}}=$ Área projetada frontal do veículo $\left(\mathrm{m}^{2}\right)$

A resistência devida à inclinação do piso citada por Gillespie (1992) pode ser equacionada como:

$$
R_{\alpha}=m \cdot g \cdot \cos \alpha
$$

Onde: $\alpha=$ Ângulo de inclinação do piso em relação ao plano horizontal $\left(^{\circ}\right)$

A resistência devido ao engrenamento $\left(\mathrm{R}_{\mathrm{E}}\right)$ citado por Gillespie (1992), corresponde à resistência existente devido á inércia dos elementos rotativos do sistema motor do veículo. No presente estudo, conforme citado nas hipóteses iniciais, tal resistência não será considerada.

Subsitiuindo as equações anteriores encontra-se a equação 22:

$$
1 / 2 \cdot m \cdot\left(v_{2}^{2}-v_{1}^{2}\right)+m \cdot g \cdot\left(Z_{2}-Z_{1}\right)+\Delta U_{\text {veiculo }}=Q-\left[\int_{v 1}^{v 2} \int_{s 1}^{s 2}\left(R_{R}+R_{a}+R_{\alpha}+R_{E}\right) \cdot d s \cdot d v\right]
$$

Adotando as simplificações apresentadas anteriormente, tem-se que:

$$
\begin{aligned}
& \Delta P E=0 \\
& \Delta U_{\text {veiculo }}=0 \\
& R_{\alpha}=0 \\
& R_{E}=0
\end{aligned}
$$

Reescrevendo a equação 22, levando em conta as simplificações necessárias obteve-se a equação 23, que define a quantidade de calor que é dissipado para o ambiente no momento da frenagem, que por sua vez consiste na energia líquida disponível para regeneração:

$$
E_{\text {liq }}=Q=1 / 2 \cdot m \cdot\left(v_{2}^{2}-v_{1}^{2}\right)-\left[\int_{v 1}^{v 2} \int_{s 1}^{s 2}\left(R_{R}+R_{a}\right) \cdot d s \cdot d v\right]
$$

Onde: $\mathrm{E}_{\mathrm{liq}}=$ Energia líquida disponível para regeneração $(\mathrm{kJ})$ 


\subsubsection{Energia disponível para Regeneração}

Para o estudo da energia disponível para regeneração, serão adotados dois ciclos de condução: aquele especificado conforme a norma ABNT NBR 6601 com duração prevista de 1370s (para veículos de passageiros) e um ciclo de desaceleração linear 40km/h - 0km/h @ 5s (para veículos de passageiros e veículos comerciais). Os dados de tais ciclos são apresentados no APÊNDICE C.

Substituindo os dados de entrada apresentados no APÊNDICE B na equação 22 e aplicando os ciclos de condução apresentados no APÊNDICE C foi possível obter os resultados relativos à energia disponível para regeneração. O APÊNDICE D apresenta a matriz com os valores, a partir de onde foram gerados os gráficos apresentados a seguir.

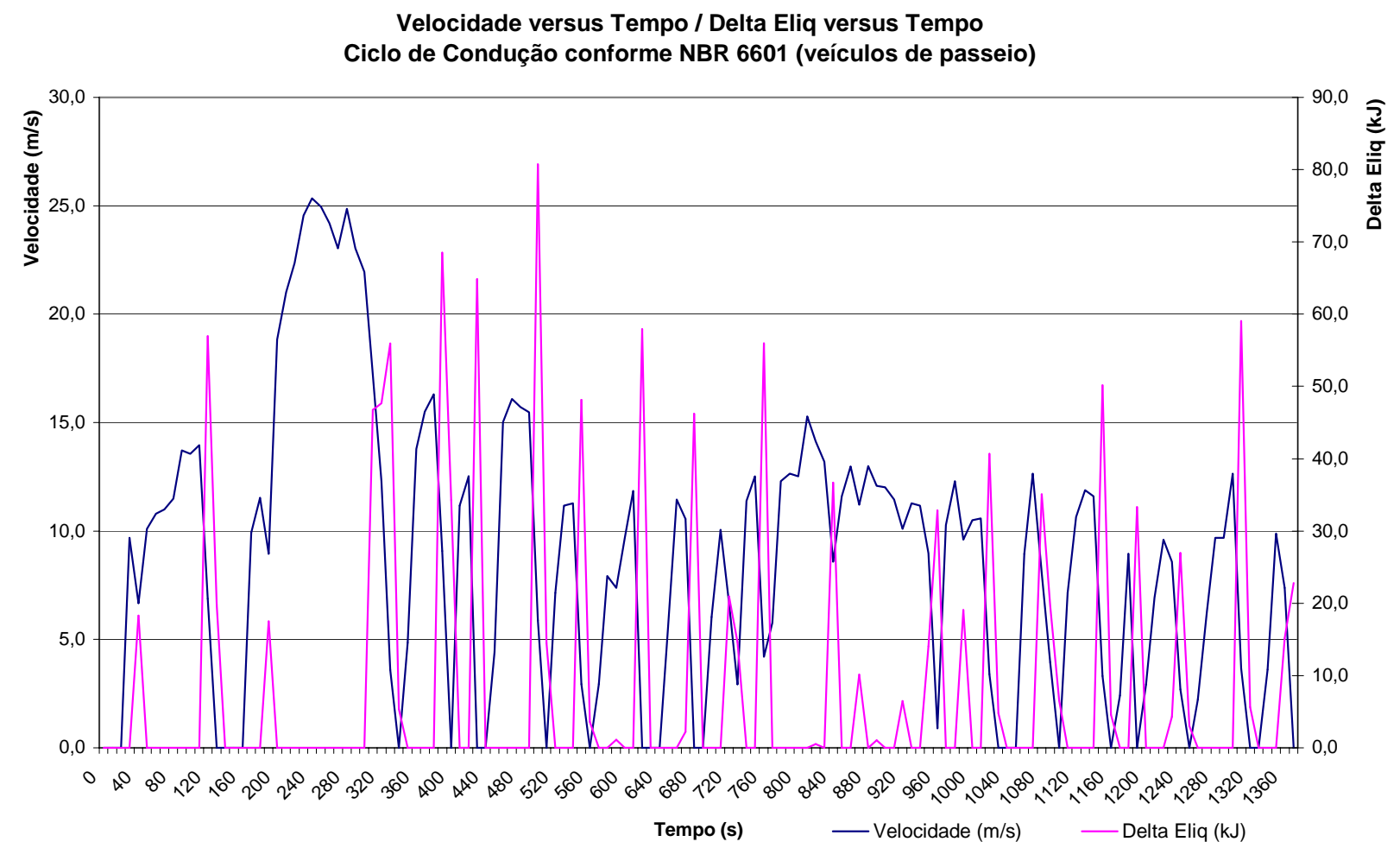

Figura 36. Gráfico da variação de velocidade e montante parcial de energia líquida disponível em função do tempo (ciclo de condução conforme NBR 6601 para veículo de passeio) 
Velocidade versus Tempo / Sum Eliq versus Tempo Ciclo de Condução conforme NBR 6601 (veículos de passeio)

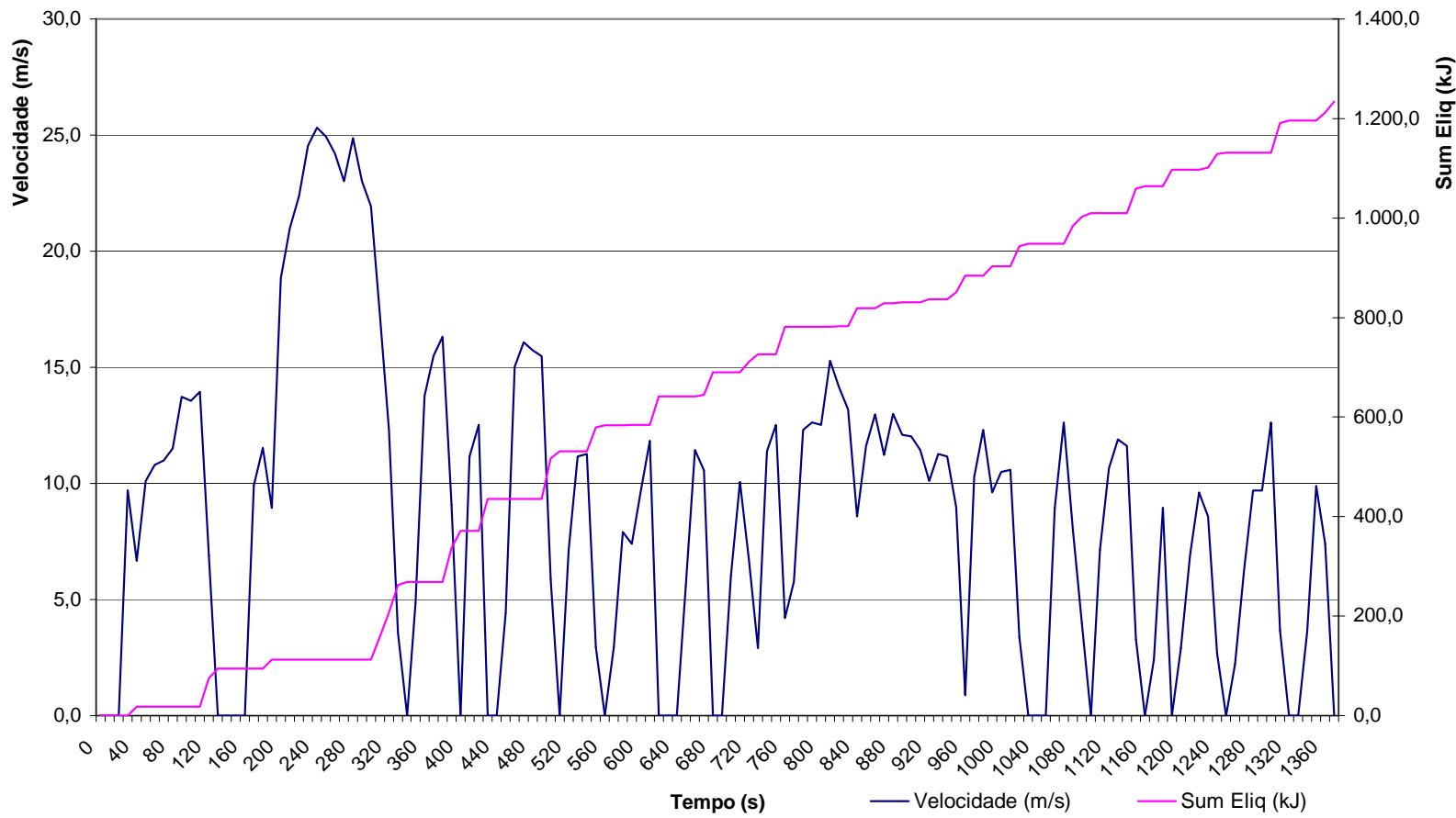

Figura 37. Gráfico da variação de velocidade e evolução da energia líquida acumulada disponível em função do tempo (ciclo de condução conforme NBR 6601 para veículo de passeio)

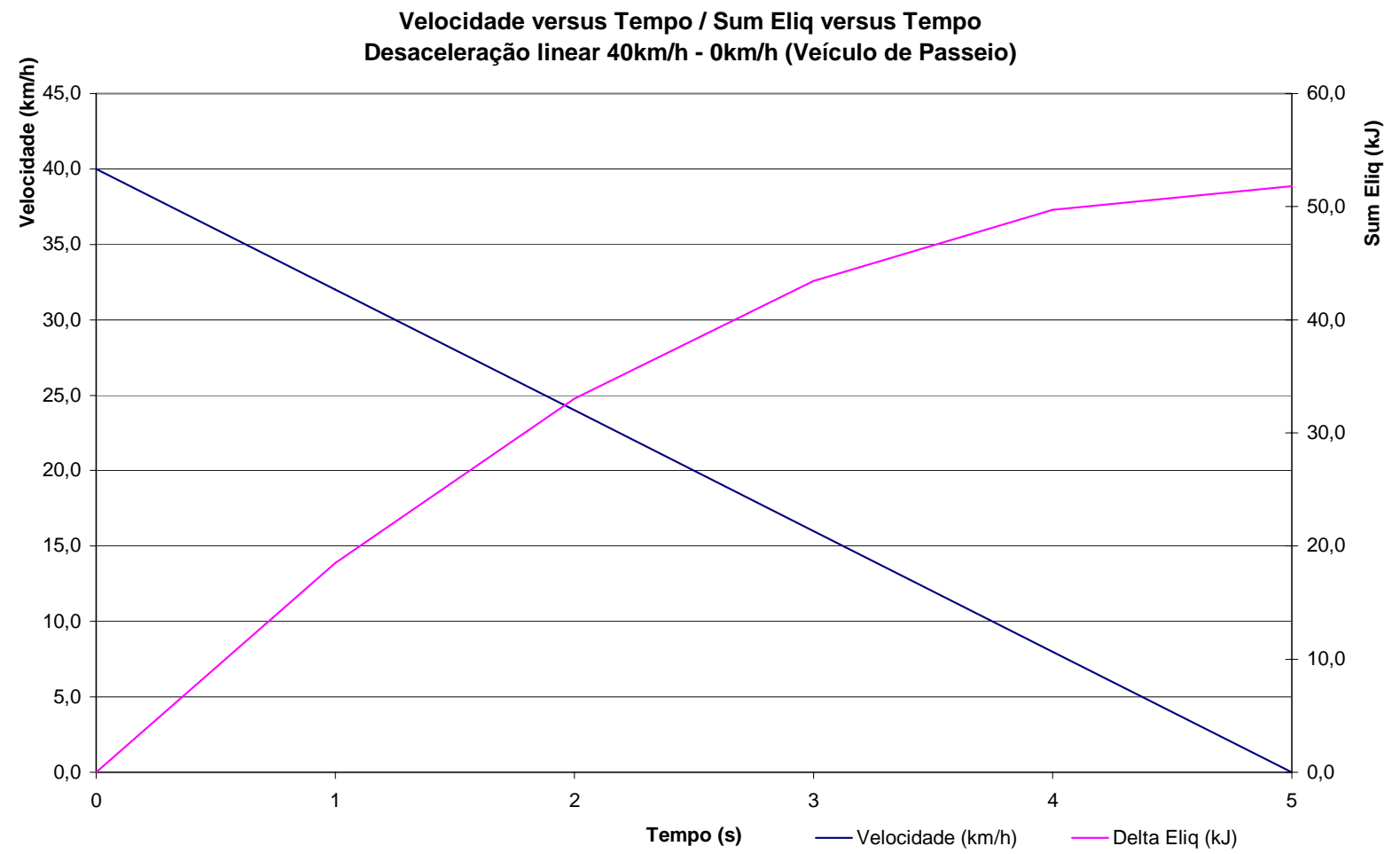

Figura 38. Gráfico da variação de velocidade e evolução da energia líquida acumulada disponível em função do tempo (desaceleração linear $40 \mathrm{~km} / \mathrm{h}$ - 0km/h para veículo de passeio) 


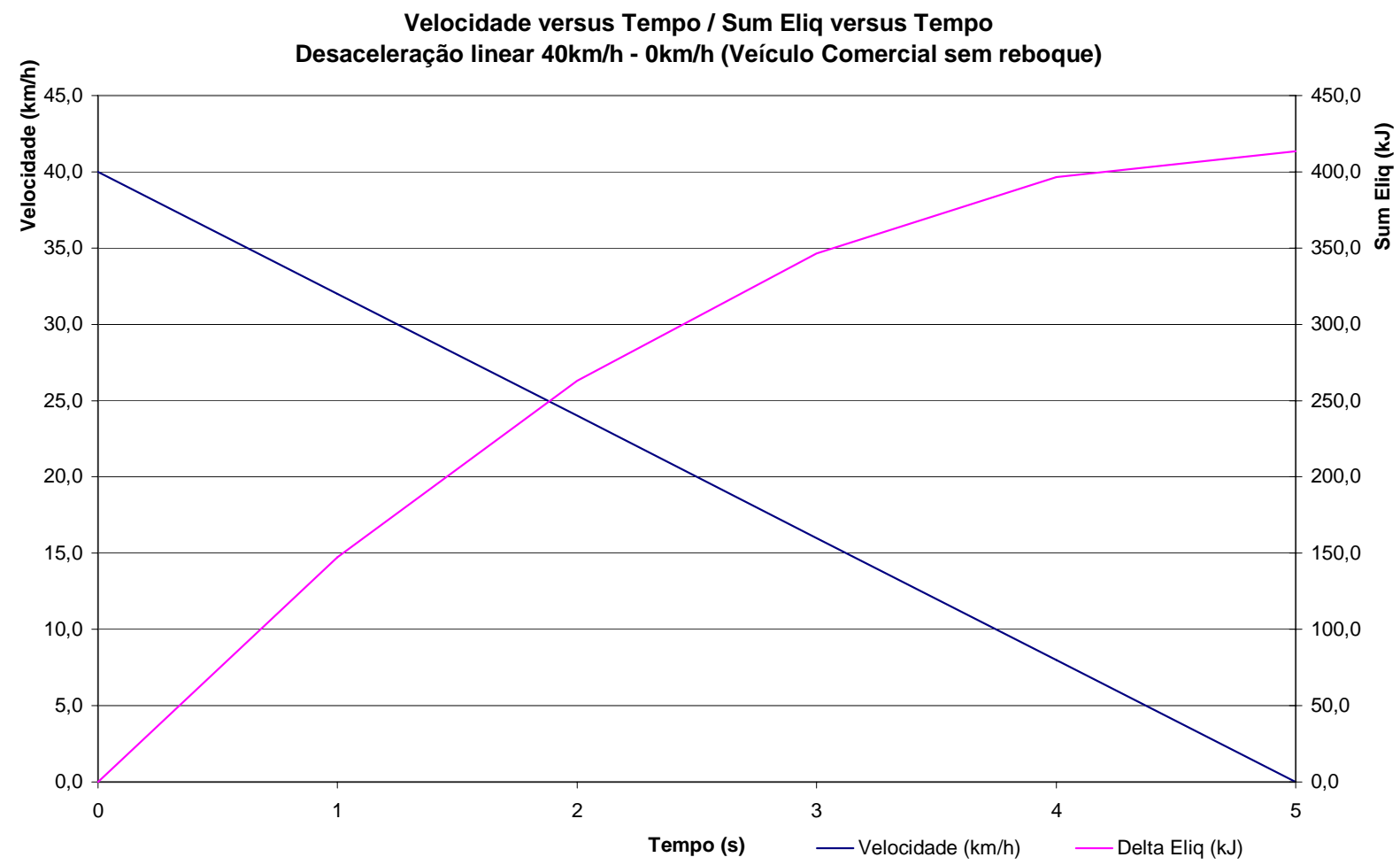

Figura 39. Gráfico da variação de velocidade e evolução da energia líquida acumulada disponível em função do tempo (desaceleração linear 40km/h - 0km/h para veículo comercial sem reboque)

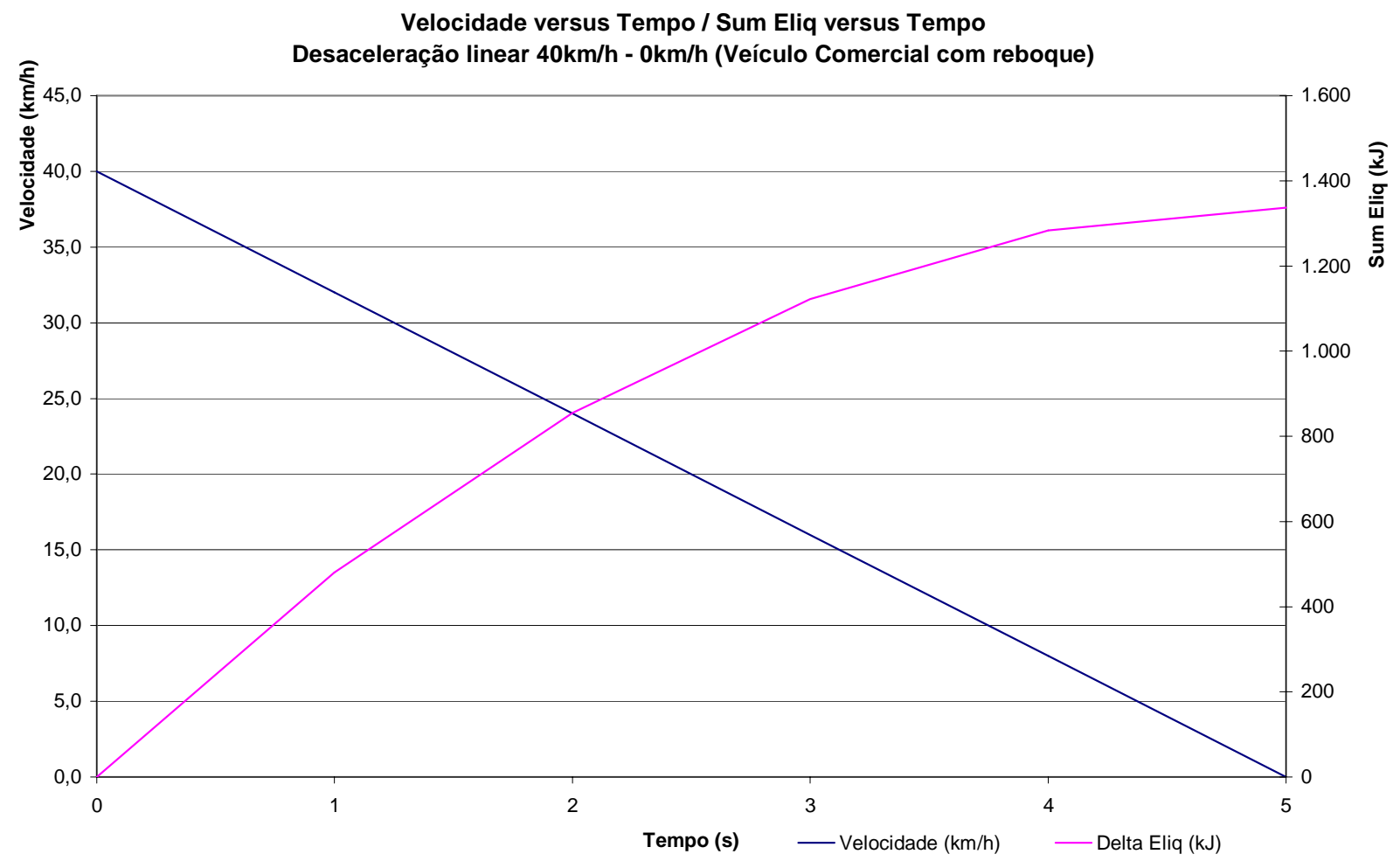

Figura 40. Gráfico da variação de velocidade e evolução da energia líquida acumulada disponível em função do tempo (desaceleração linear $40 \mathrm{~km} / \mathrm{h}$ - 0km/h para veículo comercial com reboque) 
Analisando os gráficos acima, verifica-se que ao final do ciclo de condução para veículos de passeio especificado na norma NBR 6601, a energia disponível para regeneração corresponde a aproximadamente 1200 kJ após 1370 s.

Uma segunda simulação numa condição de desaceleração isolada de $40 \mathrm{~km} / \mathrm{h}$ a $0 \mathrm{~km} / \mathrm{h}$ @ 5s para veículos de passeio, apresentou um potencial de regeneração de aproximadamente $52 \mathrm{~kJ}$.

Comparando este potencial de $52 \mathrm{~kJ}$ com o potencial de regeneração de veículos comerciais utilizando o mesmo critério de simulação, observa-se uma grande diferença: para um caminhão cavalo de força sem o reboque, o potencial de regeneração é de cerca de 420 kJ; já para o mesmo caminhão, porém acrescendo um reboque de 15t, esse valor ultrapassa 1250 kJ. Tal diferença ocorre devido à superior massa deslocada, no caso dos caminhões. 


\section{SISTEMA DE AR CONDICIONADO VEICULAR BASEADO NA APLICAÇÃO DE TUBOS DE VÓRTICES COM REGENERAÇÃO ENERGÉTICA}

No presente capítulo será apresentado uma proposta de sistema de ar condicionado baseado na aplicação de tubos de vórtices, aliado a um sistema regenerativo de energia. Uma primeira parte deste capítulo apresentará a filosofia do sistema, enquanto a segunda parte abordará tópicos relacionados à seleção dos componentes do sistema.

\subsection{Filosofia do Sistema}

Conforme apresentado por Cockerill (1998), a operação de um tubo de vórtices somente se torna possível se o sistema for composto de alguns componentes básicos: compressor de ar, tubo de vórtices e tubulações de interligação. A figura 41 apresenta um esquema do sistema.

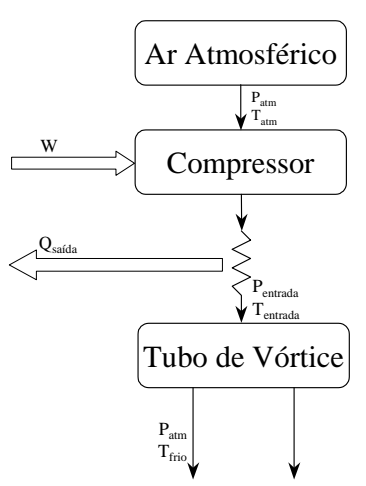

Figura 41. Esquema básico dos componentes para operação de um sistema de tubo de vórtices (COCKERILL 1998)

A fim de fornecer pressão e vazão de ar tais, que possibilitem a operação do tubo de vórtices, é necessário a existência de um compressor de ar no sistema. Para a operação do 
compressor é necessário o fornecimento de energia para que haja trabalho de compressão do ar, provendo a condição ideal de fornecimento de ar comprimido para o tubo de vórtices.

A fim de prover a interligação entre o compressor e o tubo de vórtices são necessários dutos de ligação de calibre suficiente para o transporte da massa de ar desejada.

No caso de um veículo automotor, a energia necessária para a operação do compressor pode ser proveniente através de diversas fontes, tais como: energia elétrica gerada através do alternador do veículo, energia cinética proveniente do motor de combustão interna. Um acumulador pneumático pode ser acrescido ao sistema no intuito de disponibilizar uma reserva de ar tal que possibilite a operação do sistema por alguns momentos, mesmo com o compressor não estando em funcionamento. Um esquema desse sistema proposto é apresentado na figura 42.

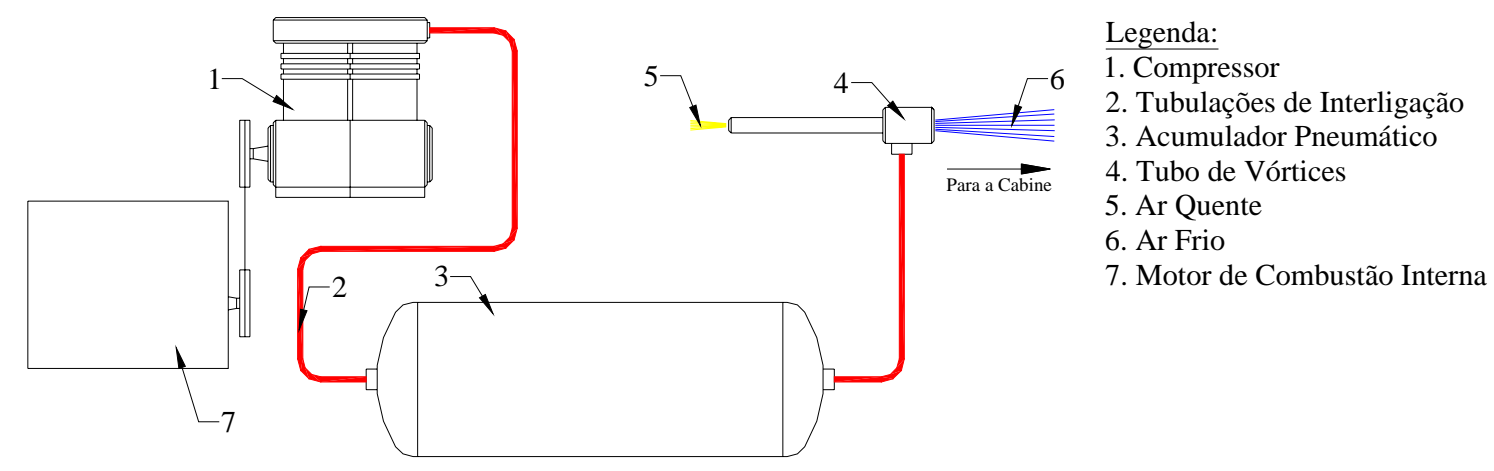

Figura 42. Proposta de sistema de Ar Condicionado com a aplicação de tubos de vórtices

Num sistema de ar condicionado convencional, a operação do compressor de fluído refrigerante se dá através do redirecionamento da energia cinética gerada pelo motor de combustão interna a partir da queima de combustível. Tal filosofia naturalmente ocasiona um maior consumo de combustível, uma vez que o motor deve queimar combustível para movimentar o veículo, assim como para possibilitar a operação do sistema de ar condicionado convencional. 
No entanto, conforme apresentado no Capítulo 4.3, existe um potencial de reaproveitamento da energia, que é dissipada ao ambiente no momento da frenagem do veículo. Uma hipótese otimizada de operação do compressor, consiste no reaproveitamento de tal energia cinética, minimizando assim o consumo de energia proveniente da queima de combustível a partir do motor de combustão interna.

No intuito de reaproveitar o máximo possível de energia, torna-se recomendável aplicar alguma forma de acumulação energética. Levando em conta que a operação do tubo de vórtices se dá apenas com a existência de ar comprimido, uma proposta seria a operação do compressor de ar através da energia cinética que seria convertida em energia térmica (e dissipada ao ambiente), no momento da frenagem do veículo. Neste caso, torna-se necessário a aplicação de um dispositivo que transfira a energia cinética do veículo, a partir da transmissão do veículo, para o compressor, apenas no momento da frenagem.

O sistema passa então a ser composto dos seguintes componentes que estão descritos na figura 43: compressor de ar (1), tubulações de interligação dos componentes (2), acumulador pneumático para armazenamento do ar (3), tubo de vórtices (4) que fornece ar quente (5) e ar frio (6), motor de combustão interna (7), transmissão do motor (8), embreagem do sistema regenerativo (lado transmissão) (9), embreagem lado motor (10), correias de transmissão de movimento (11) e pneus (12).

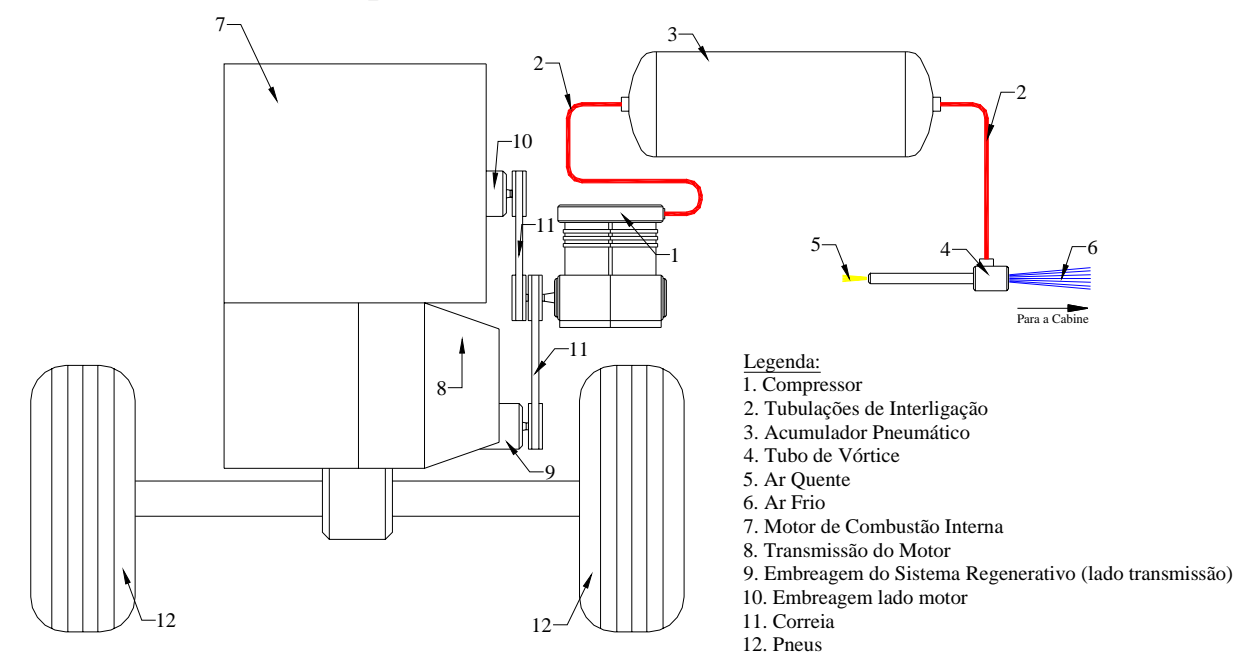

Figura 43. Proposta de sistema de Ar Condicionado com a aplicação de tubos de vórtices e regeneração energética 
Quando da operação do sistema de ar condicionado demonstrado na figura 43 em ocasiões em que não haja regeneração energética, o tubo de vórtices irá consumir o ar comprimido no reservatório pneumático. Naturalmente, o consumo do ar levará ao esvaziamento do reservatório pneumático, ocasionando uma queda de pressão do mesmo. Neste caso o compressor deverá receber energia cinética do motor do veículo, inevitavelmente resultando em consumo adicional de combustível.

Desta forma, é possível identificar basicamente três modos de operação do sistema apresentado na figura 43. A fim de simplificar o entendimento, a figura 44 apresenta um fluxograma com tais modos.

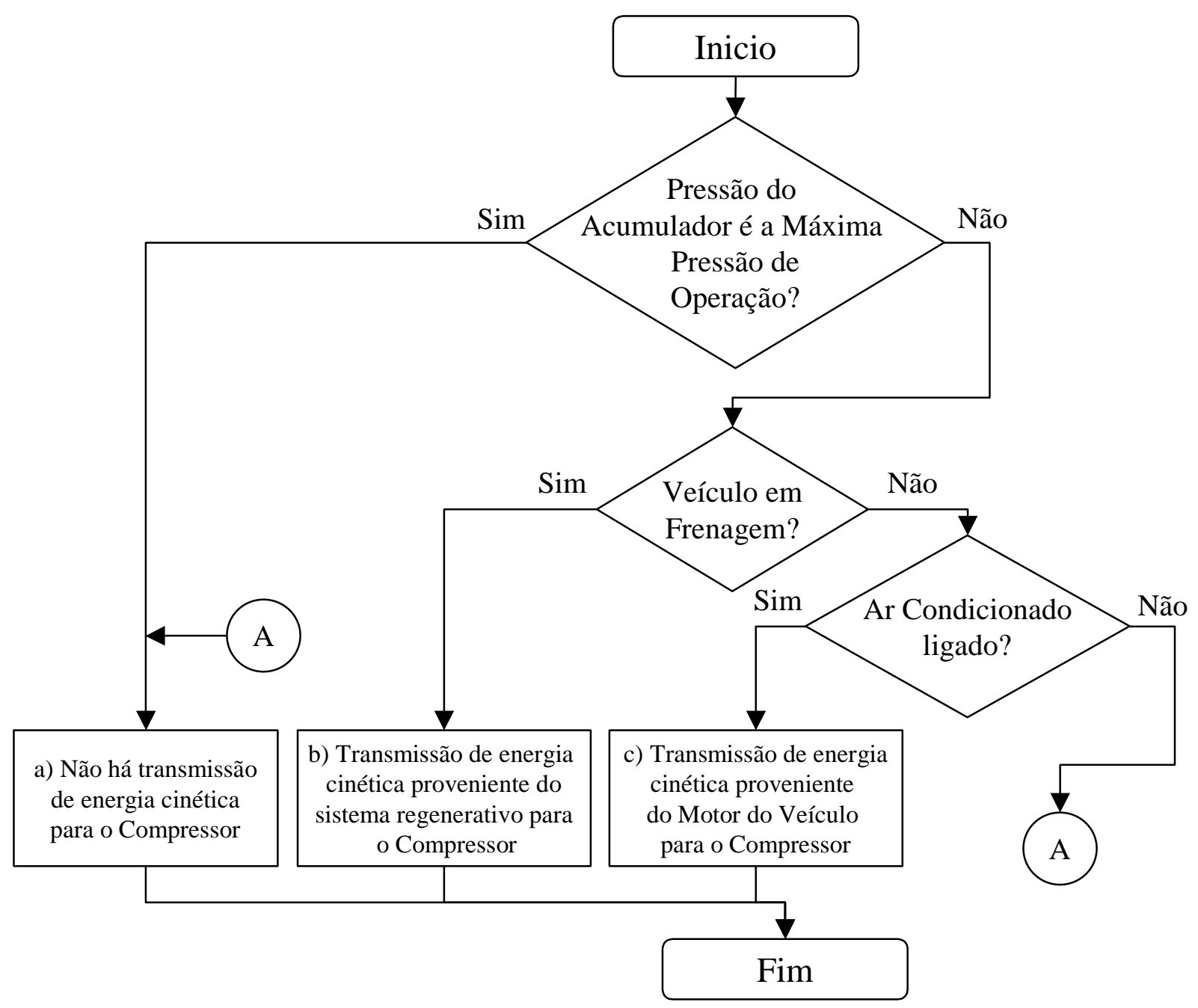

Figura 44. Fluxograma dos Modos de Operação do Sistema de Ar Condicionado com aplicação de Tubos de Vórtices e Regeneração Energética 
A fim de que o sistema possa operar conforme esses modos, é necessário a adição de sensores e modulos, que agirão de maneira a permitir o ótimo funcionamento do sistema. $\mathrm{O}$ novo sistema passa então a ser composto dos componentes descritos a seguir e demonstrados na figura 45: compressor de ar (1), tubulações de interligação dos componentes (2), acumulador pneumático para armazenamento do ar (3), tubo de vórtices (4) que fornece ar quente (5) e ar frio (6), motor de combustão interna (7), transmissão do motor (8), embreagem do sistema regenerativo (lado transmissão) (9), embreagem lado motor (10), correias de transmissão de movimento (11), pneus (12), módulo do pedal do freio (13), unidade de controle do motor (14), unidade de controle do ar condicionado (15), sensor de pressão (16) e válvula (17).

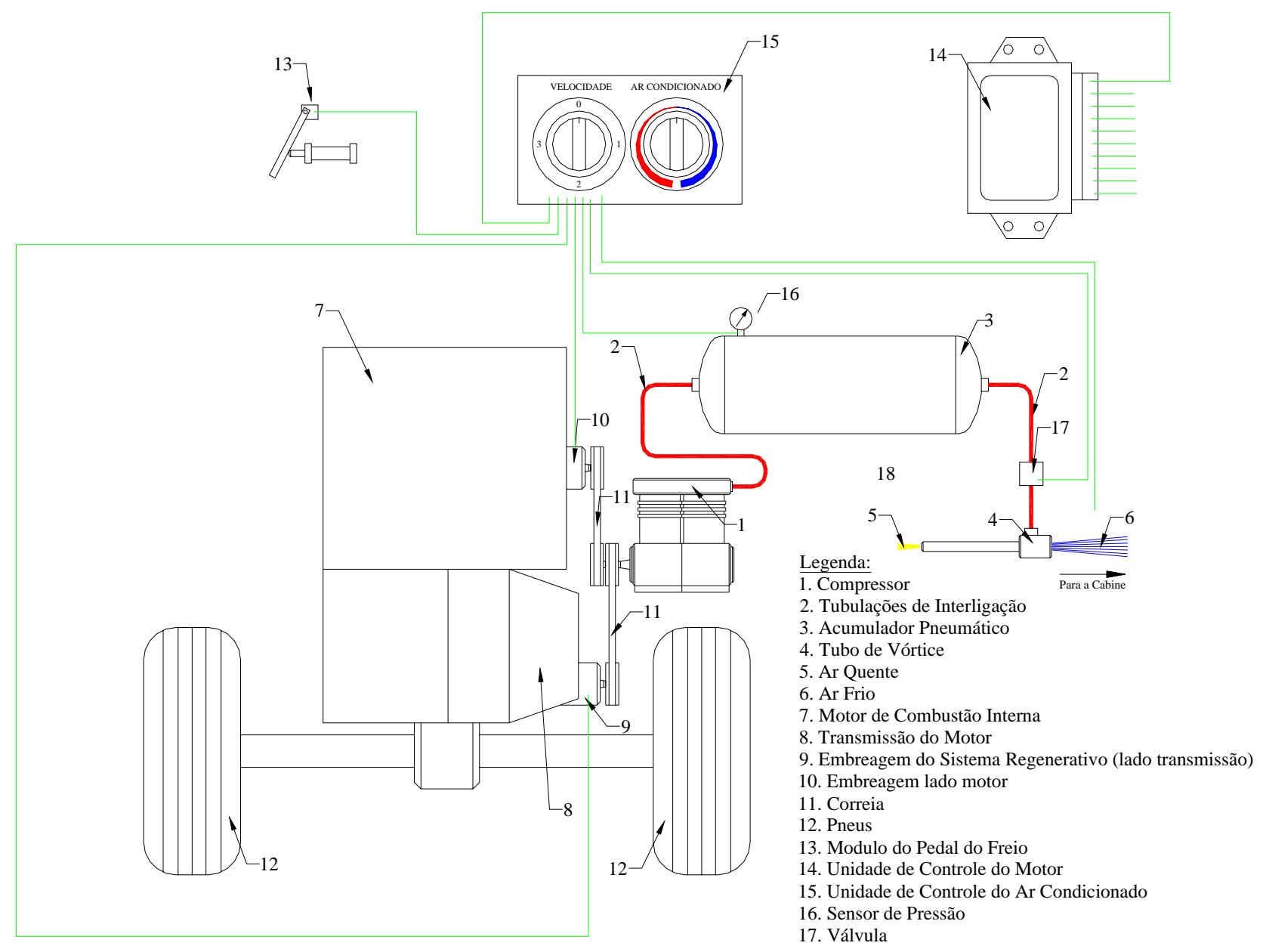

Figura 45. Proposta de sistema de Ar Condicionado com a aplicação de tubos de vórtices e regeneração energética (representação dos sensores) 
A seguir será abordado a função de cada componente do sistema em cada modo de operação descrito na figura 45.

a) Não existência de transmissão de energia cinética para o compressor: tal modo de operação pode ocorrer basicamente quando o acumulador pneumático está com sua capacidade plena, ou seja, em sua pressão máxima de operação (conforme dimensionado). Isso significa que, mesmo havendo a frenagem do veículo, não haverá o funcionamento do sistema regenerativo que transmitiria energia cinética da transmissão do veículo para o compressor. Para que isso seja possível, o sensor de pressão (16) envia um sinal ao módulo de controle de controle do Ar Condicionado que por sua vez envia sinais às embreagens (9) e (10), não permitindo assim a transmissão de energia cinética através do movimento das correias (11) para o compressor (1).

b) Transmissão de energia cinética proveniente do sistema regenerativo energético para o compressor: tal modo de operação ocorre quando há a frenagem do veículo, desde que o acumulador pneumático não esteja com sua capacidade plena (máxima pressão de operação). Neste caso, a frenagem do veículo é identificada através de um sensor localizado no módulo do pedal de freio (13), que por sua vez envia um sinal ao módulo de controle do ar condicionado (15) e reenvia um sinal à embreagem do sistema regenerativo (9) para seu acionamento e possibilite a transmissão de energia cinética para o compressor. Uma vez que a embreagem do sistema regenerativo está em operação, a embreagem lado motor (10) não deverá ser acionada. No momento em que o sensor de pressão (16) identifica a pressão máxima de operação, um sinal é recebido pela unidade de controle do Ar Condicionado (15) que por sua vez reenviará o sinal para a embreagem do sistema regenerativo (9), desativando-a. 
c) Transmissão de energia cinética proveniente do motor do veículo para o compressor: tal modo de operação ocorre quando o sistema de ar condicionado está em funcionamento e o veículo não está em ato de frenagem. Neste caso, a unidade de controle do ar condicionado (15) recebe a informação do sensor do módulo do pedal de freio (13) indicando que o mesmo não está acionado, não havendo assim a frenagem do veículo. Em paralelo, a unidade de controle do ar condicionado (15) verifica se o sistema de ar condicionado está em operação: em caso afirmativo, a unidade de controle do ar condicionado (15) envia um sinal à embreagem lado motor (10), permitindo que energia cinética produzida pelo motor do veículo (7) seja transmitida pelo compressor (1) através das correias (11). Para que não haja déficit de energia para a propulsão do veículo, a unidade de controle do ar condicionado (15) envia um sinal à unidade de controle do motor (14), para que haja a compensação de carga do motor.

O controle de vazão de ar que é fornecido ao habitáculo do sistema é feito através da válvula existente na tubulação de interligação entre o acumulador pneumático e o tubo de vórtices. Essa válvula tem a função de executar a regulagem do fluxo de vazão de ar comprimido, sendo que ela deve ser pilotada para que a unidade de controle de ar condicionado possa comandar a abertura ou fechamento da válvula conforme necessidade.

O controle de temperatura do ar que é fornecido ao habitáculo é feito através da atuação conjunta da válvula de controle de vazão com o ventilador presente na caixa de ar. A diminuição na vazão de ar que é fornecido ao tubo de vórtices acarretará na diminuição da vazão de ar de baixa temperatura. Para que a vazão permaneça constante é necessário a operação do ventilador da caixa de ar que fornecerá o montante necessário de vazão de ar para que os fluxos misturados alcancem a temperatura de ar desejado. 


\subsection{Seleção dos componentes}

A seguir serão abordados tópicos relacionados à seleção dos principais componentes do sistema apresentado no capítulo anterior.

\subsubsection{Tubos de Vórtices}

Foi apresentado no APÊNDICE A, que um sistema de ar condicionado convencional é dimensionado para uma carga térmica por volta de 1,6 TR. Para que isso seja possível, a vazão mássica de ar fornecida ao habitáculo deve ser de $0,11 \mathrm{~kg} / \mathrm{s}$ (equivalente a $0,09 \mathrm{~m}^{3} / \mathrm{s}$ para $\rho=1,225 \mathrm{~kg} / \mathrm{m}^{3}$ ) com uma queda de temperatura de $28^{\circ} \mathrm{C}$ (diferença entre a temperatura do ar externo e a temperatura requerida), para que haja a desumidificação do ar para padrões aceitáveis. Vale salientar que este dado de carga térmica, também pode ser utilizado para veículos comerciais, pois Tribess (2004) cita uma carga térmica de 1,5 TR para caminhões (bem semelhante à carga térmica calculada no APÊNDICE A).

Conforme já citado no capítulo 4.2, a variação de temperatura de ar frio que o tubo de vórtices fornece é dependente da fração de fluxo de ar frio, que foi demonstrada na Tabela 5.

Tabela 5 - Queda de temperatura do fluxo de ar frio em função da fração de ar frio em Tubos de Vórtices EXAIR ${ }^{10}($ EXAIR, 2005)

\begin{tabular}{|c|c|c|c|c|c|c|c|c|c|c|c|c|c|c|c|c|}
\hline \multirow{2}{*}{\multicolumn{3}{|c|}{$\begin{array}{c}\text { Pressão de } \\
\text { Entrada }\left(\mathbf{p}_{0}\right)\end{array}$}} & \multicolumn{14}{|c|}{ Fração de Fluxo de Ar Frio (yc) } \\
\hline & & & \multicolumn{2}{|c|}{0,2} & \multicolumn{2}{|c|}{0,3} & \multicolumn{2}{|c|}{0,4} & \multicolumn{2}{|c|}{0,5} & \multicolumn{2}{|c|}{0,6} & \multicolumn{2}{|c|}{0,7} & \multicolumn{2}{|c|}{0,8} \\
\hline psig & bar & $\mathrm{kPa}$ & $\Delta^{\circ} \mathrm{F}$ & $\Delta^{\circ} \mathrm{C}$ & $\Delta^{\mathrm{o}} \mathrm{F}$ & $\Delta^{\circ} \mathrm{C}$ & $\Delta^{\circ} \mathrm{F}$ & $\Delta^{\circ} \mathrm{C}$ & $\Delta^{\mathrm{o}} \mathrm{F}$ & $\Delta^{\circ} \mathrm{C}$ & $\Delta^{\circ} \mathrm{F}$ & $\Delta^{\circ} \mathrm{C}$ & $\Delta^{\mathrm{o}} \mathrm{F}$ & $\Delta^{\circ} \mathrm{C}$ & $\Delta^{\mathrm{o}} \mathrm{F}$ & $\Delta^{\circ} \mathrm{C}$ \\
\hline 20 & 1,4 & 138 & 62 & 34,4 & 60 & 33,3 & 56 & 31,1 & 51 & 28,3 & 44 & 24,4 & 36 & 20,0 & 28 & 15,6 \\
\hline 40 & 2,8 & 276 & 88 & 48,9 & 85 & 47,2 & 80 & 44,4 & 73 & 40,6 & 63 & 35,0 & 52 & 28,9 & 38 & 21,1 \\
\hline 60 & 4,1 & 414 & 104 & 57,8 & 100 & 55,6 & 93 & 51,7 & 84 & 46,7 & 73 & 40,6 & 60 & 33,3 & 46 & 25,6 \\
\hline 80 & 5,5 & 552 & 115 & 63,9 & 110 & 61,1 & 102 & 56,7 & 92 & 51,1 & 80 & 44,4 & 66 & 36,7 & 50 & 27,8 \\
\hline 100 & 6,9 & 689 & 123 & 68,3 & 118 & 65,6 & 110 & 61,1 & 100 & 55,6 & 86 & 47,8 & 71 & 39,4 & 54 & 30,0 \\
\hline 120 & 8,3 & 827 & 129 & 71,7 & 124 & 68,9 & 116 & 64,4 & 104 & 57,8 & 91 & 50,6 & 74 & 41,1 & 55 & 30,6 \\
\hline
\end{tabular}

Uma vez que altas frações de fluxo de ar frio resultam em baixas variações de temperatura e frações de fluxo de ar frio intermediárias resultam em maiores variações de 
temperatura, torna-se necessário analisar a melhor combinação que resulte no melhor rendimento do sistema. A figura 46 apresenta um gráfico das pressões de operação possíveis, assim como a fração de fluxo de ar frio necessária para que haja uma diferença de temperatura de $28^{\circ} \mathrm{C}$.

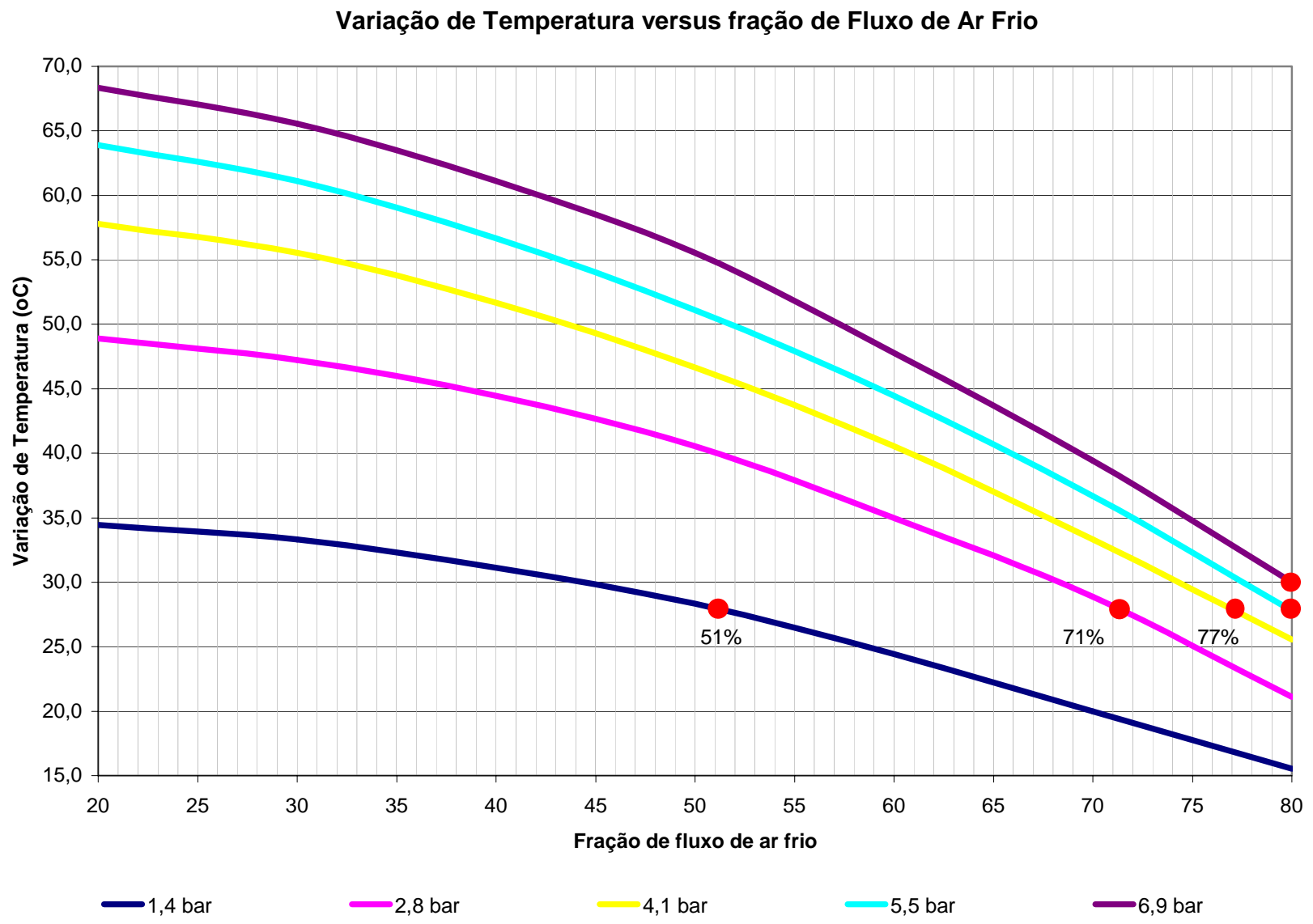

Figura 46. Variação de Temperatura em função da fração de fluxo de ar frio

Com os resultados apresentados na figura 46, foi calculado a vazão volumétrica de entrada necessária, que é apresentado na Tabela 7.

Tabela 7 - Vazões necessárias para diversas pressões de operação dos tubos de vórtices

\begin{tabular}{cccc}
\hline $\begin{array}{c}\text { Pressão de } \\
\text { entrada }\end{array}$ & $\begin{array}{c}\text { Fração de } \\
\text { fluxo frio }\end{array}$ & $\begin{array}{c}\text { Vazão Volumétrica de } \\
\text { entrada requerida }\end{array}$ & $\begin{array}{c}\text { Vazão mássica de } \\
\text { entrada requerida* }\end{array}$ \\
$\mathbf{p}_{\mathbf{0}}$ & $\mathbf{y}_{\mathbf{c}}$ & $\begin{array}{c}\dot{V}_{\text {req }} \\
\left(\mathrm{m}^{3} / \mathrm{s}\right)\end{array}$ & $\begin{array}{c}\dot{m}_{\text {req }} \\
(\mathrm{kg} / \mathrm{s})\end{array}$ \\
\hline 1,4 & 0,51 & 0,176 & 0,216 \\
2,8 & 0,71 & 0,127 & 0,155 \\
4,1 & 0,77 & 0,117 & 0,143 \\
5,5 & 0,80 & 0,113 & 0,138 \\
6,9 & 0,80 & 0,113 & 0,138 \\
\hline
\end{tabular}

$* \rho$ ar $=1,225 \mathrm{~kg} / \mathrm{m}^{3}$ 
A seleção do tubo de vórtices está intimamente relacionada com o compressor e reservatório de ar. Alterando a pressão de trabalho do tubo de vórtices altera-se também a potência requerida para compressão do ar. Desta forma é necessário analisar a potência de compressão para cada condição apresentada na figura 44. Brown (1997) apresenta o equacionamento para cálculo da potência teórica requerida:

$$
\begin{gathered}
\dot{W}_{\text {compressor }}=\frac{p_{1} \cdot \dot{V}_{\text {req }}}{\eta_{\text {compressor }}} \cdot \frac{k}{k-1} \cdot\left(r_{p}\left(\frac{k-1}{k}\right)-1\right) \\
r_{p}=p_{2} / p_{1}
\end{gathered}
$$

Tendo em mãos os dados relacionados às diversas condições de pressão de operação, efetuou-se a substituição de tais valores nas equação 24 e 25, obtendo assim a Tabela 8.

\begin{tabular}{|c|c|c|c|c|c|c|c|c|c|}
\hline \multicolumn{2}{|c|}{$\begin{array}{l}\text { Pressão de } \\
\text { saída do } \\
\text { compressor }\end{array}$} & \multirow{2}{*}{$\begin{array}{c}\text { Pressão de } \\
\text { Entrada } \\
\text { compressor } \\
\text { p }_{1} \\
(\mathrm{kPa})\end{array}$} & \multirow{2}{*}{$\begin{array}{l}\text { Fração de } \\
\text { fluxo frio } \\
\qquad \begin{array}{c}y_{c} \\
(-)\end{array}\end{array}$} & \multirow{2}{*}{$\begin{array}{c}\text { Vazão } \\
\text { Volumetrica } \\
\text { de Entrada } \\
\text { requerida } \\
\dot{V}_{\text {req }} \\
\left(\mathrm{m}^{3} / \mathrm{s}\right)\end{array}$} & \multirow{2}{*}{$\begin{array}{c}\text { Vazão } \\
\text { Volumetrica } \\
\text { de Entrada } \\
\text { requerida } \\
\dot{m}_{\text {req }} \\
(\mathrm{kg} / \mathrm{s})\end{array}$} & \multirow{2}{*}{$\begin{array}{c}\text { Razão de } \\
\text { Pressões } \\
\mathbf{r}_{\mathbf{p}} \\
(-)\end{array}$} & \multirow{2}{*}{$\begin{array}{c}\text { Razão de } \\
\text { Calor } \\
\text { Especifico }^{1} \\
\text { k } \\
(-)\end{array}$} & \multirow{2}{*}{$\begin{array}{c}\text { Eficiencia do } \\
\text { Compressor }^{1} \\
\eta_{\text {compressor }} \\
(-)\end{array}$} & \multirow{2}{*}{$\begin{array}{c}\begin{array}{c}\text { Potência } \\
\text { teórica } \\
\text { necessária }\end{array} \\
\dot{W}_{\text {COMPRESSOR }} \\
\text { (kW) }\end{array}$} \\
\hline $\begin{array}{c}\mathbf{p}_{2} \\
\text { (bar) }\end{array}$ & $\begin{array}{c}\mathbf{p}_{2} \\
(\mathbf{k P a})\end{array}$ & & & & & & & & \\
\hline 1,4 & 140 & 101,3 & 0,51 & 0,176 & 0,216 & 1,4 & 1,395 & 0,73 & 8,6 \\
\hline 2,8 & 280 & 101,3 & 0,71 & 0,127 & 0,155 & 2,8 & 1,395 & 0,81 & 19,0 \\
\hline 4,1 & 410 & 101,3 & 0,77 & 0,117 & 0,143 & 4,1 & 1,395 & 0,84 & 24,5 \\
\hline 5,5 & 550 & 101,3 & 0,80 & 0,113 & 0,138 & 5,5 & 1,395 & 0,85 & 29,4 \\
\hline 6,9 & 690 & 101,3 & 0,80 & 0,113 & 0,138 & 6,9 & 1,395 & 0,84 & 34,9 \\
\hline
\end{tabular}

Tabela 8 - Análise da potência de compressão necessária para diversas condições de operação

Analisando a Tabela 8, verifica-se que, apesar da pressão de operação de 1,4 bar obrigar a necessidade de uma vazão volumétrica de entrada que equivale ao dobro da vazão de saída do fluxo de ar frio, a potência requerida é a mais baixa de todas. Isso pode ser explicado observando a equação 23, onde a potência requerida não é proporcional à relação de pressões.

Desta forma, para o caso em análise, a operação do tubo de vórtices na pressão de 1,4 bar em fração de fluxo frio equivalente a 51\%, torna-se a hipótese mais viável de configuração. No entanto, não é possível selecionar os modelos de tubos vórtices com base na 
tabela 4 apresentada por EXAIR (2005), uma vez que os dados de vazão volumétrica presentes nesta tabela dizem respeito à operação em pressão de 6,9 bar. Seria necessário inicialmente obter a informação da vazão volumétrica para a pressão de 1,4 bar, a fim de que seja possível calcular a quantidade de tubos de vórtices, além de selecionar os modelos.

Deve-se salientar que é possível optar pela seleção de uma maior quantidade de tubos de vórtices de vazão volumétrica inferior, ficando a crtitério do projetista avaliar a melhor proposta de custo benefício do sistema.

Uma vez que o fluído é expulso do tubo de vórtices em altas velocidades é comum a apresentação de níveis altos de ruído. Dessa forma, é necessário a inclusão de dispositivos que minimizem o ruído, além de avaliar uma configuração de posicionamento no interior do veículo, de forma a minimizar esse ruído.

\subsubsection{Acumulador pneumático}

Compressed Air and Gas Institute (2004), cita que os acumuladores pneumáticos (reservatórios de ar) apresentam diversas funções, tais como: atender consumos repentinos os quais o compressor não pode suprir momentaneamente, reduzir a necessidade frequente de alteração de carga do compressor, amortecer as pulsações na tubulação de descarga e condensar alguma umidade que possa estar presente no ar comprimido. No caso da aplicação para o sistema de ar condicionado com a aplicação de tubos de vórtices, o reservatório de ar tem a função principal de armazenar o ar comprimido pelo compressor principalmente nas ocasiões de frenagem do veículo, quando há a operação do sistema regenerativo.

É citado ainda pelo Compressed Air and Gas Institute (2004) um equacionamento que relaciona o volume do reservatório, com o tempo necessário até que a pressão de operação alcance um nível mínimo que afete o desempenho do sistema: 


$$
t=V_{\text {reserv }} \cdot \frac{p_{\max }-p_{\min }}{\dot{V}_{\text {req }} \cdot p_{\text {atm }}} .60
$$

onde: $\mathrm{t}=$ tempo de descarga $(\mathrm{s})$

$$
\begin{aligned}
& \mathrm{V}_{\text {reserv }}=\text { volume do reservatório }\left(\mathrm{m}^{3}\right) \\
& \mathrm{p}_{\text {min }}=\text { pressão inicial (mínima de operação) do reservatório }(\mathrm{kPa}) \\
& \mathrm{p}_{\max }=\text { pressão final (máxima de operação) do reservatório }(\mathrm{kPa}) \\
& \dot{V}_{\text {req }}=\text { Vazão volumétrica requerida }\left(\mathrm{m}^{3} / \mathrm{s}\right) \\
& \mathrm{p}_{\mathrm{atm}}=\text { pressão atmosférica }(\mathrm{kPa})
\end{aligned}
$$

A seleção do volume do reservatório assim como sua pressão máxima de operação, está intimamente relacionada com a capacidade do compressor. Para o caso corrente, conforme estabelecido no capítulo anterior, é necessário uma pressão mínima de operação equivalente a 1,4 bar, a fim de que seja alcançada a variação de temperatura desejada $\left(28^{\circ} \mathrm{C}\right)$.

\begin{tabular}{|c|c|c|c|c|c|c|}
\hline Volume & $\begin{array}{c}\text { Pressão } \\
\text { Máxima de } \\
\text { Operação }\end{array}$ & $\begin{array}{c}\text { Pressão } \\
\text { Mínima de } \\
\text { Operação }\end{array}$ & $\begin{array}{c}\text { Vazão } \\
\text { Volumétrica } \\
\text { necessária }\end{array}$ & $\begin{array}{c}\text { Pressão } \\
\text { atmosférica }\end{array}$ & Tempo & Tempo \\
\hline $\begin{array}{l}V_{\text {reserv }} \\
\left(\mathrm{m}^{3}\right)\end{array}$ & $\begin{array}{l}\mathrm{p}_{\max } \\
\text { (bar) }\end{array}$ & $\begin{array}{l}\mathrm{P}_{\min } \\
\text { (bar) }\end{array}$ & $\begin{array}{c}\dot{V}_{r e q} \\
\left(\mathrm{~m}^{3} / \mathrm{s}\right)\end{array}$ & $\begin{array}{l}\text { Patm } \\
(\mathrm{kPa})\end{array}$ & $\begin{array}{l}\mathrm{t} \\
(\mathrm{s})\end{array}$ & $\begin{array}{c}\mathrm{t} \\
(\mathrm{min})\end{array}$ \\
\hline 2,0 & 2 & 1,4 & 0,176 & 101,3 & 7 & 0,11 \\
\hline 2,0 & 5 & 1,4 & 0,176 & 101,3 & 40 & 0,67 \\
\hline 2,0 & 8 & 1,4 & 0,176 & 101,3 & 74 & 1,23 \\
\hline 2,0 & 10 & 1,4 & 0,176 & 101,3 & 96 & 1,61 \\
\hline 2,0 & 20 & 1,4 & 0,176 & 101,3 & 209 & 3,48 \\
\hline 1,0 & 2 & 1,4 & 0,176 & 101,3 & 3 & 0,06 \\
\hline 1,0 & 5 & 1,4 & 0,176 & 101,3 & 20 & 0,34 \\
\hline 1,0 & 8 & 1,4 & 0,176 & 101,3 & 37 & 0,62 \\
\hline 1,0 & 10 & 1,4 & 0,176 & 101,3 & 48 & $\mathbf{0 , 8 0}$ \\
\hline 1,0 & 20 & 1,4 & 0,176 & 101,3 & 104 & 1,74 \\
\hline 0,8 & 2 & 1,4 & 0,176 & 101,3 & 3 & 0,04 \\
\hline 0,8 & 5 & 1,4 & 0,176 & 101,3 & 16 & 0,27 \\
\hline 0,8 & 8 & 1,4 & 0,176 & 101,3 & 30 & 0,49 \\
\hline 0,8 & 10 & 1,4 & 0,176 & 101,3 & 39 & 0,64 \\
\hline 0,8 & 20 & 1,4 & 0,176 & 101,3 & 83 & 1,39 \\
\hline 0,5 & 2 & 1,4 & 0,176 & 101,3 & 2 & 0,03 \\
\hline 0,5 & 5 & 1,4 & 0,176 & 101,3 & 10 & $\mathbf{0 , 1 7}$ \\
\hline 0,5 & 8 & 1,4 & 0,176 & 101,3 & 19 & 0,31 \\
\hline 0,5 & 10 & 1,4 & 0,176 & 101,3 & 24 & 0,40 \\
\hline 0,5 & 20 & 1,4 & 0,176 & 101,3 & 52 & 0,87 \\
\hline
\end{tabular}
Além disso, com o sistema de ar condicionado em plena carga, é necessário uma vazão volumétrica equivalente a $0,176 \mathrm{~m}^{3} / \mathrm{s}$. De posse desses dados é possível efetuar uma simulação com a equação 26, relacionando o tempo de descarga, a pressão máxima de operação e o volume necessário. Tal análise é apresentada na Tabela 9.

Tabela 9 - Tempo de descarga em função do volume do reservatório para diferentes pressões 
A partir da Tabela 9, verifica-se que o tempo de descarga aumenta quanto maior for o volume do reservatório ou quanto maior for a pressão máxima de armazenamento. É interessante a existência de um tempo de descarga grande, no entanto isso acarreta algumas consequências:

a) Em geral veículos de passeio não possuem muito espaço disponível. Além disso um grande volume ocupado por reservatórios de ar, aumenta em muito a massa do veículo, minimizando sua performance.

b) Uma alta pressão máxima de operação resulta em necessidade de maior trabalho de compressão, que é sentido principalmente quando é necessário o redirecionamento de energia cinética proveniente do motor do veículo, aumentando o consumo de combustível.

Com isso, face à analise apresentada na tabela 9, a viabilidade de aplicação do sistema em estudo para veículos de passeio é baixa, devido ao espaço disponível no veículo.

A viabilidade de aplicação se mostra maior em veículos comerciais que dispõe de maior espaço disponível. Para esta aplicação, uma proposta seria a utilização de um reservatório de ar de 0,8 $\mathrm{m}^{3}$ com uma pressão máxima de operação de 8 bar (800kPa), o que constitui um meio termo entre espaço disponível e pressão de operação. Consultando a tabela 9, verifica-se que há um tempo de descarga de 30s nessa configuração de sistema. Isso significa que o sistema de ar condicionado em questão pode operar em máxima carga durante 30s, se no início da operação a pressão de ar comprimido no reservatório for equivalente a 8 bar. 


\subsubsection{Compressor de Ar}

Atuamente existe uma gama variada de tipos de compressores disponíveis no mercado. Compressed Air and Gas Institute (2004) cita diversos tipos de compressores, sendo que sua utilização está relacionada a diversas variáveis, entre elas a pressão de descarga e capacidade de admissão. A figura 47 relaciona os tipos de compressores.

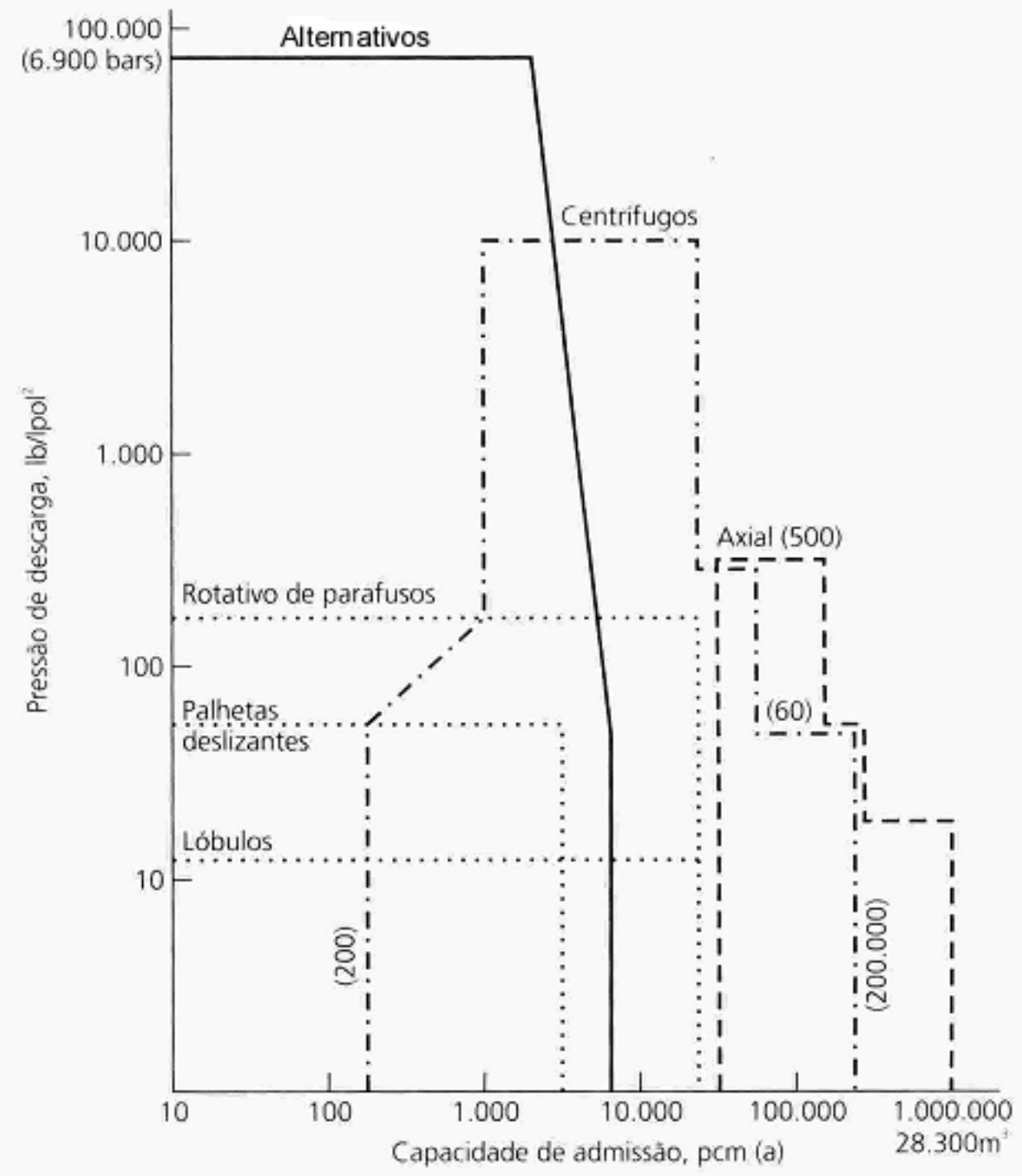

Figura 47. Aplicação do tipo de compressor conforme pressão de descarga e capacidade de admissão (COMPRESSED AIR AND GAS INSTITUTE, 2004) 
Conforme já mencionado no capítulo anterior, a potencia de compressão pode ser calculada conforme a equação 24 .

No caso de operação do sistema regenerativo, o compressor deverá operar até uma pressão máxima de 8 bar (800 kPa) a uma vazão volumétrica máxima de 0,176 m³/s. A fim de obter as potências necessárias para a pressão máxima de operação, foi feita uma simulação utilizando a equação 24 . Os resultados são apresentados na tabela 10.

Tabela 10 - Potência necessária em função da pressão de operação

\begin{tabular}{|c|c|c|c|c|c|c|c|c|}
\hline \multicolumn{2}{|c|}{$\begin{array}{l}\text { Pressão de } \\
\text { saída do } \\
\text { compressor }\end{array}$} & \multirow{2}{*}{$\begin{array}{c}\text { Pressão de } \\
\text { Entrada } \\
\text { compressor } \\
\text { p }_{1} \\
(\mathbf{k P a})\end{array}$} & \multirow{2}{*}{$\begin{array}{c}\text { Vazão } \\
\text { Volumetrica } \\
\text { de Entrada } \\
\text { requerida } \\
\dot{V}_{\text {req }} \\
\left(\mathrm{m}^{3} / \mathrm{s}\right)\end{array}$} & \multirow{2}{*}{$\begin{array}{c}\text { Vazão } \\
\text { Volumetrica } \\
\text { de Entrada } \\
\text { requerida } \\
\dot{m}_{r e q} \\
(\mathrm{~kg} / \mathrm{s})\end{array}$} & \multirow{2}{*}{$\begin{array}{c}\text { Razão de } \\
\text { Pressões } \\
\qquad \mathbf{r}_{\mathbf{p}} \\
(-)\end{array}$} & \multirow{2}{*}{$\begin{array}{c}\text { Razão de } \\
\text { Calor } \\
\text { Especifico } \\
\mathbf{k} \\
\text { k } \\
(-)\end{array}$} & \multirow{2}{*}{$\begin{array}{l}\text { Eficiencia do } \\
\text { Compressor }{ }^{1} \\
\eta_{\text {compressor }} \\
\text { (-) }\end{array}$} & \multirow{2}{*}{$\begin{array}{c}\begin{array}{c}\text { Potência } \\
\text { teórica } \\
\text { necessária }\end{array} \\
\dot{W}_{C O M P R E S S O R} \\
\text { (kW) }\end{array}$} \\
\hline $\begin{array}{c}\mathbf{p}_{2} \\
\text { (bar) }\end{array}$ & $\begin{array}{c}\mathbf{p}_{2} \\
\text { (kPa) }\end{array}$ & & & & & & & \\
\hline 2 & 200 & 101,3 & 0,176 & $\overline{0,216}$ & 2,0 & 1,395 & 0,73 & 18,8 \\
\hline 3 & 300 & 101,3 & 0,176 & 0,216 & 3,0 & 1,395 & 0,73 & 31,6 \\
\hline 4 & 400 & 101,3 & 0,176 & 0,216 & 4,0 & 1,395 & 0,73 & 41,6 \\
\hline 5 & 500 & 101,3 & 0,176 & 0,216 & 5,0 & 1,395 & 0,73 & 49,9 \\
\hline 6 & 600 & 101,3 & 0,176 & 0,216 & 6,0 & 1,395 & 0,73 & 57,2 \\
\hline 7 & 700 & 101,3 & 0,176 & 0,216 & 7,0 & 1,395 & 0,73 & 63,6 \\
\hline 8 & 800 & 101,3 & 0,176 & 0,216 & 8,0 & 1,395 & 0,73 & 69,4 \\
\hline
\end{tabular}

Analisando a tabela 10, verifica-se a necessidade de altas potências de compressão, para as condições de pressão e vazão em massa definidas anteriormente. Isso demonstra a necessidade de altas potências de regeneração.

É necessário também salientar a necessidade de um trocador de calor que minimize a temperatura do ar na saída do compressor. A temperatura do ar, conforme cita Compressed Air and Gas Institute (2004) sofre uma elevação durante o processo de compressão. A entrada de ar quente no tubo de vórtices deve ser evitada, uma vez que a temperatura de saída de fluxo de ar frio também será superior, nesta condição. 


\subsection{Comparação da energia necessária para compressão em relação ao potencial de regeneração}

No capítulo 4.3.2 foram obtidos os dados de regeneração energética para veículos de passeio e veículos comerciais em 2 ciclos básicos de operação. A fim de comparar os dados de regeneração com as necessidades de energia para compressão, foi criada a Tabela 11.

Tabela 11 - Potencial de regeneração versus potência máxima necessária para compressão

\begin{tabular}{lccccc}
\hline \multicolumn{1}{c}{ Veículo } & Ciclo & Tempo & $\begin{array}{c}\text { Energia } \\
\text { disponível }\end{array}$ & $\begin{array}{c}\text { Potencial de } \\
\text { regeneração }\end{array}$ & $\begin{array}{c}\text { Potência máxima } \\
\text { necessária para } \\
\text { compressão }\end{array}$ \\
\hline Veículo de Passeio & & $(\mathrm{s})$ & $(\mathrm{kJ})$ & $(\mathrm{kW})$ & $(\mathrm{kW})$ \\
Veículo de Passeio & NBR 6601 & 1370 & 1234 & $\sim 0,90$ & 69,4 \\
Veículo Comercial sem reboque & $40-0 \mathrm{~km} / \mathrm{h}$ & 5 & 52 & $\sim 10,4$ & 69,4 \\
Veículo Comercial com reboque & $40-0 \mathrm{~km} / \mathrm{h}$ & 5 & 413 & $\sim 82,6$ & 69,4 \\
\hline
\end{tabular}

Comparando as potências necessárias para compressão com os potenciais de regeneração, conclui-se que do ponto de vista de potência de compressão, apenas a aplicação em veículos comerciais (principalmente na condição com reboque) se torna viável. Observase que, mesmo para um veículo comercial cavalo mecânico sem o reboque, o sistema regenerativo consegue suprir a potência de compressão máxima.

Fica claro nessa comparação a magnitude de potência que pode ser regenerada (cerca de 267 kW) no caso dos veículos comerciais de carga com reboque. A utilização de compressores de maior capacidade poderia ser feito nestes casos, o que otimizaria o volume de ar armazenado. No entanto, deve-se levar em conta o aumento de volume e peso do compressor, o que pode inviabilizar o projeto. 
Partindo da hipótese de que um sistema convencional de ar condicionado necessita de potências superiores a 3,0 kW para seu funcionamento, a economia no consumo de combustível de um veículo comercial de potência equivalente a 200kW utilizando o conceito de regeneração energética pode superar os 5\%, se o sistema regenerativo também alimentar o sistema pneumático para os freios a ar e suspensão a ar. 


\section{CONCLUSÕES}

Desde a implementação do primeiro sistema de ar condicionado num automóvel, todos os sistemas ar condicionado veiculares tem sido projetados e construídos, baseados no ciclo termodinâmico de refrigeração por compressão de vapor.

Desta forma, desde os projetos mais antigos de sistemas de ar condicionado para automóveis, muitos avanços tem sido alcançados, no intuito de otimizar o funcionamento e a eficiência de tal sistema. No entanto, algumas carências podem ser sentidas ainda hoje, como por exemplo a dificuldade de uma climatização homogênea no interior do veículo.

Tal climatização mais homogênea, pode ser alcançada através do posicionamento de diversas saídas de ar refrigerado em regiões estratégicas pela cabine. Porém, o fato da dificuldade do posicionamento de evaporadores em outras partes da cabine (que não sejam a parte dianteira), acaba por atrapalhar o alcance do conforto térmico ideal pelos passageiros.

Além disso, os sistemas de refrigeração por compressão de vapor necessitam da utilização de fluídos refrigerantes, que em sua maior parte constituem poluentes ambientais. Um grande esforço tem sido aplicado no desenvolvimento de fluídos refrigerantes que não causem dano algum ao meio ambiente.

Desta forma, é interessante a pesquisa de meios de climatização, cujo conceito seja diferente dos sistemas convencionais. Uma das possibilidades que foi abordada neste trabalho são os tubos de vórtices, que possibilitam a divisão de um fluxo de ar comprimido em dois fluxos de ar frio e ar quente.

Os tubos de vórtices, por serem dispositivos compactos que não necessitam de trocadores de calor, podem ser posicionados em diversos pontos da cabine, permitindo assim 
uma melhor distribuição do ar condicionado dentro do habitáculo, minimizando a dificuldade de alcance do conforto térmico, citado anteriormente.

A filosofia da aplicação dos tubos de vórtices utilizando-se do fluxo de baixa temperatura para refrigeração veicular, foi apresentado no Capítulo 5.1. Atualmente, os tubos de vórtices já são aplicados em refrigeração para fins industriais, conforme citado por Cockerill (1998). A adaptação para a aplicação em sistemas de ar condicionado automotivos, ficou por conta do sistema de compressão de ar, que pode aproveitar o movimento de eixo do veículo para realizar a operação do compressor de ar durante a frenagem, armazenando ar comprimido para utilização futura. Além disso, foi previsto a operação do compressor de ar com energia cinética proveniente do motor de combustão interna, quando não há possibilidade de operação do sistema regenerativo.

Tal filosofia de configuração permite que mesmo com o motor desligado, haja a operação do sistema de tubos de vórtices havendo a climatização do sistema até que o reservatório de ar alcance uma pressão mínima de operação.

Baseado em dados obtidos por dimensionamento de um sistema de ar condicionado convencional, obteve-se a capacidade de refrigeração necessária para um habitáculo de um automóvel, equivalente a 1,6 TR (semelhante ao habitáculo de um veículo comercial, equivalente a 1,5 TR conforme cita Tribess (2004)). Juntamente com a necessidade de uma vazão de ar de $0,090 \mathrm{~m}^{3} / \mathrm{s}$ e um diferencial de temperatura de $28^{\circ} \mathrm{C}$, foi efetuado um prédimensionamento da pressão de operação e fração de fluxo frio necessária, relativo à operação do tubo de vórtices.

Os resultados mostraram uma menor necessidade de potência de compressão de ar, no caso de utilizar uma fração de fluxo de ar frio equivalente a 51\% com uma pressão de operação equivalente a 1,4 bar. 
Conforme citado anteriormente a pressão de operação pode determinar a viabilidade ou não do sistema. Uma alta pressão de operação demanda altas potências de compressão de ar comprimido. Dessa forma, os resultados mostraram que uma baixa pressão de operação do tubo de vórtices, mesmo com a necessidade do aumento da vazão de fornecimento de ar comprimido, possibilita uma potência de compressão inferior (8,6 kW).

A comparação dos dados de potência de regeneração e potência de compressão, mostraram a viabilidade da aplicação do sistema abordado neste trabalho, apenas para veículos comerciais. No entanto, o dimensionamento do sistema que controla a transferência de energia cinética do eixo do veículo para o compressor deve ser cuidadoso, para que a desaceleração não seja brusca a ponto de atrapalhar o controle do veículo. Para veículos comerciais que possuem massa superior (veículo comercial com reboque), esse efeito é menor, porém tal cuidado deverá também ser levado em conta.

Uma das limitações observadas no estudo efetuado neste trabalho, diz respeito ao reservatório de ar e o compressor.

Para o sistema estudado, foi selecionado um volume de reservatório de ar comprimido equivalente a $0,8 \mathrm{~m}^{3}$. Convertendo esse volume em dimensões, seriam necessários cerca de 4 reservatórios de ar de diâmetro 0,60m x 0,70m de comprimento, o que inviabiliza a aplicação do sistema para veículo de passeio devido à limitação de espaço.

No entanto, para veículo comerciais de cargas tais como caminhões, o sistema de ar condicionado com regeneração se mostra viável, principalmente se o veículo for equipado com um sistema pneumático de frenagem e/ou suspensão a ar. Nestes casos o sistema de ar condicionado em questão pode ser incorporado ao sistema pneumático já existente no caminhão de modo a otimizar o projeto.

A outra dificuldade encontra-se no compressor de ar: assim como no caso do reservatório de ar, a aplicação de um compressor de ar que possa comprimir uma alta vazão 
de ar $\left(0,176 \mathrm{~m}^{3} / \mathrm{s}\right)$ torna-se inviável em veículos leves, devido ao espaço disponível. Em veículo comerciais, essa possibilidade é mais viável devido ao espaço disponível principalmente em veículos que já disponham de algum sistema pneumático, assim como no caso anterior.

Por fim, conclue-se que a aplicação do sistema estudado neste trabalho, da forma como foi configurada e desenvolvida, mostra maior viabilidade em veículo comerciais pesados que são dotados de maior espaço disponível e possuem maior massa de deslocamento permitindo um maior potencial de regeneração energética. Para veículos leves torna-se inviável por questões de espaço, peso dos componentes e menor potencial de regeneração energética.

O presente trabalho não tratou do dimensionamento completo de todos os componentes, sendo que não era esse o objetivo de tal. Desta forma, sugere-se para estudos futuros do tema, a análise e dimensionamento detalhado dos componentes, assim como os mecanismos mecânicos e de controle do sistema regenerativo energético.

Outra sugestão de estudo é a análise de aplicação de tais sistemas em transportes ferroviários, os quais dispõe de grande massa de deslocamento, além de grande espaço físico. 


\section{REFERÊNCIAS BIBLIOGRÁFICAS}

ABNT. NBR 6601 Veículos rodoviários automotivos leves - Determinação de hidrocarbonetos, monóxido de carbono, óxidos de nitrogênio e dióxido de carbono nos gás de escapamento. Rio de Janeiro: ABNT, 2001. 29p.

AHLBORN et al. Limits of temperature separation in a vortex tube. Journal of Physics D: Applied Physics, Vol. 27, pp 480-488, 1994.

AHLBORN, B.; CAMIRE, J.; KELLER, J. Low pressure vortex tubes. Journal of Physics D: Applied Physics, Vol. 29, pp 1469-1472, 1996.

AVILA, J. Ar Condicionado Automotivo: caracterização e avanços tecnológicos. 2002. 102p. Dissertação (Mestrado Profissionalizante). Universidade de São Paulo, 2002.

BARROSO et al. Cálculo Numérico (com aplicações). 2. Ed. São Paulo: Ed.Harbra, 1987.

BIRCH, S. Maybach 57 and 62. Automotive Engineering International. Warrendale, N.10, Vol.110, p.71-76, Outubro 2002.

BIRCH, S. Porsche 911 still envolving. Automotive Engineering International. Warrendale, N.8, Vol.112, p.10-14, Agosto, 2004.

BOSCH. Automotive handbook, 5. Ed. Plochingen: Robert Bosch GmbH / SAE Internantional, 2000.

BROWN, R. Compressors: selection and sizing. 2.Ed. Houston: Gulf Publishing Company, 1997.

BROWN et al. Comparative analysis of an automotive air conditioning system operating with $\mathrm{CO}_{2}$ and R134a. International Journal of Refrigeration, 25, p. 19-32, 2002.

CHICUREL, R. A compromise solution for energy recovery in vehicle braking. Energy, Vol. 24, pp 1029-1034, 1999. 
CIKANEK, S.; BAILEY, K. Regenerative braking system for a hybrid eletric vehicle. In: AMERICAN CONTROL CONFERENCE, 2002, ANCHORAGE. Proceedings of the American Control Conference. p. 3129-3134.

COCKERILL, T. Fluid Mechanics and Thermodynamics of a Ranque-Hilsch Vortex Tubes. 1998. 294p. Dissertação (Mestrado). Universidade de Cambridge. Cambridge, 1998.

COMPRESSED AIR AND GAS INSTITUTE. manual de ar comprimido e gases. São Paulo: Pearson Prentice Hall, 2004.

DELPHI AUTOMOTIVE SYSTEMS, CONFORT \& CONVENIENCE. Disponível em:

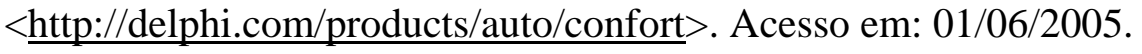

DERRY, T.; WILLIAMS, T. A Short history of Technology: from the earliest times to A.D. 1900. New York: Dover Publications, 1993.

DORNBRAND, H. Theoretical and Experimental Study of Vortex Tubes. Air Force Technical Report No. 6128. U.S. Department of Commerce Office of Technical Services. Washington DC, Junho 1950

EXAIR CORPORATION. Manufacturing compressed air for industry, Vortex Tubes. Disponível em < http://www.exair.com/vortextube/vt_page.htm>. Acesso em 01/06/2005.

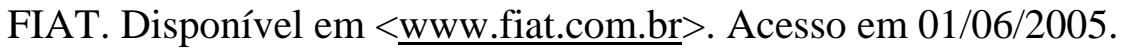

FORD. Disponível em < www.ford.com.br $>$. Acesso em 01/06/2005.

FORREST, W.; BHATTI, M. Energy efficient automotive air conditioning system. In: PROGRESS IN CLIMATE CONTROL TECHNOLOGIES. SAE 2002 World Congress. Detroit: 2002.

GENERAL MOTORS DO BRASIL. Apostila de Treinamento em ar condicionado, Assistência Técnica General Motors, 2003.

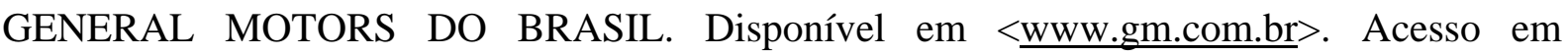
01/06/2005. 
GILLESPIE, T. Fundamentals of Vehicle Dynamics. Warrendale: Society of Automotive Engineers Inc., 1992.

GÖTZ, H.; MAYR, G. Commercial Vehicles. In: HUCHO, W. Aerodynamics of road vehicles: from fluid mechanics to vehicle engineering. 4 Ed. Warrendale: SAE, 1998.

HILSCH, R. Die Expansion von Gasen im Zentrifugalfeld als Kälteprozess. Z. Naturforschung, 1, 1946, 208-214.

JACKSON, W. The physiological aspects of automotive heating, ventilating and air conditioning. General Motors Engineering Journal. [S.l.], p.2-6, Julho-Agosto-Setembro, 1961.

JOUDI et al. Experimental and computer performance study of an automotive air conditioning system with auternative refrigerants. Energy Conversion and Management, 44, p. 29592976, 2003.

IANELLA, M. Avaliação Teórico-Experimental de um sistema de ar condicionado automotivo.1998. 139p. Dissertação (Mestrado). Escola de Engenharia de São Carlos, Universidade de São Paulo, São Carlos, 1998.

KAYNAKLI, O.; HORUZ, I. An experimental analysis of Automotive Air Conditioning System. International Community of Heat and Mass Transfer, Vol. 30, N.2, p. 273-284, 2003.

KUROSAKA, M. Acoustic Streaming in swirling flow and the Ranque-Hilsch (vortex-tube) effect. Journal of Fluid Mechanics, Vol. 124, p. 139-172, 1982.

MORAN, M.; SHAPIRO, H. Fundamentals of Engineering Thermodynamics. 5. Ed. Hoboken: John Wiley \& Sons Inc, 2004, 874p.

PENGELley, C. Flow in a Viscous Vortex. Journal of Applied Physics, Vol. 28, N. 1, p. 86-92, 1957.

PIRALISHVILI, S.; MIKHAILOV, V. Experimental investigation of a vortex tube with an additional flux. some aspects of investigations of Heat transfer and Heat Machines. Proc. Kual-Kuybyshev 56, [S.l.], p.64-74, 1973 
PIRALISHVILI, S.; POLYAEV, V. Flow and thermodynamic characteristics of energy separation in a double-circuit vortex tube - an experimental investigation. Experimental Thermal and Fluid Science, New York, Vol. 12, p. 399-410, 1996.

RANQUE, G. Expériences sur la détente giratoire avec productions simultanées d'un échappement d'air chaud et d'un échappement d'air froid. Journal de Phisique et de la Radium, IV, 1933, p.112-114.

RUTH, W. Simulation modelling of automobile confort cooling requirements. ASHRAE JOURNAL. [S.l.], p. 53-55, maio 1975

SAIDI, M.; YAZDI, M. Exergy Model of a vortex tube system with experimental results. Energy, Vol. 24, p. 625-632, 1999.

SAIDI, M.; VALIPOUR, M. Experimental modeling of vortex tube refrigerator. Applied Thermal Engineering, Vol. 23, p. 1971-1980, 2003.

SCANIA. Disponível em < wwww.scania.com.br $>$. Acesso em 06/08/2005.

SCHAIBLE, U.; SZABADOS, B. A torque controlled high speed flywheel energy storage system for peak power transfer in eletric vehicles. In: INDUSTRY APPLICATIONS SOCIETY ANNUAL MEETING, 1994. [S.I]? IEEE, p. 435-442

SIBULKIN, M. Unsteady, viscous, circular flow: Part 3 Application to the Ranque-Hilsch vortex tube. Journal of Fluid Mechanics, Vol. 12, p. 269-293, 1962.

SONI, Y.; THOMSON, W. Optimal Design of the Ranque-Hilsch Vortex Tube. Journal of Heat Transfer: Transactions of ASME, Vol. 97, N. 2, p 316-317, Maio 1975.

STEPHAN et al. An investigation of energy separation in a vortex tube. International Journal of Heat and Mass Transfer, Vol. 26, N. 3, p. 341-348, 1983.

STEPHAN et al. A similarity relation for energy separation in a vortex tube. International Journal of Heat and Mass Transfer, Vol. 27, N. 6, p. 911-920, 1984.

SUSLOV et al. Vortex Apparatus. Moscow: Mashinostroyenie, 1985 
TAKAHAMA, H.; YOKOSAWA, H. Energy separation in vortex tubes with a divergent chamber. Journal of Heat Transfer: Transactions of ASME, Vol. 103, p. 196-203, Maio 1981.

TRIBESS, A. Conforto Térmico em Veículos Automotivos. Apostila do curso de Mestrado Profissionalizante em Engenharia Automotiva. São Paulo: EPUSP, 2004.

TOYOTA, THS II. Disponível em <http:// www.toyota.co.jp/en/tech/environment/ths2/hybrid.html> Acesso em 01/06/2005

UNIVERSAL INDUSTRIAL GASES. Psychometric chart. Disponível em $<$ http://www.uigi.com/uigi_si.pdf $>$. Acesso em 15/05/2005.

WICKS, F. DONNELLY, K. Modeling regenerative braking and storage for vehicles. In: Energy Conversion Engineering Conference, 1997. IECEC-97 Proceedings of the 32nd Intersociety. Honolulu: IECEC-97, 1997, pp. 2030-2035.

VOLKSWAGEN DO BRASIL. Apostila de Treinamento em ar condicionado, Assistência Técnica Volkswagen, 1994.

VOLKSWAGEN DO BRASIL. Disponível em: <www.vw.com.br> . Acesso em 01/06/2005.

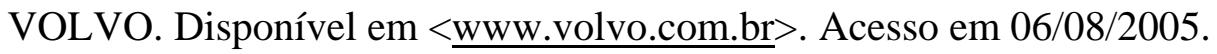

VAN WYLEN, G.; SONNTAG, R. ;BORGNAKKE, C. Fundamentos da Termodinâmica. 5. Ed. São Paulo: Ed. Edgard Blücher, 1998, 537p.

1999 ASHRAE HANDBOOK: HVAC APPLIATIONS. Atlanta: American Society of Heating, Refrigerating and Air-Conditioning Engineers Inc, 1999. 


\section{APÊNDICE A - Simulação da capacidade de refrigeração de um sistema de ar condicionado convencional para automóveis de passeio}

Conforme citado anteriormente, Forrest e Bhatti (2002) indicam alguns parâmetros utilizados em projetos de sistemas de ar condicionado. A tabela A.1 demonstra tais valores.

Tabela A.1 - Dados de operação de sistema de ar condicionado (FORREST; BHATTI, 2002)

\begin{tabular}{|c|c|c|}
\hline Descrição & $\mathbf{U N}$ & $\begin{array}{l}\text { Valor } \\
\text { Padrão }\end{array}$ \\
\hline Temperatura do ar externo & $\mathrm{T}_{0} \quad\left({ }^{\circ} \mathrm{C}\right)$ & 38 \\
\hline Umidade de relativa do ambiente externo & $\phi_{0} \quad(\%)$ & 40 \\
\hline Temperatura do ar na saída do evaporador & $\mathrm{T}_{\mathrm{E}} \quad\left({ }^{\circ} \mathrm{C}\right)$ & 10 \\
\hline Umidade de relativa no evaporador & $\phi_{\mathrm{E}} \quad(\%)$ & 100 \\
\hline Fluxo de massa de ar & $\mathrm{m}_{\mathrm{a}}^{\prime}(\mathrm{kg} / \mathrm{s})$ & 0,1285 \\
\hline
\end{tabular}

No entanto, alguns parâmetros variam conforme o tipo e classe de veículo a qual o sistema de ar condicionado está sendo desenvolvido. Santos (Informação Pessoal) ${ }^{5}$ cita que a vazão volumétrica máxima de ar de entrada no habitáculo é de cerca de 0,09 $\mathrm{m}^{3} / \mathrm{s}$, resultando em vazão em massa de ar de cerca de 0,11 kg/s (hipótese adotada: $\rho_{\mathrm{ar}}=1,225 \mathrm{~kg} / \mathrm{m}^{3}$ ).

Conforme apresentado anteriormente, a equação 9 demonstra o balanço energético para o cálculo da carga térmica necessária para um sistema de ar condicionado dotado de desumidificação.

$$
\dot{Q}=\dot{m}_{a} \cdot\left[\left(h_{a}+\omega \cdot h_{v}\right)_{2}-\left(h_{a}+\omega \cdot h_{v}\right)_{1}-\left(\omega_{2}-\omega_{1}\right) \cdot h_{w}\right]
$$

\footnotetext{
${ }^{5}$ SANTOS, E. RE: Help Mensagem recebida por dan.itao@uol.com.br em 30 de maio de 2005
} 
A obtenção das variáveis da equação foi efetuada em sua maior parte, consultando a carta psicrométrica. Para isso, foi necessário estabelecer as condições dos estados iniciais e finais. A figura A.1 apresenta a carta psicrométrica indicando as condições iniciais e finais.

A entalpia da mistura por unidade de massa do ar seco na condição $1\left(h_{a}+\omega \cdot h_{v}\right)_{1}$ e na condição $2\left(h_{\mathrm{a}}+\omega . h_{v}\right)_{2}$, podem ser obtidas através da carta psicrométrica apresentada na figura A.1. A umidade absoluta na condição $1\left(\omega_{1}\right)$ e condição $2\left(\omega_{2}\right)$ também podem ser obtidas através da carta psicrométrica apresentada na figura A.1. A entalpia específica do condensado $\left(\mathrm{h}_{\mathrm{w}}\right)$ pode ser obtida consultando tabelas de propriedades de vapor d'agua saturado.

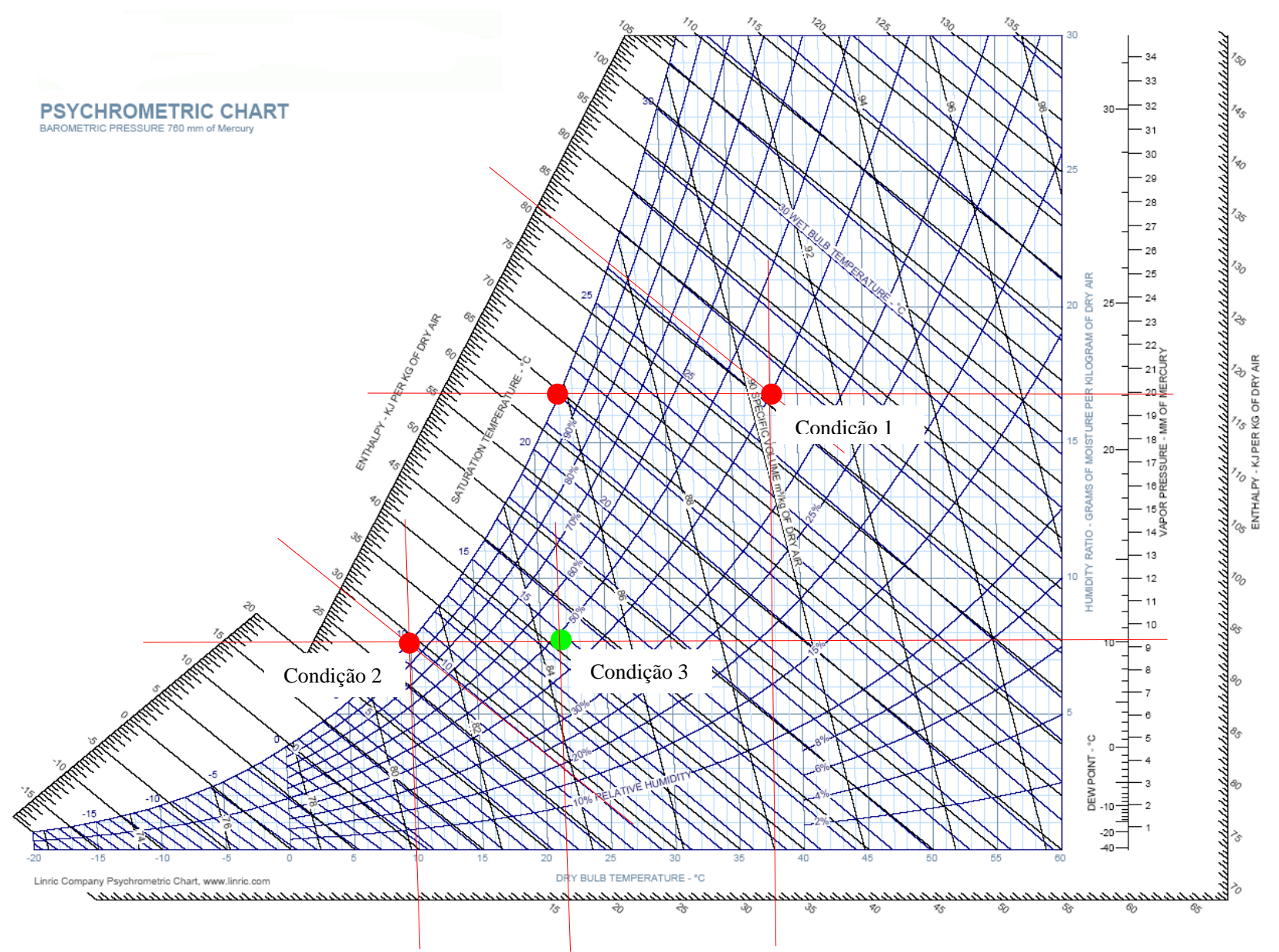

Figura A.1 Carta psicrométrica (UNIVERSAL INDUSTRIAL GASES, 2005)

Após consultar a figura A.1 e obter o valor da entalpia específica do condensado através de tabelas termodinâmicas específicas, foi criada a tabela A.2. 
Tabela A.2. Valores a serem utlizados na simulação

\begin{tabular}{lcc}
\hline VARIÁVEL & VALOR & UN \\
\hline$\dot{m}_{a}$ & $\mathbf{0 , 1 1}$ & $(\mathrm{kg} / \mathrm{s})$ \\
$\left(h_{a}+\omega \cdot h_{v}\right)_{1}$ & $\mathbf{8 1 , 0}$ & $(\mathrm{kJ} / \mathrm{kg})$ \\
$\left(h_{a}+\omega \cdot h_{v}\right)_{2}$ & $\mathbf{2 9 , 0}$ & $(\mathrm{kJ} / \mathrm{kg})$ \\
$\omega_{1}$ & $\mathbf{0 , 0 1 6 8}$ & $(\mathrm{kg} / \mathrm{kg})$ \\
$\omega_{2}$ & $\mathbf{0 , 0 0 7 8}$ & $(\mathrm{kg} / \mathrm{kg})$ \\
$h_{w}$ & $\mathbf{4 2 , 0 1}$ & $(\mathrm{kJ} / \mathrm{kg})$ \\
\hline
\end{tabular}

Substituindo os valores apresentados na tabela A.2. na equação 9, tem-se que:

$$
\begin{aligned}
& \dot{Q}=\dot{m}_{a} \cdot\left[\left(h_{a}+\omega \cdot h_{v}\right)_{2}-\left(h_{a}+\omega \cdot h_{v}\right)_{1}-\left(\omega_{2}-\omega_{1}\right) \cdot h_{w}\right] \\
& \dot{Q}=0,11 \cdot[(81,0)-(29,0)-(0,017-0,0078) \cdot 42,01] \\
& \dot{Q}=5,68 \mathrm{~kW}
\end{aligned}
$$

O resultado encontrado nesta simulação apresentou uma capacidade de refrigeração necessária de 5,68 kW, equivalente a 1,6 TR. 


\section{APÊNDICE B - Dados dos veículos base de análise}

A base de análise consiste em três configurações de veículo:

a) Veículo de passeio subcompacto de acabamento básico;

b) Veículo comercial pesado do tipo cavalo mecânico com suspensão traseira do tipo pneumática, sem o reboque;

c) Veículo comercial pesado do tipo cavalo mecânico com suspensão traseira do tipo pneumática, com o reboque carregado (15 t).

Os dados foram obtidos através da avaliação dos veículos existentes atualmente no mercado brasileiro. A média dos resultados de cada variável foi utilizada como valor base para o presente trabalho.

\begin{tabular}{|c|c|c|c|c|}
\hline Veículo de passeio & $\begin{array}{c}\text { POM } \\
(\mathrm{kg}) \\
\end{array}$ & $\begin{array}{c}\text { Cd } \\
(-) \\
\end{array}$ & $\begin{array}{c}\mathbf{A}_{\mathbf{f}} \\
\left(\mathrm{m}^{2}\right)\end{array}$ & $\begin{array}{l}\mathbf{P}_{\text {pneus }} \\
\text { (psig) }\end{array}$ \\
\hline Chevrolet Celta 1.0L 2P (CHEVROLET, 2005) & 834 & & & \\
\hline Fiat Mille Fire Flex 1.0L 2P (FIAT, 2005) & 810 & & & \\
\hline Ford Ka 1.0L 2P (FORD, 2005) & 910 & & & \\
\hline Volkswagen Gol Total Flex 1.0L 2P (VOLKSWAGEN, 2005) & 861 & & & \\
\hline Valor adotado** & 854 & $0,34 *$ & $\sim 1,7$ & $\sim 28$ \\
\hline Veículo comercial & $\begin{array}{c}\text { POM } \\
(\mathrm{kg}) \\
\end{array}$ & $\begin{array}{l}\text { Cd } \\
(-) \\
\end{array}$ & $\begin{array}{c}\mathbf{A}_{\mathbf{f}} \\
\left(\mathrm{m}^{2}\right) \\
\end{array}$ & $\begin{array}{l}\mathbf{P}_{\text {pneus }} \\
\text { (psig) }\end{array}$ \\
\hline Scania R360 4x2 (SCANIA, 2005) & 7227 & & $\sim 7,4$ & \\
\hline Volkswagen 18310 Titan 4x2 (VOLKSWAGEN, 2005) & 6163 & & $\sim 6,3$ & \\
\hline Volvo FH12 4x2 (VOLVO, 2005) & 7100 & & $\sim 7,4$ & \\
\hline Valor adotado** & 6830 & $0,90 *$ & $\sim 7,0$ & $>50$ \\
\hline Veículo comercial com reboque de 15 ton. & $\begin{array}{c}\text { POM } \\
(\mathrm{kg})\end{array}$ & $\begin{array}{l}\text { Cd } \\
(-) \\
\end{array}$ & $\begin{array}{r}\mathbf{A}_{\mathbf{f}} \\
\left(\mathrm{m}^{2}\right) \\
\end{array}$ & $\begin{array}{l}\mathbf{P}_{\text {pneus }} \\
\text { (psig) }\end{array}$ \\
\hline Valor adotado & 21830 & $0,70^{*}$ & $\sim 7,0$ & $>50$ \\
\hline
\end{tabular}

Observações:

* Dados de Cd estimados conforme Götz e Mayr (1998)

** Valor adotado de peso corresponde à média dos pesos dos veículos 


\section{APÊNDICE C - Ciclos de Condução}

Para o presente trabalho, na falta de outras fontes que especifiquem um ciclo de condução urbano, serão utilizados os seguintes ciclos de condução:

a) Ciclo de Condução descrito na norma NBR 6601: a norma NBR 6601, corresponde a uma norma cujo intuito é prescrever o método de determinação de emissões em veiculos automotores leves. Para isso, é descrito um ciclo de condução, com o fim de simular as condições de tráfego urbano. Conforme citado na norma NBR 6601, um ciclo de condução corresponde a um gráfico contínuo de velocidade em função do tempo, com o fim de simular as condições de tráfego urbano. É composto por sequências não repetidas de acelerações, desacelerações em combinações variadas e não repetidas, regime de marcha lenta e velocidade de cruzeiro. A seguir é apresentado a matriz de velocidades e tempos:

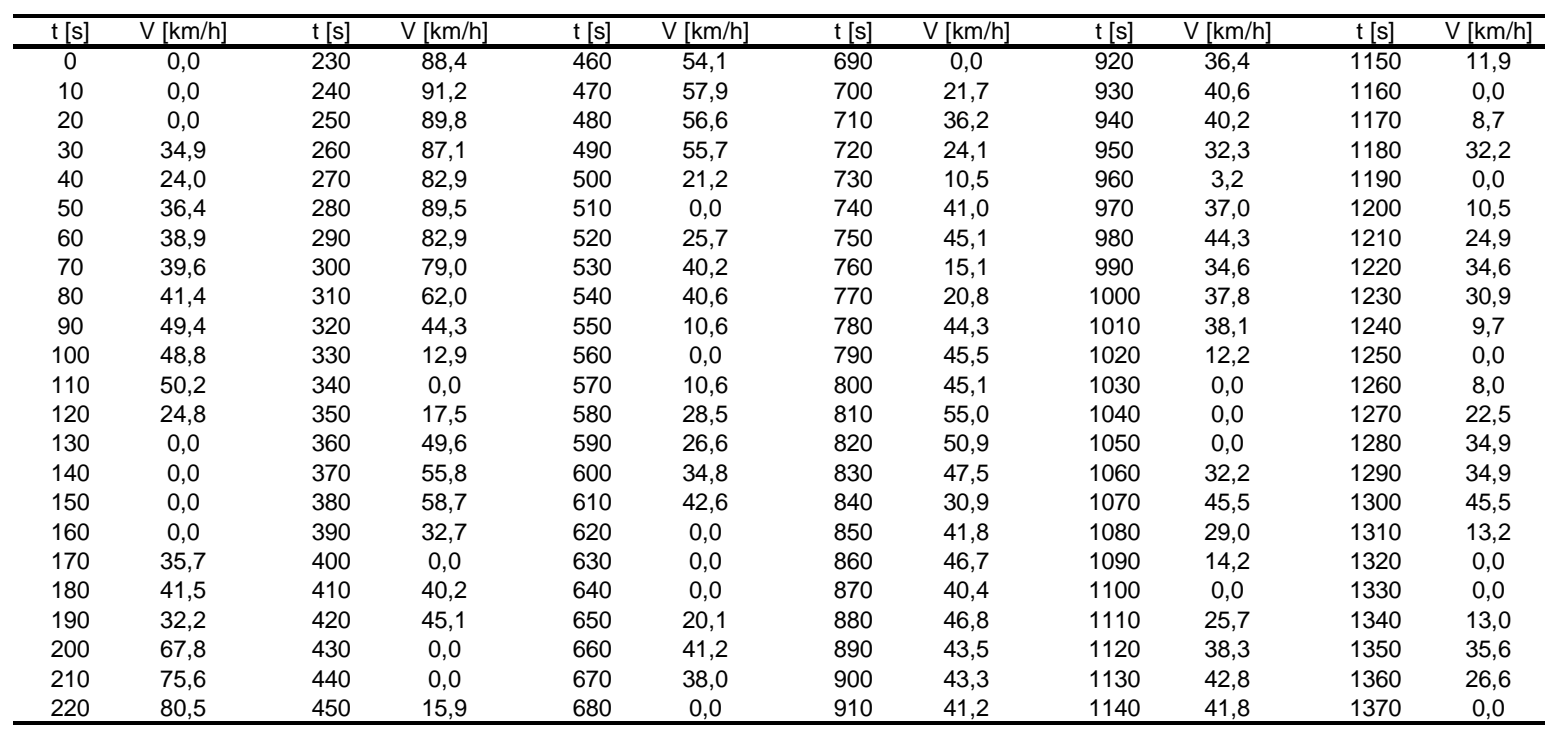


b) Desaceleração linear $40 \mathrm{~km} / \mathrm{h}$ - 0km/h: tal ciclo de condução será aplicado como meio de comparação para avaliação da autonomia e capacidade de regeneração do sistema em uma condição comum no tráfego urbano. Consiste na desaceleração linear da velocidade de $40 \mathrm{~km} / \mathrm{h}$ até a parada total do veículo, aplicado num intervalo de $5 \mathrm{~s}$, ocasionando uma desaceleração linear de $2,22 \mathrm{~m} / \mathrm{s}^{2}$. 


\section{APÊNDICE D - Cálculo do potencial de energia disponível para regeneração}

Aplicando a equação 23 aos ciclos de condução apresentados no APÊNDICE C com base nos dados apresentados no APÊNDICE B, foi possível obter a matriz da evolução da energia disponível para regeneração.

Onde: $\mathrm{t}=$ Tempo $(\mathrm{s})$

$$
\begin{aligned}
& \mathrm{v}=\text { velocidade }(\mathrm{m} / \mathrm{s}) \\
& \mathrm{a}=\text { Aceleração média }(\mathrm{m} / \mathrm{s}) \\
& \Delta \mathrm{KE}=\text { Variação da Energia Cinética }(\mathrm{kJ}) \\
& \Delta \mathrm{s}=\text { Espaço percorrido }(\mathrm{m}) \\
& \mathrm{R}_{\mathrm{R}}=\text { Resistência ao Rolamento }(\mathrm{N}) \\
& \mathrm{R}_{\mathrm{a}}=\text { Resistência Aerodinâmica (N) } \\
& \mathrm{R}_{\mathrm{T}}=\text { Resistência Total (N) } \\
& \mathrm{W}=\text { Trabalho realizado pelas forças resistentes (N) } \\
& \Delta \mathrm{E}_{\text {liq }}=\text { Energia parcial disponível para regeneração }(\mathrm{kJ}) \\
& \Sigma \mathrm{E}_{\text {liq }}=\text { Energia acumulada disponível para regeneração (kJ) }
\end{aligned}
$$

Para a integração do trabalho parcial foi utilizado o método numérico da regra dos trapézios conforme apresentada por Barroso et al. (1987).

$$
\begin{gathered}
I=l / 2\left[f(x)_{0}+f(x)_{1}\right] \\
l=\left(x_{1}-x_{0}\right)
\end{gathered}
$$

onde: $\quad$ I = Integral da função de $\mathrm{x}$

l = passo de integração 


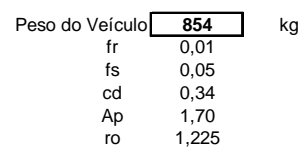

\begin{tabular}{|c|c|c|c|c|c|c|c|c|c|c|c|c|c|}
\hline$t(\min )$ & $t(s)$ & $v(\mathrm{~km} / \mathrm{h})$ & $v(\mathrm{~m} / \mathrm{s})$ & $a\left(m / \mathrm{s}^{2}\right)$ & $\Delta \mathrm{KE}(\mathrm{kJ})$ & $\Delta \mathrm{S}(\mathrm{m})$ & $\operatorname{Rr}(\mathrm{N})$ & $\mathrm{Ra}(\mathrm{N})$ & $\mathrm{Rt}(\mathrm{N})$ & $\mathrm{W}(\mathrm{kJ})$ & Regeneraçăo? & $\Delta \mathrm{E}_{\text {liq }}(\mathrm{kJ})$ & $\Sigma \mathrm{E}_{\text {liq }}(\mathrm{kJ})$ \\
\hline 0 & $\overline{0}$ & 0,0 & 0,0 & 0,00 & 0,0 & 0,0 & 0,00 & 0,0 & 0,0 & 0,0 & não & 0,0 & 0,0 \\
\hline 0 & 10 & 0,0 & 0,0 & 0,00 & 0,0 & 0,0 & 0,00 & 0,0 & 0,0 & 0,0 & não & 0,0 & 0,0 \\
\hline 0 & 20 & 0,0 & 0,0 & 0,00 & 0,0 & 0,0 & 0,00 & 0,0 & 0,0 & 0,0 & não & 0,0 & 0,0 \\
\hline 1 & 30 & 34,9 & 9,7 & 0,97 & 40,1 & 48,5 & 11,57 & 33,3 & 44,8 & 1,1 & não & 0,0 & 0,0 \\
\hline 1 & 40 & 24,0 & 6,7 & $-0,30$ & $-21,2$ & 81,8 & 9,73 & 15,7 & 25,5 & 2,9 & $\operatorname{sim}$ & 18,3 & 18,3 \\
\hline 1 & 50 & 36,4 & 10,1 & 0,34 & 24,7 & 83,9 & 11,91 & 36,2 & 48,1 & 3,1 & não & 0,0 & 18,3 \\
\hline 1 & 60 & 38,9 & 10,8 & 0,07 & 6,2 & 104,6 & 12,51 & 41,3 & 53,8 & 5,3 & não & 0,0 & 18,3 \\
\hline 1 & 70 & 39,6 & 11,0 & 0,02 & 1,8 & 109,0 & 12,70 & 42,8 & 55,5 & 6,0 & não & 0,0 & 18,3 \\
\hline 1 & 80 & 41,4 & 11,5 & 0,05 & 4,8 & 112,5 & 13,18 & 46,8 & 60,0 & 6,5 & não & 0,0 & 18,3 \\
\hline 2 & 90 & 49,4 & 13,7 & 0,22 & 23,9 & 126,1 & 15,76 & 66,7 & 82,4 & 9,0 & não & 0,0 & 18,3 \\
\hline 2 & 100 & 48,8 & 13,6 & $-0,02$ & $-1,9$ & 136,4 & 15,54 & 65,1 & 80,6 & 11,1 & não & 0,0 & 18,3 \\
\hline 2 & 110 & 50,2 & 13,9 & 0,04 & 4,6 & 137,5 & 16,06 & 68,8 & 84,9 & 11,4 & não & 0,0 & 18,3 \\
\hline 2 & 120 & 24,8 & 6,9 & $-0,71$ & $-62,8$ & 104,2 & 9,83 & 16,8 & 26,6 & 5,8 & $\operatorname{sim}$ & 57,0 & 75,2 \\
\hline 2 & 130 & 0,0 & 0,0 & $-0,69$ & $-20,3$ & 34,4 & 0,00 & 0,0 & 0,0 & 0,5 & $\operatorname{sim}$ & 19,8 & 95,0 \\
\hline 2 & 140 & 0,0 & 0,0 & 0,00 & 0,0 & 0,0 & 0,00 & 0,0 & 0,0 & 0,0 & não & 0,0 & 95,0 \\
\hline 3 & 150 & 0,0 & 0,0 & 0,00 & 0,0 & 0,0 & 0,00 & 0,0 & 0,0 & 0,0 & não & 0,0 & 95,0 \\
\hline 3 & 160 & 0,0 & 0,0 & 0,00 & 0,0 & 0,0 & 0,00 & 0,0 & 0,0 & 0,0 & não & 0,0 & 95,0 \\
\hline 3 & 170 & 35,7 & 9,9 & 0,99 & 42,0 & 49,6 & 11,75 & 34,8 & 46,6 & 1,2 & não & 0,0 & 95,0 \\
\hline 3 & 180 & 41,5 & 11,5 & 0,16 & 14,8 & 107,2 & 13,21 & 47,0 & 60,3 & 5,7 & não & 0,0 & 95,0 \\
\hline 3 & 190 & 32,2 & 8,9 & $-0,26$ & $-22,6$ & 102,4 & 11,02 & 28,3 & 39,3 & 5,1 & $\operatorname{sim}$ & 17,5 & 112,5 \\
\hline 3 & 200 & 67,8 & 18,8 & 0,99 & 117,3 & 138,9 & 24,48 & 125,6 & 150,0 & 13,2 & não & 0,0 & 112,5 \\
\hline 4 & 210 & 75,6 & 21,0 & 0,22 & 36,9 & 199,2 & 29,46 & 156,1 & 185,6 & 33,4 & não & 0,0 & 112,5 \\
\hline 4 & 220 & 80,5 & 22,4 & 0,14 & 25,2 & 216,8 & 33,02 & 177,0 & 210,0 & 42,9 & não & 0,0 & 112,5 \\
\hline 4 & 230 & 88,4 & 24,6 & 0,22 & 44,0 & 234,6 & 39,48 & 213,5 & 252,9 & 54,3 & não & 0,0 & 112,5 \\
\hline 4 & 240 & 91,2 & 25,3 & 0,08 & 16,6 & 249,4 & 41,99 & 227,2 & 269,2 & 65,1 & não & 0,0 & 112,5 \\
\hline 4 & 250 & 89,8 & 24,9 & $-0,04$ & $-8,3$ & 251,4 & 40,72 & 220,3 & 261,0 & 66,6 & não & 0,0 & 112,5 \\
\hline 4 & 260 & 87,1 & 24,2 & $-0,08$ & $-15,7$ & 245,7 & 38,35 & 207,2 & 245,6 & 62,2 & não & 0,0 & 112,5 \\
\hline 5 & 270 & 82,9 & 23,0 & $-0,12$ & $-23,5$ & 236,1 & 34,89 & 187,7 & 222,6 & 55,3 & não & 0,0 & 112,5 \\
\hline 5 & 280 & 89,5 & 24,9 & 0,18 & 37,5 & 239,4 & 40,45 & 218,8 & 259,3 & 57,7 & não & 0,0 & 112,5 \\
\hline 5 & 290 & 82,9 & 23,0 & $-0,18$ & $-37,5$ & 239,4 & 34,89 & 187,7 & 222,6 & 57,7 & não & 0,0 & 112,5 \\
\hline 5 & 300 & 79,0 & 21,9 & $-0,11$ & $-20,8$ & 224,9 & 31,90 & 170,5 & 202,4 & 47,8 & não & 0,0 & 112,5 \\
\hline 5 & 310 & 62,0 & 17,2 & $-0,47$ & $-79,0$ & 195,8 & 21,28 & 105,0 & 126,3 & 32,2 & sim & 46,8 & 159,3 \\
\hline 5 & 320 & 44,3 & 12,3 & $-0,49$ & $-62,0$ & 147,6 & 14,04 & 53,6 & 67,6 & 14,3 & sim & 47,7 & 207,0 \\
\hline 6 & 330 & 12,9 & 3,6 & $-0,87$ & $-59,2$ & 79,4 & 8,79 & 4,5 & 13,3 & 3,2 & sim & 56,0 & 263,0 \\
\hline 6 & 340 & 0,0 & 0,0 & $-0,36$ & $-5,5$ & 17,9 & 0,00 & 0,0 & 0,0 & 0,1 & sim & 5,4 & 268,3 \\
\hline 6 & 350 & 17,5 & 4,9 & 0,49 & 10,1 & 24,3 & 9,08 & 8,4 & 17,4 & 0,2 & não & 0,0 & 268,3 \\
\hline 6 & 360 & 49,6 & 13,8 & 0,89 & 71,0 & 93,2 & 15,84 & 67,2 & 83,0 & 4,7 & não & 0,0 & 268,3 \\
\hline 6 & 370 & 55,8 & 15,5 & 0,17 & 21,5 & 146,4 & 18,33 & 85,1 & 103,4 & 13,6 & não & 0,0 & 268,3 \\
\hline 6 & 380 & 58,7 & 16,3 & 0,08 & 10,9 & 159,0 & 19,66 & 94,1 & 113,8 & 17,3 & não & 0,0 & 268,3 \\
\hline 7 & 390 & 32,7 & 9,1 & $-0,72$ & $-78,3$ & 126,9 & 11,11 & 29,2 & 40,3 & 9,8 & sim & 68,5 & 336,8 \\
\hline 7 & 400 & 0,0 & 0,0 & $-0,91$ & $-35,2$ & 45,4 & 0,00 & 0,0 & 0,0 & 0,9 & sim & 34,3 & 371,1 \\
\hline 7 & 410 & 40,2 & 11,2 & 1,12 & 53,2 & 55,8 & 12,85 & 44,1 & 57,0 & 1,6 & não & 0,0 & 371,1 \\
\hline 7 & 420 & 45,1 & 12,5 & 0,14 & 13,8 & 118,5 & 14,29 & 55,6 & 69,9 & 7,5 & não & 0,0 & 371,1 \\
\hline 7 & 430 & 0,0 & 0,0 & $-1,25$ & $-67,0$ & 62,6 & 0,00 & 0,0 & 0,0 & 2,2 & sim & 64,8 & 436,0 \\
\hline 7 & 440 & 0,0 & 0,0 & 0,00 & 0,0 & 0,0 & 0,00 & 0,0 & 0,0 & 0,0 & não & 0,0 & 436,0 \\
\hline 8 & 450 & 15,9 & 4,4 & 0,44 & 8,3 & 22,1 & 8,96 & 6,9 & 15,9 & 0,2 & não & 0,0 & 436,0 \\
\hline 8 & 460 & 54,1 & 15,0 & 1,06 & 88,1 & 97,2 & 17,60 & 80,0 & 97,6 & 5,5 & não & 0,0 & 436,0 \\
\hline 8 & 470 & 57,9 & 16,1 & 0,11 & 14,0 & 155,6 & 19,28 & 91,6 & 110,9 & 16,2 & não & 0,0 & 436,0 \\
\hline 8 & 480 & 56,6 & 15,7 & $-0,04$ & $-4,9$ & 159,0 & 18,69 & 87,5 & 106,2 & 17,3 & não & 0,0 & 436,0 \\
\hline 8 & 490 & 55,7 & 15,5 & $-0,02$ & $-3,3$ & 156,0 & 18,29 & 84,7 & 103,0 & 16,3 & não & 0,0 & 436,0 \\
\hline 8 & 500 & 21,2 & 5,9 & $-0,96$ & $-87,4$ & 106,8 & 9,41 & 12,3 & 21,7 & 6,7 & sim & 80,8 & 516,7 \\
\hline 9 & 510 & 0,0 & 0,0 & $-0,59$ & $-14,8$ & 29,4 & 0,00 & 0,0 & 0,0 & 0,3 & sim & 14,5 & 531,2 \\
\hline 9 & 520 & 25,7 & 7,1 & 0,71 & 21,8 & 35,7 & 9,95 & 18,0 & 28,0 & 0,5 & não & 0,0 & 531,2 \\
\hline 9 & 530 & 40,2 & 11,2 & 0,40 & 31,5 & 91,5 & 12,85 & 44,1 & 57,0 & 3,9 & não & 0,0 & 531,2 \\
\hline 9 & 540 & 40,6 & 11,3 & 0,01 & 1,1 & 112,2 & 12,96 & 45,0 & 58,0 & 6,5 & não & 0,0 & 531,2 \\
\hline 9 & 550 & 10,6 & 2,9 & $-0,83$ & $-50,6$ & 71,1 & 8,69 & 3,1 & 11,8 & 2,5 & sim & 48,1 & 579,3 \\
\hline 9 & 560 & 0,0 & 0,0 & $-0,29$ & $-3,7$ & 14,7 & 0,00 & 0,0 & 0,0 & 0,1 & sim & 3,6 & 583,0 \\
\hline 10 & 570 & 10,6 & 2,9 & 0,29 & 3,7 & 14,7 & 8,69 & 3,1 & 11,8 & 0,1 & não & 0,0 & 583,0 \\
\hline 10 & 580 & 28,5 & 7,9 & 0,50 & 23,1 & 54,3 & 10,37 & 22,2 & 32,6 & 1,2 & não & 0,0 & 583,0 \\
\hline 10 & 590 & 26,6 & 7,4 & $-0,05$ & $-3,4$ & 76,5 & 10,08 & 19,3 & 29,4 & 2,4 & $\operatorname{sim}$ & 1,1 & 584,0 \\
\hline 10 & 600 & 34,8 & 9,7 & 0,23 & 16,6 & 85,3 & 11,55 & 33,1 & 44,6 & 3,2 & não & 0,0 & 584,0 \\
\hline 10 & 610 & 42,6 & 11,8 & 0,22 & 19,9 & 107,5 & 13,53 & 49,6 & 63,1 & 5,8 & não & 0,0 & 584,0 \\
\hline 10 & 620 & 0,0 & 0,0 & $-1,18$ & $-59,8$ & 59,2 & 0,00 & 0,0 & 0,0 & 1,9 & sim & 57,9 & 642,0 \\
\hline 11 & 630 & 0,0 & 0,0 & 0,00 & 0,0 & 0,0 & 0,00 & 0,0 & 0,0 & 0,0 & não & 0,0 & 642,0 \\
\hline 11 & 640 & 0,0 & 0,0 & 0,00 & 0,0 & 0,0 & 0,00 & 0,0 & 0,0 & 0,0 & não & 0,0 & 642,0 \\
\hline 11 & 650 & 20,1 & 5,6 & 0,56 & 13,3 & 27,9 & 9,30 & 11,0 & 20,3 & 0,3 & não & 0,0 & 642,0 \\
\hline 11 & 660 & 41,2 & 11,4 & 0,59 & 42,6 & 85,1 & 13,13 & 46,4 & 59,5 & 3,4 & não & 0,0 & 642,0 \\
\hline 11 & 670 & 38,0 & 10,6 & $-0,09$ & $-8,4$ & 110,0 & 12,29 & 39,4 & 51,7 & 6,1 & $\operatorname{sim}$ & 2,2 & 644,2 \\
\hline 11 & 680 & 0,0 & 0,0 & $-1,06$ & $-47,6$ & 52,8 & 0,00 & 0,0 & 0,0 & 1,4 & sim & 46,2 & 690,4 \\
\hline 12 & 690 & 0,0 & 0,0 & 0,00 & 0,0 & 0,0 & 0,00 & 0,0 & 0,0 & 0,0 & não & 0,0 & 690,4 \\
\hline 12 & 700 & 21,7 & 6,0 & 0,60 & 15,5 & 30,1 & 9,46 & 12,9 & 22,3 & 0,3 & não & 0,0 & 690,4 \\
\hline 12 & 710 & 36,2 & 10,1 & 0,40 & 27,7 & 80,4 & 11,86 & 35,8 & 47,7 & 2,8 & não & 0,0 & 690,4 \\
\hline 12 & 720 & 24,1 & 6,7 & $-0,34$ & $-24,0$ & 83,8 & 9,74 & 15,9 & 25,6 & 3,1 & $\operatorname{sim}$ & 21,0 & 711,4 \\
\hline 12 & 730 & 10,5 & 2,9 & $-0,38$ & $-15,5$ & 48,1 & 8,69 & 3,0 & 11,7 & 0,9 & $\operatorname{sim}$ & 14,6 & 726,0 \\
\hline 12 & 740 & 41,0 & 11,4 & 0,85 & 51,8 & 71,5 & 13,07 & 45,9 & 59,0 & 2,5 & não & 0,0 & 726,0 \\
\hline 13 & 750 & 45,1 & 12,5 & 0,11 & 11,6 & 119,6 & 14,29 & 55,6 & 69,9 & 7,7 & não & 0,0 & 726,0 \\
\hline 13 & 760 & 15,1 & 4,2 & $-0,83$ & $-59,5$ & 83,6 & 8,91 & 6,2 & 15,1 & 3,6 & $\operatorname{sim}$ & 55,9 & 781,9 \\
\hline 13 & 770 & 20,8 & 5,8 & 0,16 & 6,7 & 49,9 & 9,37 & 11,8 & 21,2 & 0,9 & não & 0,0 & 781,9 \\
\hline 13 & 780 & 44,3 & 12,3 & 0,65 & 50,4 & 90,4 & 14,04 & 53,6 & 67,6 & 4,0 & não & 0,0 & 781,9 \\
\hline 13 & 790 & 45,5 & 12,6 & 0,03 & 3,6 & 124,7 & 14,42 & 56,6 & 71,0 & 8,6 & não & 0,0 & 781,9 \\
\hline 13 & 800 & 45,1 & 12,5 & $-0,01$ & $-1,2$ & 125,8 & 14,29 & 55,6 & 69,9 & 8,9 & não & 0,0 & 781,9 \\
\hline 14 & 810 & 55,0 & 15,3 & 0,28 & 32,7 & 139,0 & 17,99 & 82,6 & 100,6 & 11,9 & não & 0,0 & 781,9 \\
\hline
\end{tabular}




\begin{tabular}{|c|c|c|c|c|c|c|c|c|c|c|c|c|c|}
\hline 14 & 820 & 50,9 & 14,1 & $-0,11$ & $-14,3$ & 147,1 & 16,32 & 70,8 & 87,1 & 13,8 & $\operatorname{sim}$ & 0,5 & 782,4 \\
\hline 14 & 830 & 47,5 & 13,2 & $-0,09$ & $-11,0$ & 136,7 & 15,09 & 61,6 & 76,7 & 11,2 & não & 0,0 & 782,4 \\
\hline 14 & 840 & 30,9 & 8,6 & $-0,46$ & $-42,9$ & 108,9 & 10,77 & 26,1 & 36,9 & 6,2 & sim & 36,7 & 819,1 \\
\hline 14 & 850 & 41,8 & 11,6 & 0,30 & 26,1 & $\begin{array}{l}101,0 \\
\end{array}$ & 13,30 & 47,7 & 61,0 & 4,9 & não & 0,0 & 819,1 \\
\hline 14 & 860 & 46,7 & 13,0 & 0,14 & 14,3 & 122,9 & 14,82 & 59,6 & 74,4 & 8,3 & não & 0,0 & 819,1 \\
\hline 15 & 870 & 40,4 & 11,2 & $-0,18$ & $-18,1$ & 121,0 & 12,91 & 44,6 & 57,5 & 8,0 & $\operatorname{sim}$ & 10,1 & 829,2 \\
\hline 15 & 880 & 46,8 & 13,0 & 0,18 & 18,4 & 121,1 & 14,85 & 59,8 & 74,7 & 8,0 & não & 0,0 & 829,2 \\
\hline 15 & 890 & 43,5 & 12,1 & $-0,09$ & $-9,8$ & 125,4 & 13,80 & 51,7 & 65,5 & 8,8 & sim & 1,0 & 830,3 \\
\hline 15 & 900 & 43,3 & 12,0 & $-0,01$ & $-0,6$ & 120,6 & 13,73 & 51,2 & 65,0 & 7,9 & não & 0,0 & 830,3 \\
\hline 15 & 910 & 41,2 & 11,4 & $-0,06$ & $-5,8$ & 117,4 & 13,13 & 46,4 & 59,5 & 7,3 & não & 0,0 & 830,3 \\
\hline 15 & 920 & 36,4 & 10,1 & $-0,13$ & $-12,3$ & 107,8 & 11,91 & 36,2 & 48,1 & 5,8 & $\mathrm{sim}$ & 6,5 & 836,7 \\
\hline 16 & 930 & 40,6 & 11,3 & 0,12 & 10,7 & 106,9 & 12,96 & 45,0 & 58,0 & 5,7 & não & 0,0 & 836,7 \\
\hline 16 & 940 & 40,2 & 11,2 & $-0,01$ & $-1,1$ & 112,2 & 12,85 & 44,1 & 57,0 & 6,5 & กão & 0,0 & 836,7 \\
\hline 16 & 950 & 32,3 & 9,0 & $-0,22$ & $-18,9$ & 100,7 & 11,04 & 28,5 & 39,5 & 4,9 & $\operatorname{sim}$ & 14,0 & 850,7 \\
\hline 16 & 960 & 3,2 & 0,9 & $-0,81$ & $-34,0$ & 49,3 & 8,55 & 0,3 & 8,8 & 1,2 & sim & 32,8 & 883,6 \\
\hline 16 & 970 & $\begin{array}{l}3,2 \\
37,0\end{array}$ & 10,3 & $\begin{array}{l}-0,01 \\
0,94\end{array}$ & 44,8 & 55,8 & $\begin{array}{l}0,30 \\
12,05\end{array}$ & $\begin{array}{l}37,4 \\
37,4\end{array}$ & $\begin{array}{l}, 0,0 \\
49,4\end{array}$ & $\begin{array}{l}1,2 \\
1,6\end{array}$ & não & $\begin{array}{c}2,0,0 \\
0,0\end{array}$ & 883,6 \\
\hline 16 & 980 & 44,3 & 12,3 & 0,20 & 19,6 & 112,9 & 14,04 & 53,6 & 67,6 & 6,6 & กão & 0,0 & 883,6 \\
\hline 17 & 990 & 34,6 & 9,6 & $-0,27$ & $-25,2$ & 109,6 & 11,51 & 32,7 & 44,2 & 6,1 & sim & 19,1 & 902,7 \\
\hline 17 & 1000 & 37,8 & 10,5 & 0,09 & 7,6 & 100,6 & 12,24 & 39,0 & 51,3 & 4,8 & não & 0,0 & 902,7 \\
\hline 17 & 1010 & 38,1 & 10,6 & 0,01 & 0,8 & 105,4 & 12,31 & 39,7 & 52,0 & 5,4 & não & 0,0 & 902,7 \\
\hline 17 & 1020 & 12,2 & 3,4 & $\begin{array}{l}-0,72 \\
\end{array}$ & $-42,9$ & 69,9 & 8,76 & 4,1 & 12,8 & 2,3 & sim & 40,7 & 943,3 \\
\hline 17 & 1030 & $\begin{array}{l}0,2 \\
0,0\end{array}$ & $\begin{array}{l}3,4 \\
0,0\end{array}$ & $-0,34$ & $\begin{array}{l}-4,9 \\
\end{array}$ & $\begin{array}{l}16,9 \\
16,9\end{array}$ & $\begin{array}{l}0,10 \\
0,00\end{array}$ & $\begin{array}{l}4,1 \\
0,0\end{array}$ & $\begin{array}{c}0,0 \\
0,0\end{array}$ & 0,1 & sim & 4,8 & 948,1 \\
\hline 17 & 1040 & 0,0 & 0,0 & 0,00 & 0,0 & 0,0 & 0,00 & 0,0 & 0,0 & 0,0 & não & 0,0 & 948,1 \\
\hline 18 & 1050 & 0,0 & 0,0 & 0,00 & 0,0 & 0,0 & 0,00 & 0,0 & 0,0 & 0,0 & não & 0,0 & 948,1 \\
\hline 18 & 1060 & 32,2 & 8,9 & 0,89 & 34,2 & 44,7 & 11,02 & 28,3 & 39,3 & 0,9 & não & 0,0 & 948,1 \\
\hline 18 & 1070 & 45,5 & 12,6 & 0,37 & 34,0 & 107,9 & 14,42 & 56,6 & 71,0 & 6,0 & กão & 0,0 & 948,1 \\
\hline $\begin{array}{l}18 \\
18\end{array}$ & 1080 & $\begin{array}{l}49,0 \\
29,0\end{array}$ & $\begin{array}{l}8,0 \\
8,1\end{array}$ & $-0,46$ & $\begin{array}{r}3,0,0 \\
-40,5\end{array}$ & 103,5 & 10,45 & $\begin{array}{r}0,0 \\
23,0\end{array}$ & $\begin{array}{l}31,4,4 \\
33\end{array}$ & 5,4 & sim & $\begin{array}{l}0,0 \\
35,1\end{array}$ & $\begin{array}{l}98,1 \\
983,2\end{array}$ \\
\hline 18 & 1090 & 14,2 & 3,9 & $-0,41$ & $-21,1$ & 60,0 & 8,86 & $\begin{array}{l}5,5 \\
5,5\end{array}$ & 14,4 & $\begin{array}{l}1,4 \\
1.4\end{array}$ & sim & $\begin{array}{l}19,1 \\
19,6\end{array}$ & $\begin{array}{l}1.002,9 \\
\end{array}$ \\
\hline 18 & 1100 & 0,0 & 0,0 & $-0,39$ & $-6,6$ & 19,7 & 0,00 & 0,0 & 0,0 & 0,1 & sim & 6,5 & $1.009,4$ \\
\hline 19 & 1110 & 25,7 & 7,1 & 0,71 & 21,8 & 35,7 & 9,95 & 18,0 & 28,0 & 0,5 & กล̃o & 0,0 & $1.009,4$ \\
\hline 19 & 1120 & 38,3 & 10,6 & 0,35 & 26,6 & 88,9 & 12,36 & 40,1 & 52,4 & 3,6 & não & 0,0 & $1.009,4$ \\
\hline 19 & 1130 & 42,8 & 11,9 & 0,13 & 12,0 & 112,6 & 13,59 & 50,0 & 63,6 & 6,5 & กล̃o & 0,0 & $1.009,4$ \\
\hline 19 & 1140 & $\begin{array}{l}41,8 \\
41,8\end{array}$ & 11,6 & $\begin{array}{l}0,10 \\
-0,03\end{array}$ & $\begin{array}{l}1,0,8 \\
-2,8\end{array}$ & $\begin{array}{l}112,0 \\
117,5\end{array}$ & 13,30 & 47,7 & $\begin{array}{l}63,0 \\
61,0\end{array}$ & $\begin{array}{l}7,3 \\
7,3\end{array}$ & não & 0,0 & $1.009,4$ \\
\hline $\begin{array}{l}19 \\
19\end{array}$ & $\begin{array}{l}1140 \\
1150\end{array}$ & $\begin{array}{l}41,6 \\
11,9\end{array}$ & $\begin{array}{l}1,0 \\
3,3\end{array}$ & $\begin{array}{l}-0,03 \\
-0,83\end{array}$ & $\begin{array}{l}-2,8 \\
-52,9\end{array}$ & $\begin{array}{l}711,5 \\
74,6\end{array}$ & $\begin{array}{l}3,300 \\
8,75\end{array}$ & $\begin{array}{l}41,1 \\
3,9\end{array}$ & 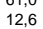 & $\begin{array}{l}2,3 \\
2,7\end{array}$ & sim & $\begin{array}{l}0,0 \\
50,2\end{array}$ & $\begin{array}{l}1.009,4 \\
1.059,5\end{array}$ \\
\hline 19 & 1160 & 0,0 & 0,0 & $-0,33$ & $-4,7$ & 16,5 & 0,00 & 0,0 & 0,0 & 0,1 & sim & 4,6 & $1.064,1$ \\
\hline 20 & 1170 & 8,7 & 2,4 & 0,24 & 2,5 & 12,1 & 8,63 & 2,1 & 10,7 & 0,1 & não & 0,0 & $1.064,1$ \\
\hline 20 & 1180 & 32,2 & 8.9 & 0,65 & 31.7 & 56,8 & 11,02 & 28,3 & 39,3 & 1.4 & não & 0,0 & $\begin{array}{l}1.064,1 \\
\end{array}$ \\
\hline 20 & 1190 & 0,0 & 0,0 & $-0,89$ & $-34,2$ & 44,7 & 0,00 & 0,0 & 0,0 & 0.9 & sim & 33,3 & $\begin{array}{l}1.097,4 \\
\end{array}$ \\
\hline 20 & 1200 & 10,5 & 2,9 & 0,29 & 3,6 & 14,6 & 8,69 & 3,0 & 11,7 & 0,1 & não & 0,0 & $1.097,4$ \\
\hline 20 & 1210 & 24,9 & 6,9 & 0,40 & $\begin{array}{l}5,0 \\
16,8\end{array}$ & 49,2 & 9,84 & $\begin{array}{l}0,0 \\
16,9\end{array}$ & $\begin{array}{l}21,1 \\
26,8\end{array}$ & $\begin{array}{l}0,1 \\
0,9\end{array}$ & não & 0,0 & $1.097,4$ \\
\hline 20 & 1220 & 34,6 & 9,6 & 0,27 & 19,0 & 82,6 & 11,51 & 32,7 & 44,2 & 2,9 & กão & 0,0 & $1.097,4$ \\
\hline 21 & 1230 & 30,9 & 8,6 & $-0,10$ & $-8,0$ & 91,0 & 10,77 & 26,1 & 36,9 & 3,7 & sim & 4,3 & $1.101,7$ \\
\hline 21 & 1240 & 9,7 & 2,7 & $-0,59$ & $-28,4$ & 56,4 & 8,66 & 2,6 & 11,2 & 1,4 & sim & 27,0 & $1.128,7$ \\
\hline 21 & 1250 & 0,0 & 0,0 & $-0,27$ & $-3,1$ & 13,5 & 0,00 & 0,0 & $\begin{array}{l}0,0 \\
0,0\end{array}$ & 0,1 & sim & 3,0 & $1.131,7$ \\
\hline $\begin{array}{l}21 \\
21\end{array}$ & 1260 & 8,0 & 2,2 & $\begin{array}{r}-0,27 \\
0,22\end{array}$ & 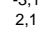 & $\begin{array}{l}11,5 \\
11,1\end{array}$ & $\begin{array}{l}8,00 \\
8,62\end{array}$ & $\begin{array}{l}0,0 \\
1,7\end{array}$ & $\begin{array}{l}10,4 \\
10,4\end{array}$ & $\begin{array}{l}0,1 \\
0,1\end{array}$ & não & $\begin{array}{l}3,0 \\
0,0\end{array}$ & $\begin{array}{l}1.131,1 \\
1.131,7\end{array}$ \\
\hline 21 & 1270 & 22,5 & 6,3 & 0,40 & $\begin{array}{l}2,1 \\
14,6\end{array}$ & 42,4 & 9,55 & $\begin{array}{l}1,1 \\
13,8\end{array}$ & 23,4 & 0,7 & não & 0,0 & $1.131,7$ \\
\hline 21 & 1280 & 34,9 & 9,7 & 0,34 & 23,5 & 79,7 & 11,57 & 33,3 & 44,8 & 2,7 & não & 0,0 & $1.131,7$ \\
\hline 22 & 1290 & 34,9 & 9,7 & 0,00 & 0,0 & 0,0 & 11,57 & 33,3 & 44 & 0,0 & năc & 0,0 & $1.131,7$ \\
\hline 22 & 1300 & 45,5 & 12,6 & 0,29 & 28,1 & 111.7 & 14,42 & 56,6 & 71,0 & 6.5 & não & 0,0 & $1.131,7$ \\
\hline 22 & 1310 & 13,2 & 3,7 & $-0,90$ & $-62,5$ & 81,5 & 8,81 & 4,8 & 13,6 & 3,4 & sim & 59,0 & 1.19 \\
\hline 22 & 1320 & $\begin{array}{l}1,2 \\
0,0\end{array}$ & $\begin{array}{l}0,1 \\
0,0\end{array}$ & $-0,37$ & $\begin{array}{l}-5,7 \\
\text { 作 }\end{array}$ & 18,3 & 0,0 & $\begin{array}{l}0,0 \\
0,0\end{array}$ & $\begin{array}{l}0,0 \\
0,0\end{array}$ & $\begin{array}{l}0,4 \\
0,1\end{array}$ & sim & 5,6 & 1.196 \\
\hline 22 & 1330 & 0,0 & 0,0 & 0,00 & 0,0 & 0,0 & 0,00 & 0,0 & 0,0 & $\begin{array}{l}0,1 \\
0,0\end{array}$ & não & 0,0 & 1.196,3 \\
\hline 22 & 1340 & 13,0 & 3,6 & 0,36 & 5,6 & 18,1 & 8,80 & 4,6 & 13,4 & 0,1 & não & 0,0 & $1.196,3$ \\
\hline 23 & 1350 & 35,6 & 9,9 & 0,63 & 36,2 & 67,5 & 11,72 & 34,6 & 46,3 & 2,0 & กão & 0,0 & $1.196,3$ \\
\hline 23 & 1360 & 26,6 & 7,4 & $-0,25$ & -18.4 & 86,4 & 10,08 & 19,3 & 29,4 & 3,3 & sim & 15,2 & $1.211,5$ \\
\hline 23 & 1370 & 00 & 00 & -074 & -233 & 369 & 0.00 & 0.0 & 00 & 0.5 & sim & 228 & 12343 \\
\hline
\end{tabular}
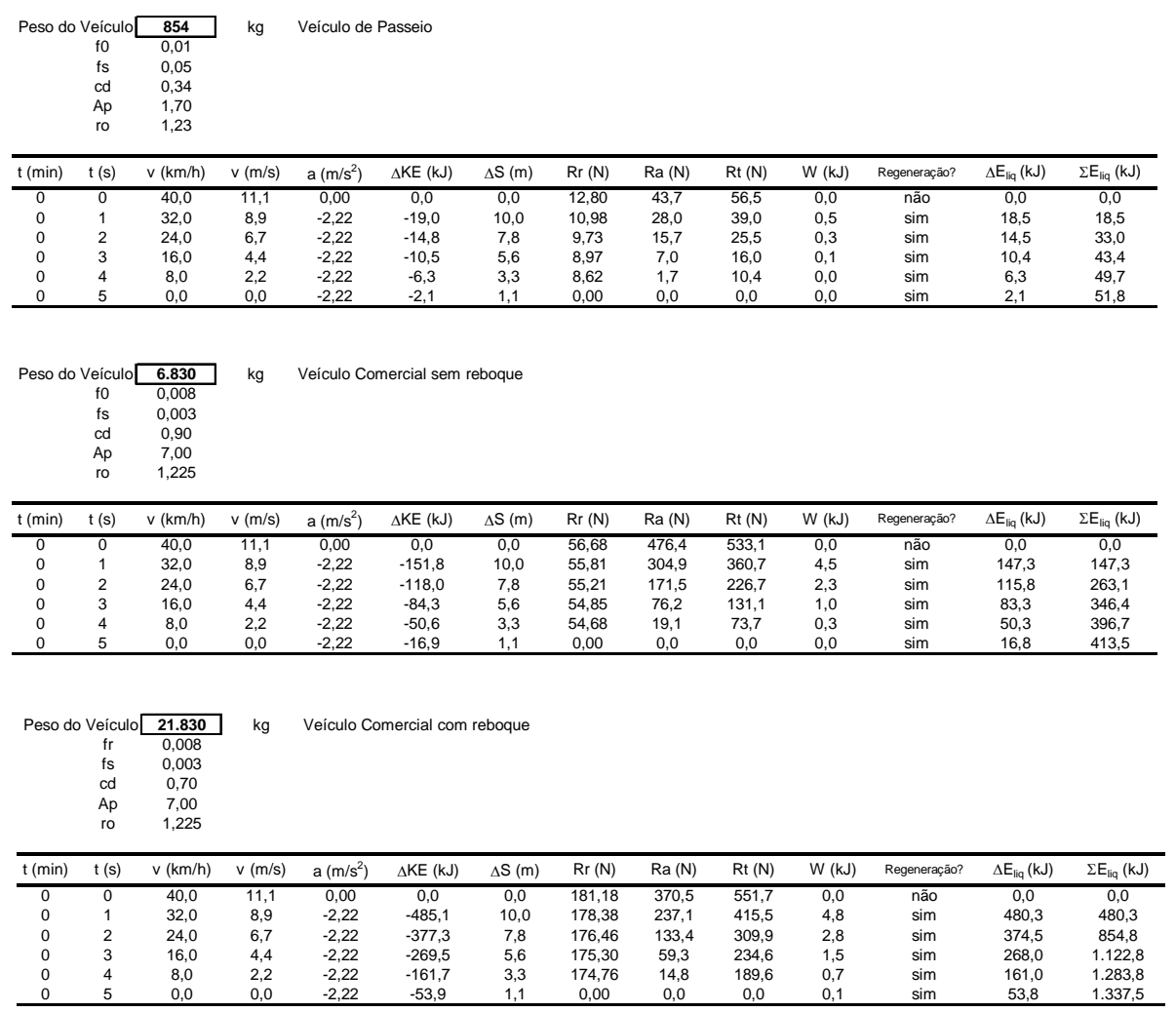